FERNÁNDEZ, José Manuel; OLAVARRÍA, Malva. "Examinando de nuevo la acción de revisión”. Polit. crim. Vol. 13, No 26 (Diciembre 2018) Art. 15, pp. 1190 - 1285.

[http://www.politicacriminal.cl/Vol_13/n_26/Vol13N26A15.pdf]

\title{
Examinando de nuevo la acción de revisión
}

\section{Revisiting the wrongful conviction claim}

\author{
José Manuel Fernandez Ruiz \\ Abogado, Licenciado en Ciencias Jurídicas y Sociales. Universidad de Chile. Chile. LLM \\ University of Toronto. Canadá. PhD law Glasgow University. Reino Unido \\ Profesor de Derecho Penal de la Universidad Alberto Hurtado \\ jmfernandez@uahurtado.cl \\ Malva Olavarría Avendaño \\ Abogada, Licenciada en Ciencias Jurídicas y Sociales. Universidad de Chile. Chile. Pos- \\ titulado en Gerencia Pública, Escuela de Ingeniería Industrial, Universidad de Chile \\ omalva@gmail.com
}

\section{Resumen}

El objetivo de este trabajo es re-examinar, desde un punto de vista analítico e informado empíricamente, el estado de la interpretación de la acción de revisión previsto en el Código Procesal Penal Chileno durante los últimos 10 años. Específicamente, enfatizaremos la necesidad de comprender la estructura del recurso de revisión de acuerdo a una descripción que si bien parece controversial, no es la descripción correcta del modelo previsto por el legislador. Del examen de las acciones de revisión presentadas los últimos 10 años se desprenderá con claridad que la Corte Suprema no ha podido comprender los aspectos centrales de lo que llamaremos "modelo adversarial de revisión". Dicha incomprensión se sostiene en la tradicional descripción de la doctrina chilena que caracteriza la revisión como una acción excepcional y que sólo procede ante casos de "manifiesta injusticia". Explicaremos estos aspectos centrales desde un punto de vista teórico y práctico, examinando la jurisprudencia y el derecho comparado, tomando en consideración los datos obtenidos por recientes investigaciones empíricas en la materia. Cabe hacer presente que el objetivo central de la presente investigación no es el examen etiológico de los factores que explican la existencia de condenas erróneas, sino el examen substantivo de las sentencias de la Corte Suprema en el período 2007-2017 desde un punto de vista analítico y práctico a la luz de la, correctamente interpretada, regulación chilena.

\section{Palabras clave}

Acción de revisión - condenas erróneas - errores judiciales - nueva evidencia.

\begin{abstract}
The aim of the present research is to re-examine, from an analytical yet empirically informed point of view, the state of the interpretation of the wrongful conviction claim as regulated by the Chilean Code of Criminal Procedure during the last 10 years. Specifically, we will emphasise the necessity to understand the structure of such remedy through a description which though controversial we claim is the correct description of the model
\end{abstract}


Polit. crim. Vol. 13, № 26 (Diciembre 2018) Art. 15, pp. 1190 - 1285.

[http://www.politicacriminal.cl/Vol_13/n_26/Vol13N26A15.pdf]

provided by the legislator. From the examination of the wrongful conviction claim it will appear clearly that the Supreme Court has been unable to grasp de central aspects of what we designate "adversarial model". The inaccurate grasping of this model, as we show, is supported on the traditional doctrinal description that characterizes the claim as exceptional and admissible only before instances of "manifest injustice". We explain those central aspects from a theoretical and practical point of view, examining cases and comparative law, considering the recent data from empirical research done on the matter. The central aim of the research is not the examination of the ethology of the factors that may explain the existence of wrongful convictions, but to provide a substantive examination of the rulings of the Supreme Court during the 2007-2017 period, from an analytic and practical point of view in light of the correct interpretation of the legal regulation.

\section{Key words}

Wrongful conviction claim - wrongful conviction - judicial errors - newly discovered evidence.

\section{Introducción}

\section{La acción de revisión y los estudios de inocencia}

El presente estudio de las acciones de revisión presentados y fallados por la Corte Suprema se enmarca en el tema más amplio de estudio de los errores del sistema judicial. En el derecho comparado anglosajón, donde más se ha investigado este tópico, se designa como "errors of justice" ${ }^{1}$ (lo que puede traducirse como "errores del sistema de justicia") haciendo alusión a todos aquellos casos en que el sistema de justicia se equivoca de alguna u otra manera, sea en perjuicio o en beneficio del inocente o del culpable. Dentro del proceso penal, esto significa específicamente poner atención en aquellos errores que implican absolver a quien no se debía absolver o condenar a quien no se debía condenar. Este fenómeno suele denominarse "miscarriages of justice"2 (expresión que no as fácil de traducir pero que equivale más o menos a "yerros de la justicia"). Sin embargo, y en su mayoría, los estudios del derecho comparado se enfocan en una sub-clase de yerros de la justicia criminal; aquellos casos en que una persona que debió ser declarada inocente fue, sin embargo, condenada.

Este estudio se enmarca en esta última línea de investigación, esto es, toma en consideración aquellos casos de errónea condena de inocentes, adoptando una perspectiva substantiva o conceptual del proceso penal e informada empíricamente. Específicamente, analizará y explicará las innumerables dificultades que debe enfrentar una persona condenada cuando presenta evidencia que apunta a demostrar su inocencia a través de la acción de revisión. Como se verá en este estudio, los resultados no son para nada

\footnotetext{
${ }^{1}$ FORST, Brian, Errors of Justice, Nature, Sources, and Remedies, New York: Cambridge University Press, 2004, pp. 3-4.

${ }^{2}$ FORST, Brian, "Wrongful Convictions in a World of Miscarriages of Justice", en HUFF, Ronald; KILLIAS, Marrin (eds.), Wrongful Convictions and Miscarriages of Justice: Causes and Remedies in North American and European Criminal Justice Systems, London y New York: Routledge, 2013, pp. 15-16.
} 
FERNÁNDEZ, José Manuel; OLAVARRÍA, Malva. "Examinando de nuevo la acción de revisión”.

alentadores, porque tal y como se entiende doctrinariamente la revisión y como se aplica por los tribunales, esta no tiende a mejorar, como se esperaría, la posición de aquel que se encuentra erróneamente condenado. Por el contrario, la aplicación que la Corte Suprema hace de las normas de la revisión tiende a ser ad-hoc, no elabora criterios comprensibles de interpretación ni sigue los criterios que ella misma va estableciendo con el resultado que asigna y cambia el sentido del texto legal dependiendo del caso, lo que plantea incertidumbre acerca de qué es lo que el inocente debería probar en sede de revisión para acreditar su inocencia. Como se verá, en muchos casos la posición que la Corte adopta implica la imposibilidad de demostrar la inocencia.

En esta investigación demostraremos que estos problemas que aquejan a la acción de revisión han sido facilitados por la doctrina y la jurisprudencia, y que no es producto de una deficiente regulación legal. Por el contrario, demostraremos que el modelo de revisión de sentencias condenatorias previsto por el legislador es uno mucho más flexible de lo que normalmente se asume, y que debería manifestarse en la práctica como un instrumento jurisdiccional efectivo de control de sentencias condenatorias erróneas. En otras palabras, demostraremos que reconocer que aquélla es un mecanismo flexible y sensible a los casos de inocencia no requiere de una modificación legal, sino de una interpretación correcta del mecanismo de revisión de sentencias firmes. Naturalmente una modificación legal podría eventualmente mejorar este instituto procesal penal, sin embargo sin una adecuada interpretación de los mismos se llegaría a una anquilosada interpretación no mejor que el estado en que hoy se encuentra el inocente.

Los casos de sentencias condenatorias injustas pueden interpretarse y examinarse desde un punto de vista empírico, para el cual lo relevante es primero cuantificar el problema para conocer su dimensión real, segundo explicar sus causas, y tercero proponer posibles soluciones a los errores detectados. El primer estudio empírico en Chile al respecto lo realizamos el año $2009^{3}$, examinando todos los recursos de revisión presentados ante la Corte Suprema durante el período de enero 2007 y abril 2009. El estudio era restringido en sus ambiciones pero representó por primera vez un acercamiento a dimensionar el problema, y por lo tanto, a su cuantificación. Sin embargo, la preocupación del estudio era primariamente analizar la forma en que la Corte Suprema conocía y fallaba las acciones de revisión, y no la identificación de las causas que explicaban las condenas erróneas.

Con posterioridad, y probablemente en atención a los importantes resultados del estudio que por primera vez ponía algo de luz sobre el tema, se han realizado dos estudios de carácter empírico ${ }^{4}$ que, apoyándose en la experiencia de estudios comparados sobre los errores más comunes que causan condenas injustas, intenta elucidar preliminarmente la magnitud del problema, identificar cuales podrían ser las causas, y proponer algunas

\footnotetext{
${ }^{3}$ FERNÁNDEZ RUIZ, José Manuel; OLAVARRÍA AVENDAÑO, Malva, “Teoría y Práctica de la Acción de Revisión en el Nuevo Código Procesal Penal, Causal Letra D) del Artículo 473”, Ius Et Praxis, n 15 (2009), pp. 215-255.

${ }^{4}$ DUCE, Mauricio, "La condena de inocentes en Chile: una aproximación empírica a partir de los resultados de los recursos de revisión acogidos por la Corte Suprema en el período 2007-2013", Política Criminal, n 10 (2015), pp. 159-191, y DUCE, Julio Mauricio, "Algunas Lecciones a Partir de Cuatro Casos de Condena de Inocentes en Chile”, Revista de Derecho Universidad Católica del Norte, $\mathrm{n}^{\circ} 22$ (2015), pp. 149-208.
} 
Polít. crim. Vol. 13, № 26 (Diciembre 2018) Art. 15, pp. 1190 - 1285.

[http://www.politicacriminal.cl/Vol_13/n_26/Vol13N26A15.pdf]

soluciones a los problemas detectados. Otro estudio del año 2013, aunque no de carácter empírico, también analiza y desarrolla hipotéticamente cuales podrían ser las causas de condenas injustas en nuestro país ${ }^{5}$. Todas estas investigaciones se avocan al estudio de la inocencia sobre la base del total de las acciones de revisión acogidas durante un cierto período, por lo cual vale la pena examinar con mayor detenimiento el rol de la revisión dentro de dichos estudios, es decir, el rol de la revisión dentro de los estudios sobre la inocencia. De paso, se aclarará la relevancia de la revisión y cual es el marco en el que debe ser entendida.

A primera vista, uno podría cuestionar el énfasis exclusivo en la acción de revisión, puesto que si de lo que se trata es de identificar errores en perjuicio de un inocente, los errores ciertamente pueden producirse antes de la fase en que la sentencia condenatoria se encuentre ejecutoriada. En efecto, si una sentencia errónea condena a un inocente, la explicación debe residir, en parte, en un evento que sucedió con anterioridad a dicha sentencia. Desde este punto de vista, la sentencia definitiva condenatoria, que es lo que ataca la revisión, sólo transmite errores acaecidos con anterioridad, sin embargo, los errores pueden acaecer con anterioridad e incluso sin que exista sentencia condenatoria. Ciertamente, este cuestionamiento es válido porque la inocencia es relevante desde el primer momento en que se inicia la investigación hasta la completa ejecución de la sentencia, e incluso, con posterioridad a que ésta se encuentra cumplida. La referencia a la sentencia condenatoria es relevante porque permite vincular el problema de la inocencia, más en general, al proceso penal. Es decir, la inocencia debe ser entendida y por lo tanto puede ser analizada legalmente. En otras palabras, tiene sentido preguntarse por la inocencia durante un específico intervalo temporal $t_{1}-t_{2}$ y que se encuentra definido en referencia a un sistema de justicia criminal en funcionamiento. La pregunta por la inocencia es pues una pregunta jurídico procesal penal.

$\mathrm{T}_{1}-\mathrm{t}_{2}$ define el rango temporal de eventos relevantes para la comprensión y análisis de la inocencia. $\mathrm{T}_{1}$ marca el inicio del lapso temporal en el que puede producirse este fenómeno. Con anterioridad a $t_{1}$, es decir, con anterioridad a la existencia de una investigación penal en contra de una persona no tiene mucho sentido, conceptualmente hablando, hablar de inocencia, y esto incluso si el hecho delictivo que será objeto de la investigación ya ocurrió. En efecto, si nunca se produce el inicio de una investigación, no puede hablarse de inocente para efectos procesal penales. $T_{2}$ marca el término del lapso temporal durante el cual puede producirse el fenómeno de la inocencia. Cuando $T_{2}$ concluye en una sentencia condenatoria tiene sentido referirse a una persona como aquella en la condición de encontrarse cumpliendo una sentencia condenatoria errónea. Desde luego que también son importantes objetos de análisis e investigación aquellas detenciones injustas y aquellos casos de prisión preventiva injustas, y más en general, toda pérdida de libertad no justificada en el hecho de que la persona objeto de la medida restrictiva de libertad no es el autor, en sentido amplio, del delito. En este punto, cabe resaltar el proyecto "Inocentes" de la Defensoría Penal Pública, el que entrega información importante precisamente de aquellas fases anteriores a

\footnotetext{
${ }^{5}$ CASTILLO, Ignacio, "Enjuiciando al proceso penal chileno desde el inocentrismo (algunos apuntes sobre la necesidad de tomarse en serio a los inocentes)", Política Criminal, no 8 (2013), pp. 249-313.
} 
FERNÁNDEZ, José Manuel; OLAVARRÍA, Malva. "Examinando de nuevo la acción de revisión”.

la sentencia condenatoria, sin perjuicio de que la información que éste entrega sea limitada, como aparece en la pagina web de dicha institución ${ }^{6}$ :

El criterio de identificación de las causas que pueden ser incorporadas al proyecto es el siguiente:

Personas inocentes que han estado sometidas a la cautelar de prisión preventiva o cuya detención fue ampliada injustificadamente y cuyas causas terminaron bajo los siguientes términos:

Facultad de no perseverar del Ministerio Público.

Sobreseimiento definitivo por inocencia o por ausencia del hecho punible Art. 250, letra a) y b).

Absoluciones en las cuales quedó demostrada la causa de error que permitió la injusta privación de libertad, al establecerse en la investigación una prueba exculpatoria.

La sentencia condenatoria como punto referencial para la investigación de las condenas erróneas se explica en que es éste el momento a partir del cual una persona pasa a estar condenada, y respecto de la cual el sistema de justicia criminal no requiere la comprobación de más hechos, a través de más evidencia, para cumplir la sentencia. Este momento marca el fin del proceso penal, sus efectos ya no son transitorios y la condena ya no es más eventual, los medios procesales para recurrir se han acabado y sólo resta cumplir la sentencia. Este estado de definitividad, denominado cosa juzgada, introduce la certeza de que una persona está condenada. A partir de esta caracterización de la situación procesal penal de un condenado, cabe el examen de si dicha sentencia condenatoria es errónea o no. Como puede verse, es en este marco en que la acción de revisión adquiere importancia porque ataca precisamente dicho estado de definitividad del proceso penal, esto es, el estado de las sentencias firmes que se encuentran en condiciones de cumplirse, o que están siendo actualmente cumplidas, o que ya han sido totalmente cumplidas. Así mismo, la existencia de una sentencia permite dimensionar y cuantificar el problema de las condenas erróneas y por lo tanto estudiar sus causas.

Volviendo en general a los estudios de carácter empírico debe remarcarse que el inicio del interés por la materia debe ser celebrado pero así como Mauricio Duce lo reconoce, todavía falta mucha investigación cuantitativa y cualitativa de carácter empírico para conocer el alcance y con profundidad suficiente los detalles y problemas de la condena de inocentes en Chile. Ciertamente es muy interesante notar que en nuestro país no hay estudios empíricos sobre abusos policiales o abusos del Ministerio Público, tampoco sobre casos sobre prestación indebida del derecho de defensa que se haya judicializado, lo que considerado conjuntamente explica en el derecho comparado más del 50\% de casos de condenas erróneas. Cabe notar que el panorama no es, al menos hoy, tan negativo. Hay ciertamente casos en que se ha demostrado que el Ministerio Público no ha revelado a la defensa evidencias exculpatorias, como en el caso de Pedro Lobos en que se acreditó que una fiscal

\footnotetext{
${ }^{6}$ http://www.proyectoinocentes.cl
} 
Polit. crim. Vol. 13, № 26 (Diciembre 2018) Art. 15, pp. 1190 - 1285.

[http://www.politicacriminal.cl/Vol_13/n_26/Vol13N26A15.pdf]

adjunto ocultó a la defensa evidencia que con posterioridad la Corte utilizara para fundar el acogimiento de la acción de revisión ${ }^{7}$. Casos en que la policía ha empleado medios inductivos y por lo tanto poco fiables, como en el caso de Julio Robles también acogido por la Corte Suprema ${ }^{8}$. Y ciertamente hay casos en que no hubo asistencia jurídica constitutiva del derecho de defensa y condición necesaria del debido proceso, como se sugiere de la sentencia recientemente acogida por la Corte Suprema respecto de condenados que fueron objeto de torturas durante la dictadura militar $^{9}$. Sin embargo, las investigaciones son incipientes lo que denota la ausencia de una preocupación seria por el problema tanto en la academia como en la jurisprudencia.

Posiblemente la explicación a esta carencia de estudios empíricos de las sentencias condenatorias erróneas y sus causas reside en que el interés de los académicos del derecho y criminólogos es muy reciente. Efectivamente, el campo no tiene más de 30 años, pues fue en 1987 cuando se publicó en la Stanford Law Review un artículo académico que examinaba a la fecha la mayor cantidad de casos de condenas erróneas ${ }^{10}$, específicamente un estudio sobre condenas de inocentes sentenciados a pena de muerte que fueron exonerados por prueba distinta de ADN, la que todavía no estaba disponible ${ }^{11}$. Inicialmente hubo mucho escepticismo ${ }^{12}$ respecto de lo que aquél y otros estudios revelaban, tanto en el público, en la práctica y en la academia, pues la mayoría consideraba como impensable que el proceso penal pudiera ser tan poco fiable, especialmente en sentencias que condenaban a muerte. No mucho después, la masificación de la prueba de ADN trajo una revolución en el

\footnotetext{
${ }^{7}$ Véase al respecto el análisis que efectúa Mauricio Duce, DuCE, “Algunas Lecciones”, cit. nota n 6, pp. 154159.

${ }^{8}$ Sentencia de la Corte Suprema (en adelante SCS), Rol 11109-2013.

${ }^{9}$ SCS, Rol 27543-2016.

${ }^{10}$ BEDAU, Hugo; RADELET, Michael, "Miscarriages of justice in potentially capital cases", Stanford Law Review, no 40 (1987), pp. 21-179. 3 analizaron 350 casos en un lapso de 85 anos, desde 1900 hasta 1985. Otros estudios que lo preceden no examinaron una cantidad de casos suficientemente representativa del problemas, como BORCHARD, Edwin, Convicting The Innocent: Sixty-Five Actual Errors of Criminal Justice, New Haven: Yale University Press, 1932, examinó 65 casos; GARDNER, Erle Stanley, The Court of Last Resort, USA: William Sloane Associates, 1952, 18 casos; FRANK, Barbara; FRANK, Jerome, Not Guilty, Garden City, N. Y.: Doubleday \& Company Inc., 1957, 34 casos; RADIN, Edward, The Innocents, USA: Morrow, 1964, 80 casos.

${ }^{11}$ En Inglaterra el primer estudio empírico fue realizado en 1973, BRANDON, Rut; DAVIES, Christie, Wrongful Imprisonment: Mistaken Convictions and their Consequences, London: Allen an Unwin, 1973, sin embargo, probablemente ni Inglaterra, ni el de Bedau en Estados Unidos, causó mucho impacto porque no se contaba con pruebas irrefutables de inocencia, y no fue sino hasta anos después la Runciman Commission, que puso de manifiesto públicamente el problema sistemático de errores de la justicia, que poco después motivara reformas legislativas que concluyeron con la creación de la Criminal Cases Review Commission. En el caso de Estados Unido el trabajo del Innocent Proyect ha sido fundamental para crear conciencia sobre el problema de la condena errónea de inocentes.

${ }^{12}$ Véase, entre ellos MARQUIS, Joshua, "The Myth of Innocence", The Journal of Criminal Law and Criminology, no 95 (2005), pp. 501-522; CASSELL, Paul, "The Guilty and The 'Innocent': An Examination Of Alleged Cases Of Wrongful Conviction From False Confessions”, Harvard Journal of Law and Public Policy, no 22 (1998), pp. 523-603, a este grupo famosamente se unió el ya fallecido juez de la Corte Suprema Norteamericana, Antonin Scalia. Para una crítica de estas posiciones, embarazosa por la demás, ya que revela la falta de conocimiento estadístico básico y que lleva invariablemente a conclusiones erróneas sobre la tasa promedio de condenas erróneas de inocentes, y por lo tanto, a minimizar su incidencia, véase Gross, Samuel, "Convicting the Innocent", Annual Review of Law and Social Science, no 4 (2008), pp. 173-192.
} 
FERNÁNDEZ, José Manuel; OLAVARRÍA, Malva. "Examinando de nuevo la acción de revisión”.

campo de las condenas injustas, porque se pudo evidenciar de manera concluyente que en muchos casos de condenas erróneas los condenados eran efectivamente inocentes. En ello el Innocence Project ${ }^{13}$, fundado en la Cardozo Law School, fue fundamental, porque suministró de asistencia jurídica gratuita a los condenados para que pudieran presentar nueva evidencia y lograr su exoneración. Esto también determinó la trayectoria del tipo de investigación sobre la inocencia y que ya tendremos la oportunidad de comentar, porque el estudio de las condenas injustas parte ligado a un entendimiento fáctico de inocencia ${ }^{14}$, cuyas implicancias examinaremos en la sección 2.2.

El estudio inicial sobre condenas de inocentes motivó numerosos estudios empíricos y conceptuales que lograron identificar las causas más comunes de condenas erróneas y a la propuesta institucional de reformas, pero también motivó importantes cambios jurisprudenciales y legales en el derecho comparado. Sin embargo, este shock y cambio de mentalidad en relación a la condena de inocentes tanto en el público como en los operadores del sistema de justicia criminal, se generó luego del impacto que provocó las pruebas de ADN, efecto que lamentablemente en Chile no se ha vivido hasta la fecha. Es de notar que Chile no es la excepción en la materia, pues muchos otros países de orientación procesal penal continental, tampoco experimentaron dicho shock, y en consecuencia, todavía carecen de una masa crítica de estudios empíricos que demuestren con exactitud las tasas de condenas erróneas, como en Alemania, España, Italia y Francia entre otros.

Sin perjuicio de que todavía estamos frente a un contexto en el que no hay un conocimiento detallado de las causas que explican la condena de inocentes, como hemos notado con anterioridad, todavía se puede avanzar más en la correcta comprensión de la acción de revisión como instituto procesal penal. Esta es la orientación que sigue esta investigación. Los aspectos procesales penales que serán objeto de examen son lo que debe entenderse por prueba nueva, los estándares que hacen procedente un nuevo juicio, la definición de inocente, y en general como caracterizar el mecanismo de revisión chileno. Desde esta perspectiva y, en comparación con modelos de revisión de otros países, donde es muy complejo y costoso sortear las dificultades procesales y evidenciales para solicitar una revisión de la sentencia condenatoria, se hará presente que Chile ofrece un modelo relativamente simple para cuestionar dichas sentencias. Sin embargo, facilitado por la interpretación estándar de la doctrina chilena, la jurisprudencia a sub-utilizado este recurso, con el resultado, como se verá con posterioridad, que en Chile todavía no estamos cerca siquiera de vislumbrar la punta del iceberg en lo que se refiere al conocimiento de la condena errónea de inocentes.

\section{Caracterizando la acción de revisión}

\subsection{El modelo adversarial de revisión vs el modelo inquisitivo de revisión}

Para caracterizar la acción de revisión en Chile es útil hacer una comparación con el modelo de revisión en España, no sólo porque hay diferencias fundamentales que el

\footnotetext{
${ }^{13} \mathrm{https} / / /$ www.innocenceproject.org/cases/

${ }^{14}$ RICHARD, Leo, "Rethinking the Study of Miscarriages of Justice: Developing a Criminology of Wrongful Conviction", Journal of Contemporary Criminal Justice, $\mathrm{n}^{\mathrm{o}} 21$ (2005), p. 205.
} 
Polit. crim. Vol. 13, № 26 (Diciembre 2018) Art. 15, pp. 1190 - 1285.

[http://www.politicacriminal.cl/Vol_13/n_26/Vol13N26A15.pdf]

contraste nos permite resaltar, sino porque ambas presentan propiedades procesales similares que una vez que se asumen presentes en el modelo chileno, facilitan evadir la comprensión de las diferencias entre ambos modelos. En general la doctrina Española considera que la acción de revisión no es un recurso, sino una acción excepcional de impugnación. Con ello, no sólo se pretende describir a la revisión como un procedimiento excepcional, en la medida que se interpone contra sentencias que generan cosa juzgada, sino que también describir cómo el tribunal, procedimentalmente, debe fallar la acción. La descripción de la acción de revisión en Chile supone lo mismo: no sólo se describe la revisión como mecanismo jurisdiccional sino que se describe cómo el tribunal debe fallar al conocer la acción.

En un trabajo reciente donde se examina la acción de revisión en España, se sintetizan las descripciones comunes que la doctrina y la jurisprudencia hacen de la revisión

"La revisión de la sentencia firme en el proceso penal representa uno de los institutos procesales que posiblemente mejor refleja la idea de justicia, pues a través de ésta se trata de dar solución a los casos en los que, pese a contar con una sentencia firme, se demuestra la existencia de un error judicial. Por ese mismo motivo, precisamente, no estamos en presencia de un recurso, sino de una acción autónoma de impugnación dirigida a conseguir la revocación de la cosa juzgada en aquellos casos de injusticia flagrante previstos por nuestro legislador procesal penal."15

Cualquiera que esté relativamente familiarizado con la acción de revisión en Chile encontrará que estas descripciones reflejan la misma comprensión de la acción de revisión de la doctrina ${ }^{16}$ y jurisprudencia chilena.

Ahora bien, como hemos notado hay dos descripciones que cabe diferenciar aquí. Una persigue describir la revisión como un mecanismo extraordinario en atención a su propósito: impugnar sentencias que generan cosa juzgada. Otra persigue describir adicionalmente cómo la Corte debe proceder al conocimiento y fallo del recurso de revisión. Ambas descripciones son consideradas por la doctrina como inherentemente

\footnotetext{
${ }^{15}$ VERNENGO PELLEJERO, Nancy Carina, La Revisión de la Sentencia Firme en el Proceso Penal, Tesis Doctoral, Universitat de Barcelona, 2015, p. 13. Así también, entre otros, GOMEZ DE LIANO, F., El proceso penal: tratamiento jurisprudencial, Oviedo: Editorial Forum, 1992, pp. 389 y ss.; AROCA, Juan Montero; GOMEZ COLOMER, Juan-Luis; MONTON REDONDO, Alberto; BARONA VILAR, Silvia, Derecho Jurisdiccional: Proceso Penal, Valencia: Tirant Lo Blanch, 2001, pp. 392-393; SANCHEZ MONTENEGRO, J.C, El recurso de revisión penal, Madrid: Edisofer, 2005, pp. 27 y ss.; COBO DEL ROSAL, M, Tratado de Derecho procesal penal Español, Madrid: Centro de Estudios Superiores de Especialidades Jurídicas, 2008, p. 825; SENDRA, Vicente Gimeno, Manual de Derecho Procesal Penal, Madrid: $2^{\mathrm{a}}$ Edición, Colex, 2010, p. 523.

${ }^{16}$ NÚÑEZ VÁSQUEZ, Cristóbal, Tratado del Proceso Penal y del Juicio Oral, Chile: Editorial Jurídica de Chile, 2003, p. 363; CERDA SAN MARTÍN, Rodrigo, Etapa Intermedia. Juicio Oral y Recursos, Chile: Librotecnia, 2003, p. 311; CAROCCA PÉREZ, Alex, El Nuevo Sistema Procesal Penal, Chile: LexisNexis, 2005, p. 286; HORVITZ LENNON, María Inés; LÓPEZ MASLE, Julián, Derecho Procesal Penal Chileno, $t$. II, Chile: Editorial Jurídica de Chile, 2004, p. 447; CORREA SELAMÉ, Jorge Danilo, Recursos Procesales Penales, Chile: LexisNexis, 2005, p. 339; CHAHUÁN SARRÁS, Sabas, Manual del Nuevo Procedimiento Penal, Chile: 6 a Edición, LegalPublishing, 2009, p. 364; MOSQUERA RUIZ, Mario; MATURANA MIQUEL, Cristián, Los Recursos Procesales, Chile: Editorial Jurídica de Chile, 2010, p. 574.
} 
FERNÁNDEZ, José Manuel; OLAVARRÍA, Malva. "Examinando de nuevo la acción de revisión”.

conectadas en razón de la finalidad que unánimemente se adscribe a la revisión; alcanzar la justicia y la verdad. Es decir, la finalidad de la revisión media entre la descripción de la acción como medio excepcional y la descripción procedimental de la forma como se debe fallar, así se indica que

"La revisión no consiste, en ningún caso, en la emisión de un juicio de valor alternativo a las pruebas presentadas en el proceso cuya sentencia se pretende revisar, sino en una suerte de verificación de la inocencia o culpabilidad a la luz de nuevas pruebas aportadas a la solicitud de revisión y que evidencien un error en la sentencia de condena." $" 17$

En razón de lo anterior,

“... la revisión representa una garantía de justicia, cuya aplicación se circunscribe, únicamente, a casos excepcionales y motivos tasados; factores que no dejan margen de maniobra a la arbitrariedad, ni a la vulneración del principio de seguridad jurídica."18.

Aparece entonces que la descripción de la revisión como acción excepcional está estrechamente conectada con la forma cómo se asume que el juez debe resolverla: sin emitir juicio de valor alguno, restringiéndose a verificar si concurre alguno de los motivos tasados que hacen procedente la acción. Garantizado que el tribunal deliberará de esta manera aparece que la seguridad jurídica representada por la cosa juzgada, y la justicia/verdad representada por la acción de revisión, llegan al siguiente compromiso: una sentencia condenatoria protegida por la cosa juzgada sólo puede anularse bajo la condición de describir la labor del juez como una labor mecánica. En otras palabras, el compromiso entre la seguridad jurídica y la justicia define la labor del juez como desprovista de aquello que precisamente caracteriza a la función judicial: la debida atención a las propiedades del caso concreto. Esta comprensión de la acción de revisión es, como veremos, perjudicial para la identificación de errores judiciales en perjuicio del condenado. Ahora bien, nótese que el compromiso entre seguridad jurídica y la justicia/verdad es aparente, porque si la labor del juez es mecánica no hay propiamente afectación de la seguridad jurídica. En efecto, si la revisión no supone ningún tipo de evaluación por parte del juez de la evidencia o razones hechas valer por el recurrente, porque la labor del juez es descrita como una aplicación mecánica de la ley que se activa automáticamente frente a motivos tasados, entonces no podría haber, por definición, ningún problema de seguridad jurídica porque no es el juez el que razona, sino la ley. La seguridad jurídica viene garantizada bajo la descripción del juez como aplicador mecánico de la ley.

Esta idea preconcebida de la "verdad" como correspondencia, fue una de la razones que nos llevaron a examinar tentativamente la noción de verdad desde un punto de vista filosófico y lingüístico en la investigación de 2009, porque esta idea de "verdad" como "hechos"19 que

\footnotetext{
${ }^{17}$ VERNENGO, La Revisión, cit. nota n ${ }^{\circ} 17$, p. 66.

${ }^{18}$ VERNENGO, La Revisión, cit. nota n' 17, p. 68.

${ }^{19}$ Aquí interpretamos el término "hechos" como aquello a lo que corresponde la verdad de una sentencia, pero como afirma Donald Davidson, si pretendemos defender la idea de verdad como aquello que es independiente de nuestras creencias, ello sólo puede hacerse sosteniendo la idea de correspondencia con hechos, pero entonces, como la idea de correspondencia se encuentra vacía de contenido (porque afirmar que la sentencia
} 
Polit. crim. Vol. 13, № 26 (Diciembre 2018) Art. 15, pp. 1190 - 1285.

[http://www.politicacriminal.cl/Vol_13/n_26/Vol13N26A15.pdf]

se encuentran "allá afuera" y que son independientes de nuestras prácticas, concibe al juez que conoce de la revisión como un aplicador mecánico de la ley, y en consecuencia tergiversa, como veremos, el modelo de revisión que el legislador estableció en el Código Procesal Penal. El efecto de esta concepción es que reduce de manera drástica las posibilidades de identificar condenas erróneas. Posiblemente esta idea de "verdad" persiste en la doctrina y jurisprudencia porque no ha pasado mucho tiempo desde que en Chile se abandonara el proceso penal inquisitivo que sí se auto-definía como avocado a la búsqueda de la verdad, y ello aunque en definitiva no fuera más que nada una auto-descripción sin asidero en la práctica misma del proceso penal chileno.

La adopción de un sistema adversarial de justicia penal debió significar, entre otras cosas, el abandono de la imagen del juez como un aplicador mecánico de la ley, porque lo que se abandona es fundamentalmente la forma en como el juez debe valorar las pruebas en el nuevo proceso penal. En efecto, ya no existe la prueba tasada, la expresión de la desconfianza del legislador soberano en la labor judicial y por la que pretendía relevar legislativamente al juez de la valoración de la prueba. El sistema de valoración legislativa de la prueba fue reemplazado por un sistema de sana crítica que reconoce que el juez es independiente frente al legislador, y que lo obliga a dar razones que justifiquen su decisión ${ }^{20}$. Este cambio institucional también debería haber reflejado un cambio en la idea de verdad sobre la que se asienta la comprensión de la revisión, porque estrictamente no es la verdad como correspondencia lo que en definitiva es parte del proceso penal. Piénsese en dos aspectos de nuestro modelo, y así hay muchos otros, que son instancias de la misma idea: la facultad de no perseverar y todas aquellas disposiciones que excluyen la prueba por infracción de garantías fundamentales. Ambos incorporan al ordenamiento procesal normas que antes no se encontraban fuertemente institucionalizadas; los derechos fundamentales de la persona humana y la noción de evidencia como justificación, y que no obstante son inconsistentes con la tradicional idea de verdad como correspondencia. Ciertamente, desde la perspectiva de la consecución de la verdad dichas normas son consistentes con un sentido construccionista de verdad ${ }^{21}$, un sentido que obliga en ciertos casos a carecer de los medios

A corresponde al "hecho" C, es afirmar que A corresponde al universo), entonces también es vano el intento de defender el término "verdad" como aquello que es independiente de nuestras creencias, DAVIDSON, Donald; Truth and Predication, Cambridge Massachusetts: Harvard University Press, 2005, pp. 39-42.

${ }^{20}$ Esto no significa que al juez sea "libre" en el sentido que evalúe de manera puramente subjetiva sus propias creencias. Por el contrario, el juez se encuentra sometido a estándares objetivos de racionalidad tanto en su razonamiento como en la evaluación de la evidencia sobre la que debe justificar su decisión. Sobre esta posición véase entre otros, LASO CORDERO, Jaime, "Lógica y sana crítica", Revista Chilena de Derecho, $\mathrm{n}^{\circ}$ 36 (2009), pp. 143-164; ACCATINO SCAGLIOTTI, Daniela, "Certezas, dudas y propuestas en torno al estándar de la prueba penal”, Revista de Derecho de la Pontificia Universidad Católica de Valparaíso, no 37 (2011), pp. 483-511; LAUDAN, Larry, Truth, Error, and Criminal Law: An Essay in Legal Epistemology, Cambridge: Cambridge University Press, 2006. En general sobre la valoración racional de la prueba como una valoración objetiva véase FERRER BELTRAN, Jordi, La Valoración General de la Prueba, Madrid: Marcial Pons, 2007, y sobre la conexión entre razonabilidad, racionalidad y objetividad, MACCORMICK, Neil, "Reasonableness and Objectivity", Notre Dame Law Review, no 74 (1999), pp.1575-1604; GREENAWALT, Kent, Law and Objectivity, Oxford y New York: Oxford University Press, 1992; PAVLAKOS, George, Our Knowledge of the Law: Objectivity and Practice in Legal Theory, Oxford: Hart Publishing, 2007.

${ }^{21}$ El acento no sólo esta en la verdad, sino en la justificación de los enunciados, véase SÁNCHEZ BRÍGIDO, Rodrigo; SELEME, Hugo Omar, "Justificación sin verdad”, Analisi e Diritto, 2001, pp. 285-294. Nótese que esto no significa que la verdad no sea importante. Como Taruffo reconoce, incluso aún aceptando que el 
FERNÁNDEZ, José Manuel; OLAVARRÍA, Malva. "Examinando de nuevo la acción de revisión”.

probatorios que permitirían justificar la condena de una persona por existir una violación de derechos que el sistema de justicia se ha comprometido a proteger, en muchos casos, de forma categórica, y que en otros casos faculta a no iniciar la investigación evitando la formulación de una acusación sin evidencia.

Lo precedente tiene implicaciones para la adecuada comprensión de la revisión, porque esta acción no es un elemento aislado en el sentido que sea una parte de un antiguo sistema procesal penal que se incorporó a uno nuevo, es decir, no se trata de un mecanismo de prueba tasada que se incorpora a un sistema adversarial. Por el contrario, se trata de un nuevo mecanismo de revisión de sentencias, de un mecanismo que es parte de un sistema integrado, que asentándose sobre nuevos principios y normas obligan a una nueva comprensión de este instituto, carácter y alcance. Este es un punto que debe enfatizarse: la revisión se entiende de distintas maneras dependiendo del tipo de sistema de justicia criminal que integra. Se sigue, en consecuencia, que al integrar un nuevo sistema procesal penal, la revisión debe ser caracterizada de manera diferente. Cabe notar que el nuevo modelo no implica el rechazo de reglas diferenciadas en el contexto de revisión, en particular, la existencia de reglas que establecen un estándar más estricto con arreglo al cual el juez debe valorar la prueba. Por el contrario, dichos estándares tienen una justificación plausible, como se verá con posterioridad. Sin embargo, el entender el nuevo modelo de revisión dentro de un nuevo sistema de justicia penal si implica abandonar la implausible visión del juez que aplica mecánicamente la ley, es decir, el sentido peyorativo del juez como mera boca de la ley ${ }^{22}$. Veamos ahora uno de los problemas fundamentales de entender la revisión de esta manera, la que no obstante se ajustaba a un modelo distinto, y que llamaremos "modelo inquisitivo de revisión".

Lo fundamentalmente problemático de entender la revisión como medio extraordinario y por ende bajo la descripción del juez como aplicador mecánico de la ley, es que se justifica la práctica de la Corte Suprema de evaluar la prueba que se hace valer en la revisión de acuerdo a un único estándar: que la inocencia sea acreditada de manera fehaciente. Es decir, justifica la práctica que reduce el modelo de revisión chileno a la disyuntiva entre rechazar o absolver y dictar sentencia de reemplazo. Esto es precisamente lo que esta investigación se propone controvertir y demostrar que es errado, porque dicha práctica elimina del ordenamiento jurídico las disposiciones y normas sobre la realización de un nuevo juicio. Aquí es donde aparece útil el contraste con el modelo Español, porque el caracterizar la revisión como un modelo disyuntivo es correcto si uno considera este modelo. De acuerdo a la Ley de Enjuiciamiento Criminal, si el Tribunal Supremo considera que la acción debe ser acogida, éste debe anular la sentencia y reenviar el juicio a la instancia correspondiente

proceso tiene como fin la búsqueda de la verdad, en el proceso se tiene un tiempo y recursos limitados para encontrarla, por lo que sin abandonar la idea de verdad, uno podría hablar de verdad relativa, TARUFFO, Michele, "Algunas Consideraciones sobre la Relación entre Prueba y Verdad", en Michel Taruffo, La Prueba: Artículos y Conferencias, Chile: Editorial Metropolitana, 2009, p. 68.

${ }^{22}$ MONTESQUIEU, Charles de Secondat Baron de, Del Espíritu de las Leyes, Madrid: Tecnos, 1995, p. 112. Naturalmente, esta no es la única lectura posible de este texto de Montesquieu, pues como nota Fernando Atria, lo que a el le preocupaba era entregar una comprensión de la función judicial encaminada a la protección de la libertad individual, lo que sólo podía favorecerse en condiciones de división de poderes, véase ATRIA, Fernando, "Jurisdicción e Independencia Judicial: El Poder Judicial Como Poder Nulo", Revista de Estudios de la Justicia, no 5 (2004), pp. 119-142. 
Polít. crim. Vol. 13, № 26 (Diciembre 2018) Art. 15, pp. 1190 - 1285.

[http://www.politicacriminal.cl/Vol_13/n_26/Vol13N26A15.pdf]

para que se dicte inmediatamente sentencia absolutoria ${ }^{23}$. Es decir, o el tribunal rechaza o acoge sin que exista la posibilidad de un nuevo juicio. En efecto, si acoge el reenvío a la instancia correspondiente

“...no obliga al Tribunal de instancia a resolver nuevamente sobre el fondo del asunto, sino que por contra se limitará a dictar una sentencia absolutoria en la causa, siguiendo los postulados que le impone la sentencia rescindente dictada por el Tribunal Supremo en sede de revisión." ${ }^{24}$.

Naturalmente, el reenvío a la instancia correspondiente hace a este sistema merecedor de la crítica expuesta por Vernengo, porque evidentemente, es contrario a la economía procesal, pues podría el propio Tribunal Supremo decretar la sentencia absolutoria ${ }^{25}$. Ahora bien, si esta es la descripción correcta del ordenamiento procesal penal español, entonces pareciera que la revisión es, en efecto, un vestigio de un sistema inquisitivo fenecido que perdura en un modelo más adversarial, porque el Tribunal Supremo se ve forzado a rechazar o a acoger si la nueva prueba hecha valer hubiera "...determinado la absolución..."26. Es decir, en el modelo español es la prueba la que valora en vez del juez, el juez no evalúa sólo aplica la ley, por ende, si se trata de un aplicador mecánico de la ley, es la ley la que valora la prueba y no el juez.

Es precisamente uno de los objetivos de esta investigación demostrar que la interpretación de la Corte Suprema que elimina normas válidas sobre la posibilidad de un nuevo juicio es errada, esto es, que el modelo actual de revisión no es un modelo inquisitivo sino un modelo adversarial de revisión, lo que ya fuera en todo caso sugerido en la investigación del 2009. Obviamente, la vigencia no autorizada del modelo inquisitivo de revisión repercute en los casos de inocencia. Como veremos, la práctica de la Corte Suprema invariablemente rechaza aquellos casos en que el recurrente hace valer nueva evidencia que, si bien no acredita fehacientemente la inocencia del condenado, si hubiera sido incluida en el juicio oral si la habría acreditado de manera suficiente. Ciertamente, un sistema de revisión en que la prueba no es valorada por el juez, porque éste es visto como la mera boca de la ley, es uno en el que el legislador admite la anulación de una sentencia sólo en casos de manifiesta injusticia, en palabras del Código Procesal Penal (en adelante CPP), en casos que se acredite fehacientemente la inocencia del condenado. En otras palabras, un modelo inquisitivo en el que el legislador valora por el juez. Nótese que esto tiene serias implicancias para cualquiera que sostenga que la revisión, bajo la descripción precedente, es una acción encaminada a hacer valer consideraciones de justicia material por sobre consideraciones de seguridad jurídica. En efecto, si se interpone una acción de revisión disponiéndose de nueva evidencia suficiente, pero que no alcance a satisfacer el estándar más elevado de manifiesta injusticia, un sistema de justicia como el Español rechazará la

\footnotetext{
${ }^{23}$ Artículo 958.4 LECrim.

${ }^{24}$ VERNENGO, La Revisión, cit. nota $\mathrm{n}^{\mathrm{o}} 17$, p. 382.

${ }^{25}$ VERNENGO, La Revisión, cit. nota $\mathrm{n}^{\circ} 17$, p. 384.

${ }^{26}$ El texto completo del artículo 954 de la Ley de Enjuiciamiento Criminal establece:

"1. Se podrá solicitar la revisión de las sentencias firmes en los casos siguientes:

d) Cuando después de la sentencia sobrevenga el conocimiento de hechos o elementos de prueba, que, de haber sido aportados, hubieran determinado la absolución o una condena menos grave."
} 
FERNÁNDEZ, José Manuel; OLAVARRÍA, Malva. "Examinando de nuevo la acción de revisión”.

acción fundada en lo que dice la ley. En Chile, tal caso, sería también rechazado, sin embargo, dicho rechazo no estaría fundado en la ley, sino en la práctica de la Corte que permite hacer subsistir el modelo inquisitivo de revisión.

La situación en España no puede resolverse jurisprudencialmente, a diferencia del caso chileno, y esto es importante. En efecto, hoy se sabe gracias a las investigaciones empíricas en materia de condenas erróneas de inocentes, que es probable que muchos inocentes no dispongan de medios para recabar evidencia que podría demostrar su inocencia, sobre todo si se encuentran en prisión. Si asumimos que estos casos de inocentes forman parte de las acciones que fueron rechazadas por no haber acreditado el estándar de manifiesta la injusticia, y que justificaremos con posterioridad, ocurre que la apelación a la idea de justicia/verdad o es errónea, o en el peor de los casos, re-define situaciones de injusticia como situaciones de justicia. En otras palabras, si el sistema de justica penal no da cabida para que los casos en que se cuenta con nueva evidencia suficiente sean racionalmente evaluados, lo que significaría, por ejemplo, que se permita que sean oídos durante un nuevo juicio oral, el sistema se compromete no con la justicia sino con la injusticia, no, ciertamente, con la verdad $^{27}$.

Lamentablemente, el modelo inquisitivo de revisión, si bien no se encuentra vigente en Chile, continúa siendo aplicado por la Corte Suprema al entender la revisión como un modelo disyuntivo, requiriendo para acoger la acción que se satisfaga únicamente el estándar de manifiesta injusticia o evidencia fehaciente. Este proceder se soporta y justifica en la comprensión de la revisión como una acción excepcional y extraordinaria, como un recurso encaminado a restablecer la justicia y la verdad, estableciendo una narrativa en que el juez mecánicamente puede identificar y discriminar aquellos casos que son evidentemente de inocentes, y aquellos que no. Es tiempo de abandonar esta comprensión de la labor jurisdiccional. En efecto, el modelo vigente de revisión se integra en un sistema de justicia adversarial que se toma en serio la justicia, la verdad y los derechos fundamentales, lo que debería conducir a interpretar la institución de la revisión como un mecanismo, que si bien no es la última solución al problema de la condena errónea de inocentes, si puede contribuir a disminuir su incidencia.

Desde luego, un proceso penal realmente inspirado en principios de justicia y verdad debe tener un modelo de revisión que permita un examen jurisdiccional racional de los casos en que se hace valer nueva evidencia relevante, de modo que no queden relegados a un rechazo de plano por no cumplir con en el estándar de manifiesta injusticia basado en la aplicación mecánica de la ley. En la práctica, ello debería significar que la Corte Suprema

\footnotetext{
${ }^{27}$ De la examinación empírica de las sentencias del Tribunal Supremo Español, Vernengo distingue las causas más comunes de revisión de sentencias firmes, entre las que se incluye el hacer valer nueva evidencia, y por lo tanto, refuerza las sospechas de condenas de inocentes que sin embargo no tienen cabida en el modelo disyuntivo adoptado por el legislador español "En la mayoría de casos, la revisión ha pretendido demostrar alguna de las siguientes circunstancias: a) Casos de error en la [258] identificación de la persona (entre otras, la suplantación de identidad); b) La condena a un sujeto que se encontraba en prisión por otro delito, en el momento en que se cometió otro por el cual fue condenado; c) Minoría de edad o incapacidad del condenado; y d) Concurrencia de evidencias de origen orgánico y sobre las cuales no se pudo practicar la prueba, en su momento, por falta de medios.”, VERNENGO, La Revisión, cit. nota n 17, p. 259.
} 
Polít. crim. Vol. 13, № 26 (Diciembre 2018) Art. 15, pp. 1190 - 1285.

[http://www.politicacriminal.cl/Vol_13/n_26/Vol13N26A15.pdf]

considere, en los casos que ello corresponde, que si bien la nueva evidencia no tiene fuerza suficiente para acreditar la inocencia del condenado, sin embargo debería permitirse la realización de un nuevo juicio si el Ministerio Público considera que hay pruebas suficientes para ello. Este es el modelo adversarial de revisión que fue adoptado por el legislador en Chile, el que no obstante, ha quedado relegado a una opción meramente teórica. La ventaja del modelo adversarial es que la Corte Suprema no está obligada a ser invariablemente estricta en la evaluación de la fuerza probatoria de la nueva evidencia hecha valer, porque existirán casos en que la prueba sólo acreditará "suficientemente" y no "fehacientemente" la inocencia del condenado, por lo que será en definitiva el Ministerio Público el encargado de decidir si iniciar o no una nueva investigación por los mismos hechos. Para el modelo adversarial no es real la disyuntiva entre acoger o rechazar, sino que existe una tercera alternativa consistente en permitir la realización de un nuevo juicio.

En suma, de acuerdo a la regulación vigente del CPP, el modelo adversarial de revisión no se puede caracterizar como una acción de impugnación solamente dirigida a revocar la cosa juzgada en casos de injusticia manifiesta, porque en el modelo chileno el juez no está confrontado únicamente con la disyuntiva de acoger o rechazar, sino que hay una tercera alternativa que consiste en permitir un nuevo juicio para evaluar, en la instancia que corresponda y si así lo decide el Ministerio Público, la nueva evidencia hecha valer por el condenado. Desde este punto de vista es más ajustado caracterizar la revisión no como un mecanismo que asegura la justicia material, sino que persigue la custodia de la racionalidad del derecho a castigar penalmente, lo que sólo puede considerarse satisfecho cuando las evidencias lo justifican. Es cierto que la revisión esta inclinada exclusivamente a favor del condenado, pero dicha inclinación se encuentra mejor recepcionada en la formulación propuesta precedentemente, la que por lo demás no sólo admite que en el nuevo juicio se confirme la condena, sino que se conforma con el modelo previsto por el legislador. Si la justicia fuera la única justificación del modelo adversarial de revisión, deberían incluirse también las sentencias condenatorias por faltas y los casos en que la evidencia demuestra que las circunstancias modificatorias de responsabilidad penal se aplicaron incorrectamente. Sin embargo, tanto las faltas como las circunstancias modificatorias de responsabilidad penal se encuentran excluidas de la revisión.

Antes de iniciar la sección siguiente, es necesario ilustrar con un ejemplo lo real de la influencia del discurso que caracteriza la revisión como una acción excepcional, extraordinaria y destinada a realizar la justicia en detrimento de la seguridad jurídica, esto en el evento que dicho discurso se considere inerte desde el punto de vista explicativo del procedimiento de revisión. Se trata de un delito de manejo en estado de ebriedad con resultado de daños materiales en que el imputado, renunciando a su derecho al juicio oral, acuerda con el fiscal la suspensión condicional del procedimiento en septiembre de 2009, decretándose el sobreseimiento definitivo en noviembre de 2011 en conformidad al artículo 240 del CPP. En forma paralela a dicho procedimiento se inició por vía de Policía Local una investigación en contra del mismo imputado por los mismos hechos, el que con posterioridad, al remitirse los antecedentes al Ministerio Público, suscitó el inicio de un procedimiento penal ante la autoridad competente sin advertirse que se trataba de los mismos hechos y del mismo imputado, procedimiento por el que fue en definitiva condenado. Sin embargo, como ya se notara, la acción penal para la persecución de dicho 
FERNÁNDEZ, José Manuel; OLAVARRÍA, Malva. "Examinando de nuevo la acción de revisión”.

delito se encontraba extinta en atención al sobreseimiento definitivo decretado el 2011. Una vez que la Defensoría Penal Publica advirtió la existencia del problema solicitaron ante el Juzgado de Garantía una cautela de garantías en la que se decretó la suspensión de la sentencia definitiva hasta encontrarse ejecutoriada la sentencia que acogiera la acción de revisión, lo que ocurrió el mismo año 2011. Sin embargo, la decisión de la Corte Suprema, lo que parece inconcebible, no fue unánime, pues el voto minoritario consideró que dicho sobreseimiento había afectado de alguna manera la "justicia", y ello a pesar de que el Ministerio Público, el organismo encargado de investigar, también consideró que se había producido una afectación de derechos fundamentales lo suficientemente seria como para acordar una audiencia de cautela de garantías. La sentencia contó con el voto en contra de los jueces Segura y Rodríguez, los que fundamentaron su voto de la siguiente manera:

"PRIMERO: Que la acción de revisión encuentra de razón de existencia en el fin superior y extraordinario de justicia mediante la posibilidad de examinar la validez de una sentencia condenatoria por parte del más alto Tribunal de la República, fundada en motivaciones que no pertenecen al proceso mismo en que la resolución impugnada se dicta, sino que son extrínsecas a dicho proceso y determinan, por tanto, la existencia de vicios trascendentes a él, la realización de la justicia impone el reconocimiento de un recurso de este tipo que prohíbe que los resultados transcendentalmente injustos se consolidan definitivamente, pese al conocimiento y a la prueba de las causas de que esta injusticia se origina... De ello resulta, entonces, que se trata de una acción excepcional, altamente especial y extraordinaria, que debe, necesariamente, fundarse en hechos de tal trascendencia que por sí mismos sean suficientes para desprenderse la plena inocencia del imputado en los hechos los cuales se le ha condenado por sentencia ejecutoriada.

TERCERO: Que, en esencia, el hecho cuya ocurrencia se invoca no se ha producido por un acontecimiento de una acción ajena a la voluntad del imputado. En efecto, conocedor, como no podía ser de otro modo, de la existencia de dos procedimientos en su contra por un hecho en el cual él había tenido intervención, claramente pone de manifiesto que sólo una vez que fue sancionado en aquel que derivó de la incompetencia declarada por el Tercer Juzgado de Policía Local de Santiago, y en vías de obtener el beneficio de sobreseimiento definitivo en el otro, contribuye con su renuncia a la ejecutoriedad de la condena, y expresamente reclama sea aquel declarado, ocultando la existencia de esa condena anterior, logrado lo cual se funda finalmente la presente demanda de revisión.

De lo dicho, se concluye, entonces, que la pretensión no se funda en resultados transcendentalmente injustos, como se anotara más arriba, acusándose, por el contrario, una manifiesta mala fe de parte del imputado que, después de haber logrado la resolución de sobreseimiento definitivo en uno de dos procedimientos seguidos en paralelo en su contra, pretenda ahora liberarse absolutamente de sanción. No es el sentido de la ley y del carácter particular de la acción de revisión, de modo que no concurra en su favor la causal de la letra d) del artículo 473 del Código de Procedimiento Penal." 28.

Ahora bien, la suspensión condicional del procedimiento, como forma alternativa de resolver un conflicto penal, se justifica en un compromiso en el que las partes implicadas

\footnotetext{
${ }^{28}$ SCS, Rol 2227-11.
} 
Polít. crim. Vol. 13, № 26 (Diciembre 2018) Art. 15, pp. 1190 - 1285.

[http://www.politicacriminal.cl/Vol_13/n_26/Vol13N26A15.pdf]

renuncian a ciertas pretensiones en atención a consideraciones más valiosas. Por una parte, el imputado se somete a medidas restrictivas de su libertad sin que exista un juicio oral donde, respetando todos sus derechos, se compruebe más allá de duda razonable que le ha cabido una participación culpable en un delito, y por otra el estado renuncia al esclarecimiento del hecho y a la punición completa del culpable. Así María Elena Horvitz y Julián López señalan, entre otras consideraciones valiosas, y respecto del estado, el ahorro de recursos, la evitación de las consecuencias del encierro que generan gastos presentes (y posiblemente futuros), el cumplimiento de ciertas condiciones en beneficio de la víctima, y otros como el reconocimiento, prima facie, de la realización de un delito menos grave, y respecto del imputado, la evitación de las consecuencias de la privación de libertad ${ }^{29}$ y la evitación de que, en caso de un nuevo delito, pueda ser considerado como reincidente.

Todas estas consideraciones, importantes por lo demás, y que justifican la suspensión condicional del procedimiento parecen ser superfluas para el voto disidente, en atención, como puede verse en el texto resaltado del fallo, a que lo único relevante es la "realización de la justicia". En la concepción del voto disidente la justicia parece realizarse ya no sólo requiriendo del imputado que cumpla ciertas condiciones restrictivas de su libertad por más de dos años, sino además que sea efectivamente condenado por el mismo hecho. En otras palabras, el voto disidente considera que infringir el non bis in ídem es la manera de hacer justicia. La comprensión de la acción de revisión como forma de hacer justicia tiene, entonces, no sólo implicancias que afectan el diseño original del legislador, sino implicancias en la comprensión de los eventos que hacen procedente las causales de revisión, esto es, como procedimentalmente la Corte debe fallar al conocer de la acción. Ello apunta y refuerza lo que se ha venido sosteniendo; lo pernicioso de caracterizar esta acción en atención a la idea de justicia y paradójico, porque facilita y permite un tipo de razonamiento judicial que con nitidez infringe principios de justicia penal firmemente arraigados a nuestro sistema procesal penal, y tiende a obstaculizar que la nueva evidencia relevante hecha valer por el inocente pueda ser evaluada racionalmente en sede jurisdiccional.

\subsection{Definiendo inocencia}

Si bien el modelo adversarial de revisión chileno alude a la "inocencia del condenado" en el artículo 473 del CPP, en ninguna parte define que debe entenderse por tal. El asunto no es redundante, porque la mayor parte de las investigaciones empíricas sobre la inocencia consideran exclusivamente al "fácticamente inocente". Así, entre nosotros Castillo distingue entre f-inocente (fácticamente inocente) como aquellos que son inocentes “...porque no han cometido el delito que se les imputa, sea porque el verdadero autor fue un tercero o porque el delito no existió..." ${ }^{\natural 0}$ y $n$-inocente (normativamente inocente) como aquellos que son "... aunque realmente culpables del delito, son declarados inocentes por razones normativas, sea porque el Ministerio Público no pudo alcanzar el estándar de prueba necesario para obtener una condena, porque parte importante de la evidencia no

\footnotetext{
${ }^{29}$ HORVITZ / LOPEZ, Derecho Procesal, tomo I, cit. nota ${ }^{\circ}$ 18, p. 552.

${ }^{30}$ CASTILlO, "Enjuiciando al", cit. nota $n^{\circ} 7$, p. 252.
} 
FERNÁNDEZ, José Manuel; OLAVARRÍA, Malva. "Examinando de nuevo la acción de revisión”.

pudo ser utilizada en el juicio..."31. Esta distinción, adoptada del derecho comparado, es muy útil en lo que se refiere al trabajo empírico inicial sobre la revisión, distinción que también es adoptada por Mauricio Duce. Esto es particularmente importante en Chile en atención a que recién comienzan a cuantificarse y a investigarse las causas que pueden llevar a la condena errónea de inocentes, lo que, dado la experiencia comparada, no parece ser un aspecto transitorio sino sistémico de la justicia penal. Sin embargo, emplear el término "fácticamente inocente" no parece ser completamente adecuado cuando el propósito es describir los mecanismos que el sistema procesal penal dispone, desde el punto de vista de la calidad de la prueba que justifica una sentencia condenatoria, para corregir situaciones que si bien transitoriamente son estables, como lo es una sentencia condenatoria, pueden volverse inestables o injustificadas, cuando aparecen nuevos antecedentes probatorios que demuestran que la condena fue errónea. Como veremos, estas situaciones están integradas al sistema adversarial de revisión chileno, no obstante, la Corte Suprema no las ha reconocido en la práctica.

Ahora bien, el problema es como interpretar el término "inocente" previsto por el artículo 473 letra d) del CPP. Identificar el término "inocente" con la inocencia fáctica tiene consecuencias prácticas importantes. En efecto, interpretado de este modo, ello excluiría de la aplicación del artículo 473 letra d) todas aquellas circunstancias no fácticas que eventualmente podrían invalidar una sentencia, como, por ejemplo, evidencia nueva que demuestra que el condenado tenía una seria enfermedad mental o que fue torturado y que por éstas u otras razones se justifica la invalidación de la sentencia. Lo mismo se ha puesto de relieve en el derecho comparado, específicamente en Estados Unidos donde el uso de la prueba de ADN, y que dio inicio a un movimiento social y académico por hacer públicos los errores del sistema de justicia penal en un intento de corregirlos, denominado movimiento inocentrista ${ }^{32}$, ha definido el camino de la investigación de las condenas erróneas en términos que excluyen casos que deberíamos considerar como inocentes ${ }^{33}$. Como señala Keith Findley, incluso la prueba de ADN tiene muchos matices ${ }^{34}$ porque no siempre es concluyente para demostrar que el condenado es inocente. Sin embargo, la fuerza probatoria del ADN parece empujar a un entendimiento fáctico de inocencia dejando de lado estos otros casos que también son de interés teórico y práctico. Como enfatiza Susan Bandes, la prueba de ADN ha motivado la creencia que existen pruebas que pueden entregar certezas absolutas, es decir, que pueden confirmar con un $100 \%$ de seguridad la inocencia y la culpabilidad del condenado ${ }^{35}$. Lo que parece explicar la fuerza del ADN y lo que facilita la posición privilegiada que el ADN ocupa en las investigaciones sobre la inocencia, es una cierta caracterización del proceso penal como proceso encaminado a obtener la "verdad" 36 . Es decir, lo que se encuentra en el trasfondo del imaginario que

\footnotetext{
${ }^{31}$ CASTILlO, "Enjuiciando al", cit. nota no 7, pp. 252-253.

${ }^{32}$ Así definido por MEDWED, Daniel, “Innocentrism”, University of Illinois Law Review, 2008, pp. 15491572.

${ }^{33}$ La misma crítica se hace en Inglaterra, véase entre otros NAUGHTON, Michael, "Redefining Miscarriages of Justice: A Revived Human-Rights Approach to Unearth Subjugated Discourses of Wrongful Criminal Conviction", The British Journal of Criminology, no 45 (2005), pp. 165-182.

${ }^{34}$ FINDLEY, Keith, “Defining Innocence”, Albany Law Review, no 74 (2010), p. 1161.

${ }^{35}$ BANDES, Susan, "Framing Wrongful Convictions", Utah Law Review, no 5 (2008), p. 10.

${ }^{36}$ William Twining ha explicitado el conjunto de premisas que soportan el modelo del proceso como "búsqueda de la verdad" y que él denomina modelo racionalista, para un examen detallado de este modelo
} 
Polit. crim. Vol. 13, № 26 (Diciembre 2018) Art. 15, pp. 1190 - 1285.

[http://www.politicacriminal.cl/Vol_13/n_26/Vol13N26A15.pdf]

considera el ADN como una prueba irrefutable, es entender al proceso penal encaminado exclusivamente al establecimiento de la verdad.

Como expresión de este imaginario la prueba de ADN aparece capaz, al menos en muchos casos, de demostrar de manera irrefutable la inocencia o la culpabilidad del condenado. Es decir, la prueba de ADN calza perfectamente con el tipo de evidencia que se esperaría de un modelo del proceso penal avocado a la búsqueda de la verdad, porque este tipo de evidencia maximiza la precisión de la determinación de los hechos. No obstante, como hemos visto, este tipo de evidencia no refleja la realidad del proceso penal, en el que este tipo de evidencia no siempre es relevante o se encuentra disponible, y en el que se dispone normalmente de medios de prueba que las partes controvierten durante el proceso y durante el juicio, el que además persigue otros valores como el respeto de los derechos fundamentales de la persona. En efecto, el ADN como evidencia es ciertamente muy valiosa, pero por sí misma es incapaz de discriminar con exactitud el inocente del culpable porque en el moderno proceso penal, siempre falible, debe reconocerse que no hay ni pueden haber pruebas absolutas ${ }^{37}$. Esto tiene implicancias para la definición de inocente. Debido a que la determinación de quien es inocente o culpable no puede establecerse en términos absolutos, sino que se trata de un continuum con un punto de inicio y uno de conclusión, es necesario emplear un concepto amplio de inocente adecuado a dicho continuum. Desde nuestra perspectiva ya hemos tomado posición en lo que respecta al examen de las sentencias de condenas para efectos de la revisión, lo que implica, respecto de la definición de inocente, tomar como punto de referencia la existencia del proceso penal, contexto en el cual adquiere sentido el término inocencia. Ello significa considerar como inocente a toda persona que no cumpla con el estándar para ser considerado culpable $^{38}$, porque la calidad de inocente puede deberse a un conjunto de razones más amplio que lo que se entiende por fácticamente inocente.

De no seguirse este concepto amplio de inocente el inocentrismo quizás podría estancarse en un futuro cercano. Así como señala Findley respecto de Estados Unidos:

"El movimiento [de defensa de inocentes] ha llegado a un punto donde debe abiertamente empujar la definición de 'inocente' más allá de la estrecha banda indisputable de casos establecida por las exoneraciones de ADN. Mientras que las exoneraciones por ADN han cambiado el escenario legal y los entendimientos populares acerca de nuestro sistema de justicia, ya esta emergiendo una fatiga del inocente." ${ }^{39}$.

Esta forma de entender la inocencia en el proceso penal ha llevado al movimiento inocentrista a expandir las investigaciones sobre la inocencia. Esta orientación ha sido tomada por uno de los criminólogos más influyentes en el ámbito de la investigación de los

\footnotetext{
véase TWINING, William, Rethinking Evidence: Exploratory Essays, Cambridge: Second Edition, Cambridge University Press, 2006, p. 75 y ss.

${ }^{37}$ BANDES, “Framing Wrongful”, cit. nota no 37, p. 11; FINDLEY, "Defining Innocence", cit. nota no 36, p. 1161.

${ }^{38}$ En el mismo sentido, véase FINDLEY, "Defining Innocence", cit. nota no 63, p. 1162.

${ }^{39}$ FINDLEY, "Defining Innocence”, cit. nota no 36, p. 1192.
} 
FERNÁNDEZ, José Manuel; OLAVARRÍA, Malva. "Examinando de nuevo la acción de revisión”.

erróneamente condenados. Así, Samuel Gross se encuentra actualmente trabajando en un estudio empírico sobre la retractación de testigos y víctimas, cuyos resultados preliminares informan acerca del porcentaje de retractación y cuales pueden ser la causas que llevan a una persona a rectificar lo que ha declarado en juicio o durante el proceso penal ${ }^{40}$. Si bien las conclusiones del estudio son limitadas, porque examina las retractaciones dentro de la clase de condenados que han sido exonerados y no la de no-exonerados, el estudio entiende por exoneración no sólo casos en que esta se produjo por ADN sino que incluye también inocentes en sentido amplio ${ }^{41}$, informando sobre un mínimo esperable de casos de retractación que contribuyen a la obtención de condenas erróneas. En definitiva, aparece justificada la utilidad de emplear un sentido amplio de inocencia, no sólo para efectos de realizar estudios empíricos, sino para identificar que partes del proceso penal pueden estar funcionando incorrectamente y podrían ser, eventualmente, mejoradas.

\section{3. ¿Es la revisión un procedimiento técnico o jurisdiccional?}

La necesidad de mejorar la respuesta jurisdiccional frente a los casos de inocentes erróneamente condenados, conduce a preguntarse por cuál podría ser la mejor manera de proteger al inocente, lo que indirectamente incide en cómo se caracteriza la acción de revisión porque la pregunta cuestiona si el examen jurisdiccional es la mejor alternativa para identificar las sentencias condenatorias erróneas. La pregunta es relevante hoy, en atención a que la investigación sobre las condenas erróneas ha llevado a identificar las causas del problema con la estructura del proceso penal. Es decir, ya que el problema de la condena errónea de inocentes es un aspecto inherente al sistema de justicia procesal penal, las propuestas hoy formulan modificaciones sustantivas o estructurales al proceso penal. En simposios recientes en la New York Law School Law Review ${ }^{42}$, Albany Law Review ${ }^{43}$, y el del año 2017 de la Northwestern University Law Review, se han presentado influyentes nuevos modelos de justicia procesal penal que se consideran superiores a la forma presente de manejar las condenas erróneas, y que apuntan, en general, a disminuir la adversarialidad del proceso penal en favor de ciertos procedimientos de carácter inquisitivo. En general, este tipo de propuestas, en nuestra opinión, no sólo cuestionan el, a veces, excesivo carácter adversarial del proceso penal de Estados Unidos, sino también y más en general si el problema que representan las condenas erróneas debe y puede ser solucionado en vía jurisdiccional. Samuel Gross, por ejemplo, considerando que el estado actual del conocimiento sobre causas de condenas de inocentes permite diseñar predictores de inocencia, postula incorporar procedimientos específicos para aquellos casos en que

\footnotetext{
${ }^{40}$ GROSS, Samuel; GROSS, Alexandra, "Witness Recantation Study: Preliminary Findings: National Registry of Exonerations", University of Michigan Law School Scholarship Repository, 2013, descargable en http://repository.law.umich.edu/cgi/viewcontent.cgi?article=1090\&context=other (visto en Junio del 2017).

${ }^{41}$ La base de datos utilizada por dicho estudio ha sida creada como resultado de un proyecto llevado adelante por la Universidad de Michigan y la Universidad de Northwestern, y que da origen al "National Registry of Exonerations" (Registro Nacional de Exoneraciones). Actualmente, se entiende que este registro reemplaza y sustituye la base de datos del Innocent Proyect precisamente porque adopta un concepto de inocente en sentido amplio, yendo más allá del sentido estricto ocupado por este último y que se basaba en la prueba concluyente de AND. El director de este proyecto es Samuel Gross.

422012 Vol. 56.

${ }^{43}$ En esta revista han habido al menos 4 simposios al respecto, 2015 Vol. 78, 2014 Vol. 77, 2014 Vol. 76, 2011 Vol. 74, y próximamente otro volumen especialmente dedicado durante el 2017.
} 
Polit. crim. Vol. 13, № 26 (Diciembre 2018) Art. 15, pp. 1190 - 1285.

[http://www.politicacriminal.cl/Vol_13/n_26/Vol13N26A15.pdf]

concurren dichos predictores ${ }^{44}$. La gran mayoría de los académicos, si bien difieren en sus alcances y sus condiciones de aplicación, todos más o menos concuerdan en que se requiere de procedimientos especiales de inocencia que puedan ser elegidos por el imputado al inicio del procedimiento y que se encuentren diseñados y destinados exclusivamente a determinar la inocencia. En otras palabras, los objetivos tradicionales del proceso penal dejan de ser aplicables dentro de estos procedimientos especiales, porque éstos tienen como único propósito determinar la inocencia del condenado.

Un problema fundamental que parece afectar a todos estas propuestas, y que todavía no parece definitivamente solucionado, es que genera una distinción perversa entre aquellos imputados que deciden someterse a este procedimiento especial de inocencia, donde entre otras cosas, prometen decir la verdad y colaborar con el procedimiento de investigación sin contar con un abogado defensor, y aquellos que no. Esta distinción es perversa porque genera, al parecer inevitablemente, prejuicio, porque que el jurado y el juez conocerán qué imputados han decidido elegir el procedimiento de inocencia y aquellos que no. Ciertamente, parece imposible aislar al jurado y al juez que conoce de estos casos del conocimiento de la elección del imputado, y si ello es así, antes de iniciar el juicio, el conjunto de creencias del jurado y el juez contendrá el hecho que el imputado eligió el procedimiento especial, lo que facilita la inferencia que si lo eligió es entonces posiblemente inocente. Éste, ya es un prejuicio creado en beneficio del potencialmente inocente pero que eventualmente también puede favorecer al culpable. El problema más grave, en nuestro parecer, es otro tipo de potencial prejuicio. En efecto, si el hecho que integra las creencias del jurado y el juez, es el hecho que el condenado no eligió dicho procedimiento, se facilita la inferencia que si no lo eligió es entonces posiblemente culpable. Luego, el juicio iniciará con dichas creencias en detrimento de quien es potencialmente inocente. Si bien los modelos están comenzando a ser discutidos, parece posible idear un procedimiento que no produzca estos tipos de perjuicio. Siendo este el caso, vale la pena preguntarse, si no sería mejor, establecer un panel de expertos que determinen si el condenado es inocente o no. Es decir, la pregunta es porqué dejar la identificación del inocente a cargo de un sistema jurisdiccional, si posiblemente un panel de expertos es mejor en la maximización de la precisión de la determinación de los hechos, y por lo tanto, la identificación de si la persona es culpable o inocente. Con ello, el inocentrismo entra en otro terreno porque aparece cuestionando no ya la fiabilidad del proceso penal, sino si la solución debe o no ser de carácter jurisdiccional.

\footnotetext{
${ }^{44}$ GROSS, Samuel, "Pretrial Incentives, Post-Conviction Review, and Sorting Criminal Prosecutions by Guilt or Innocence", New York Law School Law Review, n 56 (2012), pp. 1009-1030. En forma similar, y con propuestas relativamente equivalentes, porque todos consideran que deben existir procedimientos especiales para este tipo de casos, véase también, BAKKEN, Tim, "Exonerating the Innocent: Pretrial Innocence Procedure", New York Law School Law Review, n' 56 (2012), pp. 826-834; BAKKEN, Tim, "Models of Justice to Protect Innocent Persons", New York Law School Law Review, no 56 (2012), pp. 838-867, RISINGER, Michael; RISINGER, Lesley, "Innocence Is Different: Taking Innocence into Account in Reforming Criminal Procedure", New York Law School Law Review, no 56 (2012), pp. 869-909; FINDLEY, Keith, "Adversarial Inquisitions: Rethinking the Search for the Truth", New York Law School Law Review, ${ }^{\circ}$ 56 (2012), pp. 911-941; BAKKEN, Tim, "Truth and Innocence Procedures To Free Innocent Persons: Beyond The Adversarial System", University of Michigan Journal of Law Reform, $\mathrm{n}^{\circ} 41$ (2008), pp. 547-583, RISINGER, Michael, "Unsafe Verdicts: The Need For Reformed Standards For The Trial And Review Of Factual Innocence Claims", Houston Law Review, no 41 (2004), p. 1281-1336.
} 
FERNÁNDEZ, José Manuel; OLAVARRÍA, Malva. "Examinando de nuevo la acción de revisión”.

Ciertamente, antes de mostrarnos escépticos respecto de posibles modificaciones al proceso penal en el sentido sugerido por estas nuevas tendencias comparadas, parece que primero necesitamos de la información empírica que nos permita conocer, respecto de la realidad Chilena, la cuantificación del problema de los erróneamente condenados y sus causas. Claramente estamos años atrás en relación al derecho comparado donde ya existen predictores de condenas erróneas, y claramente existe una mínima, aunque incipiente, conciencia académica y social respecto del problema. Sin perjuicio de lo anterior y antes de evaluar las posiciones revisionistas radicales en torno al proceso penal, hay un tema previo al de las soluciones, una tensión implícita en la descripción del modelo del proceso penal avocado a la averiguación de la verdad y que ya examináramos críticamente con anterioridad. Este modelo, si bien puede ser aceptado como una buena descripción de nuestra posición legal y moral sobre que tipo de proceso es adecuado para el conocimiento y resolución de los eventos definidos como delito.

En efecto, más allá de las normas específicas que se apartan u obstan a la averiguación de la verdad, hay una faceta fundamental del proceso penal que ha sido dejada de lado al definirlo exclusivamente en atención a dicho propósito: el modelo no sólo se dirige a la averiguación de la verdad porque se trata de un modelo adversarial. La pregunta entonces es, de acuerdo a Michael Risinger, si lo adversarial del proceso penal es compatible con el modelo de averiguación de la verdad ${ }^{45}$, por que muchos aspectos del proceso penal que ya resaltáramos, como la exclusión de evidencia y la discrecionalidad del fiscal para iniciar la investigación, no se explican de acuerdo a lo primero, sino en base a experiencias históricas particulares, diversas tradiciones jurídicas y el objetivo de servir a otros valores o principios. Si bien Risinger considera que la adversarialidad es compatible con la averiguación de la verdad en la medida que los procedimientos que constituyen al proceso penal maximicen la precisión del conocimiento disponible de los hechos, lo cierto es que ello no elimina la tensión entre ambos. Expliquemos un poco esta tensión entre el modelo de búsqueda de la verdad y el principio de adversarialidad.

Esta tensión aparece de manifiesto si aceptamos, como asevera Brandon Garrett ${ }^{46}$, que gran parte de las reglas que nosotros asumimos que protegen al ciudadano durante el proceso penal, reglas aplicables en Estados Unidos pero que también, con modificaciones, son aplicables en Chile, como las reglas sobre información que obligan a la policía a informar al detenido sobre sus derechos (artículo 135 CPP y artículo 137 CPP), otras sobre el deber del Ministerio Público de verificar si se ha dado cumplimiento a lo anterior (artículo 136 CPP), otras que regulan la prueba ilícita (artículo 276 y ss. CPP) y la facultad de no perseverar (artículo 248 del CPP), no son estrictamente reglas que tienen como propósito maximizar la precisión del conocimiento disponible. Si la preocupación es la maximización de la precisión de la determinación de los hechos, eso no llevaría sólo a establecer un procedimiento específico para el inocente, sino a modificar gran parte de las reglas del proceso penal, y por ende, su estructura, significado y sus efectos.

\footnotetext{
${ }^{45}$ RISINGER, “Unsafe Verdicts", cit. nota no 46, p. 1281.

${ }^{46}$ GARRETT, Brandon, Convicting the Innocent: Where Criminal Prosecutions Go Wrong, Cambridge Massachusetts: Harvard University Press, 2011, p. 8.
} 
Polit. crim. Vol. 13, № 26 (Diciembre 2018) Art. 15, pp. 1190 - 1285.

[http://www.politicacriminal.cl/Vol_13/n_26/Vol13N26A15.pdf]

Hay quienes han sostenido que el proceso penal debe ser modificado en este sentido. Por ejemplo, Larry Laudan en su influyente libro sobre la epistemología y la verdad en el proceso penal, considera que las normas protectoras de derechos no deberían excluir el valor probatorio de los actos de investigación ${ }^{47}$, porque la tasa de inocentes que estamos dispuestos a condenar ya viene excluida en la regla de distribución de riesgo expresada en el estándar más allá de duda razonable ${ }^{48}$. Laudan tiene razón si el propósito es tomarse en serio la averiguación de "verdad", porque el proceso penal ya dispone de una regla, el estándar de duda razonable, para excluir una determinada tasa de inocentes, y con ello, una determinada tasa de culpables. Sin embargo, no todas las normas del CPP se encuentran justificadas en cálculos utilitaristas, que es el tipo de justificación que Laudan identifica sustentando la estructura del proceso penal. Por el contrario, muchas disposiciones y procedimientos del proceso penal ofrecen una justificación deontológica en base a ciertos derechos, y si ello es correcto, entonces la propuesta de Laudan no parece aplicable a aquellas partes del proceso penal que reposan en razones para tener ciertas reglas ${ }^{49}$, y su propuesta, por lo mismo, aparece injustificada.

Ahora bien, esta discusión conduce a la pregunta más importante y que es previa a la evaluación de las soluciones al problema sistémico de las sentencias condenatorias erróneas, tanto en sus versiones revisionistas como en sus versiones moderadas ${ }^{50}$, y que está relacionada con la justificación del estándar de duda razonable aplicable al juicio oral. Efectivamente, como lo ha mostrado Laudan, dicho estándar esta justificado en una distribución del riesgo de error en beneficio del imputado y en perjuicio del Estado o la comunidad política $^{51}$. Esto es relevante porque incluso en el caso hipotético que el sistema fuera modificado de manera radical o moderada, de todas maneras se producirían, invariablemente, sentencias condenatorias erróneas. Nótese que ya en la filosofía política de los años 70', específicamente John Rawls aseveraba lo mismo, es decir, que incluso si se

\footnotetext{
${ }^{47}$ LAUDAN, Truth, Error, part II, cit. nota $\mathrm{n}^{\circ} 22$.

${ }^{48}$ LAUDAN, Truth, Error, part I, cit. nota $\mathrm{n}^{\circ} 22$.

${ }^{49}$ Para una crítica en esta líneas, véase PARDO, Michael, “On Misshapen Stones and Criminal Law's Epistemology", Texas Law Review, no 86 (2007), pp. 347-383; ALLEN, Ronald, "Laudan, Stein, and the Limits of Theorizing About Juridical Proof", Law and Philosophy, n’ 29 (2010), pp. 195-230.

${ }^{50}$ CASSELL, Paul, "Freeing the Guilty Without Protecting the Innocent: Some Skeptical Observations on Proposed New "Innocence" Procedures", New York Law School Law Review, cit. nota no 56 (2012), pp. 10631096; GRIFFIN, Lissa, "Pretrial Procedures for Innocent People: Reforming Brady", New York Law School Law Review, no 56 (2012), pp. 969-1006; WARE, Mike, "Dallas County Conviction Integrity Unit and the Importance of Getting It Right the First Time”, New York Law School Law Review, no 56 (2012), pp. 10331050, FRIEDMAN, Leon, "Problem of Convicting Innocent Persons- How Often Does It Occur and How Can It Be Prevented?," New York Law School Law Review, nº 56 (2012), pp. 1053-1061.

${ }^{51}$ Históricamente este estándar tiene raíces religiosas, vinculadas con el tipo de certeza que un buen cristiano debía tener al momento de proferir una sentencia. La justificación de esta regla se refería a la protección del espíritu de la persona que juzgaba, porque el alma podía corromperse si el sujeto que juzgaba tenía seguridad en casos que eran, como todos, dudosos. Este es, de manera muy sucinta, el argumento desarrollado por WHITMAN, James, The Origins of the Reasonable Doubt: Theological Roots of the Criminal Trial, New Heaven: Yale University Press, 2008.
} 
FERNÁNDEZ, José Manuel; OLAVARRÍA, Malva. "Examinando de nuevo la acción de revisión”.

respetan las reglas del proceso penal y dichas reglas están diseñadas para minimizar los errores, ello no impediría la existencia de errores judiciales ${ }^{52}$.

Según Rawls el proceso penal debe ser entendido como una instancia de lo que el denomina justicia procesal imperfecta ${ }^{53}$, porque “...si bien hay un criterio independiente para el resultado correcto [la condena de un inocente no puede ser correcta, pero si la condena del culpable], no hay procedimiento posible que con certeza pueda realizarlo."54. Ahora bien, las palabras de Rawls deben ser cualificadas, porque al describir el proceso penal él ya parecía unirse al coro de escépticos que consideraban, antes de las investigaciones empíricas sobre ADN, que el sistema de justicia criminal funcionaba perfectamente en atención a que sus reglas estaban destinadas a maximizar la precisión de la determinación de los hechos. No obstante, el punto central que debe enfatizarse es que teóricamente incluso si el proceso penal fuera corregido en aquellos aspectos todavía sería cierto que se producirían errores. Por lo mismo, parece más apropiado caracterizar al proceso penal como un proceso en el que algunos aspectos son consistentes con un modelo, también desarrollado por Rawls, de justicia procesal pura, en que no existe un criterio independiente del proceso para determinar el resultado correcto, porque la sentencia del juicio oral puede estar válidamente decretada y aún así condenar a un inocente. Sin embargo, el procedimiento de revisión, por el contrario, sí parece asimilarse a un modelo de justicia procesal imperfecta, porque aquí si existe un criterio independiente del resultado correcto, la inocencia, y lo que dicho procedimiento debería estar destinado a establecer, porque lo que persigue la revisión es declarar inocentes a aquellos que en base a nueva evidencia pueden demostrar que fueron erróneamente condenados.

Esta breve digresión en el terreno de la filosofía política nos ha indicado algo importante. El proceso penal bajo el estándar de la duda razonable se encuentra justificado incluso si existen condenas de inocentes. No hay duda de que en el estado actual de nuestro proceso penal hay razones para creer que no estamos cerca de la tasa culpable/inocente en que dicho estándar está asentado, es decir, que hay dudas fundadas para creer que hay muchos más inocentes erróneamente condenados de lo que el sistema debería generar dado la tasa de culpables. Sin embargo, como hemos visto, aún si se introducen mejoras en el sistema los errores se producirán inevitablemente, lo que parece ser no sólo aceptado como efecto secundario del proceso penal, sino también considerado insuficiente para remover las justificaciones sobre las que se soporta el sistema procesal penal. Ahora bien, si con posterioridad al intervalo temporal donde la tasa de condena de inocentes por cierto número de culpables está justificada, aparece prueba nueva que desacredita la justificación sobre la que se asienta la sentencia condenatoria, entramos en otra secuencia de procedimientos, si bien vinculada al anterior, requiere de un tratamiento diferenciado y por lo mismo de otras consideraciones que lo justifiquen. Es decir, un aspecto consiste en mejorar el proceso penal para que sea más fiable en sus mecanismos de averiguación de la verdad, y otro distinto es resolver, en un proceso diferente y también fiable, como proceder con la

\footnotetext{
${ }^{52}$ RAWLS, John, A Theory of Justice, Cambridge Massachusetts: Second Edition, Harvard University Press, 1999, p. 75.

${ }^{53}$ RAWLS, A Theory of Justice, cit. nota $\mathrm{n}^{\circ} 54, \mathrm{p} .74$.

${ }^{54}$ RAWLS, A Theory of Justice, cit. nota $\mathrm{n}^{\circ} 54$, p. 75.
} 
Polit. crim. Vol. 13, № 26 (Diciembre 2018) Art. 15, pp. 1190 - 1285.

[http://www.politicacriminal.cl/Vol_13/n_26/Vol13N26A15.pdf]

evidencia que se presenta con posterioridad y que se dirige a acreditar la inocencia de la persona condenada.

Como ya puede advertirse, este último es el espacio institucional que le corresponde a la acción de revisión, lo que también significa defender el proceso penal como modelo jurisdiccional para manejar ciertos casos de condenas de inocentes, los casos en que la inocencia se basa en evidencia nueva. Ello significa también defender los principios y valores sobre los que se asienta la búsqueda de la verdad en el proceso penal, valores y principios, que como hemos venido enfatizando, no se agotan en la obtención de la mayor precisión y fiabilidad de los mecanismos para averiguar lo que como comunidad política hemos definido como delito. En las próximas secciones examinaremos con detalle la práctica de la acción de revisión ante la Corte Suprema, pero antes evaluaremos en general la acción de revisión chilena en relación con la probable tasa de inocentes que nuestro sistema de justicia penal debería generar.

\subsection{El milagroso proceso penal chileno}

Recientemente, Mauricio Duce ha desarrollado un interesante estudio empírico sobre las acciones de revisión y que aparece relevante para evaluar el funcionamiento de la jurisdicción como mecanismo para detectar y corregir errores judiciales, en particular, la existencia de sentencias condenatoria erróneas. El estudio de Duce constata 44 acciones de revisión acogidas en el período 2007-2014 ${ }^{55}$. Para examinar un período de 10 años de la práctica de la revisión ante la Corte Suprema se consideró en el presente estudio el período 2015-2017. En suma, a las 44 acciones de revisión constatadas deben sumarse otras 7 sentencias acogidas y otras 2 más pertenecientes al sistema del antiguo Código de Procedimiento Penal (en adelante antiguo CPP), una del año 2007 y otra del año 2011. Considerando entonces el total de las acciones de revisión presentadas, éstas resultan ser 550, y de ese total las acciones acogidas suman 53. En términos porcentuales, si 550 acciones de revisión presentadas constituyen el 100\%, entonces aproximadamente el $9.6 \%$ de las acciones de revisión son acogidas. Estos resultados, en principio, permitirían concluir que la tasa promedio de exoneraciones en Chile duplicaría la tasa esperable de condenas erróneas en otros países, porque en el derecho comparado la tasa estándar de casos acogidos no supera el $4.5 \%$.

Si esta conclusión sobre la tasa de exoneraciones chilena en comparación con el derecho comparado fuera correcta, habría razones para estar orgullosos de nuestro sistema de justicia penal. En efecto, aparece que el sistema procesal penal chileno logra identificar con precisión numerosos casos de condenas erróneas, incluso logra identificar más que otros sistemas comparados con una tradición y experiencia en la práctica adversarial considerablemente mayor. Sin embargo, como se constatará a continuación, no hay muchas razones para estar orgullosos, porque la conclusión es errada, y por el contrario, hay más razones que apuntan a ser pesimistas. En primer lugar, de este restringido universo de acciones de revisión acogidas Duce identifica 36 acciones de revisión acogidas por el mismo motivo, es decir, casos cuya acogida se justifica en instancias de suplantación de

${ }^{55}$ DUCE, "La condena”, cit. nota n ${ }^{\circ}$ 6, p. 176. 
FERNÁNDEZ, José Manuel; OLAVARRÍA, Malva. "Examinando de nuevo la acción de revisión”.

identidad en que el verdadero culpable se hace pasar por otra persona que en definitiva resulta condenada. A dicho número cabe agregar otras 6 acciones de revisión acogidas en el período posterior a su examen. Es decir, a la fecha, de 53 acciones de revisión acogidas 42 se explican en los mismos defectos del procedimiento; suplantaciones de identidad que son descubiertas con posterioridad.

Los casos de suplantación de identidad obligan a re-identificar los casos propiamente de revisión. En efecto, a nuestro juicio de estas 53 acciones acogidas deben descontarse los 42 casos de suplantaciones de identidad, porque esto no manifiesta la superioridad de nuestro sistema procesal penal en la identificación de condenas erróneas, sino por el contrario, hace público lo poco riguroso de los sistemas de identificación chilenos a nivel investigativo e institucional. En segundo lugar, de los 11 casos restantes creemos que debe descontarse otros 7 , en razón de que éstos presentan similitudes con los casos de suplantación de identidad. Efectivamente, todos estos casos, en palabras de Mauricio Duce, revelan una seria “...falta de rigor de las agencias de persecución penal..." ". Ciertamente, en uno de estos casos la revisión se acoge porque no había delito de giro doloso de cheques, ya que el condenado había pagado íntegramente la deuda con anterioridad a que se encontrara ejecutoriada la sentencia ${ }^{57}$; en otro similar la gestión preparatoria de notificación del protesto había sido anulada por el juzgado respectivo ${ }^{58}$, por lo que así mismo no había giro doloso. En otro caso la revisión se acoge porque no había delito de tenencia ilegal de arma de fuego, porque con posterioridad se acreditó que el arma se encontraba debidamente inscrita $^{59}$. En otro caso la acción de revisión fue acogida porque fue acreditado que la medida cautelar supuestamente infringida, y que tuvo como resultado la condena por el delito de desacato, no estaba vigente al momento de su incumplimiento ${ }^{60}$. En otro caso, la acción de revisión fue acogida porque se acreditó que la licencia de conducir era auténtica, y que por lo tanto el acusado no podía ser condenado por el delito de uso de licencia de conducir falsa ${ }^{61}$. En un caso, que ya hemos mencionado, la acción de revisión se acogió porque se había decretado con anterioridad el sobreseimiento definitivo de la causa como consecuencia del cumplimiento de las condiciones integrantes de una suspensión condicional del procedimiento $^{62}$. Finalmente, en otro caso la acción de revisión fue acogida porque un fiscal ocultó a la defensa, y por lo tanto al juez, que el verdadero culpable se encontraba cumpliendo condena y se encontraba confeso por los delitos por los que el inocente había sido condenado ${ }^{63}$.

Todos estos 7 casos podrían haber sido resueltos si los órganos de investigación, incluyendo al Ministerio Público, hubieran sido más rigurosos y prolijos. En efecto, estas condenas dan cuenta de defectos flagrantes en los órganos de investigación y cuya consecuencia fue la condena de quienes eran evidentemente inocentes. Esto tiene

\footnotetext{
${ }^{56}$ DUCE, "La condena", cit. nota no 6, p. 183.

${ }^{57}$ SCS, Rol 5546-2007.

${ }^{58}$ SCS, Rol 8884-2012.

${ }^{59}$ SCS, Rol 1558-2011.

${ }^{60}$ SCS, Rol 6720-2013.

${ }^{61}$ SCS, Rol 4308-2013.

${ }^{62}$ SCS, Rol 2227-2011.

${ }^{63}$ SCS, Rol 12018-2011.
} 
Polít. crim. Vol. 13, № 26 (Diciembre 2018) Art. 15, pp. 1190 - 1285.

[http://www.politicacriminal.cl/Vol_13/n_26/Vol13N26A15.pdf]

consecuencias para la cuantificación de los casos de condenas erróneas, porque este tipo de errores, presentes en 49 casos, se explican exclusivamente en defectos de la mecánica del sistema de investigación, y que nunca deberían haber llegado a la instancia de revisión. Aparecen no sólo, y naturalmente, malgastados los recursos del estado que debieran destinarse a facilitar el ejercicio de la jurisdicción y no a corregir errores mecánicos del sistema, sino que también evidente que no hay preocupación por los acusados que pueden ser inocentes. Efectivamente, parece inaceptable que existan 42 casos de suplantaciones de identidad que tuvieron que esperar a ser resueltos por la Corte Suprema, y así mismo parece inaceptable que otros 7 casos hallan llegado a dicha instancia por defectos mecánicos del sistema que debieron haber sido corregidos en su oportunidad. Si se consideraran todos estos casos de defectos inaceptables del sistema, se haría imposible comparar el sistema chileno con otros modelos de revisión, porque en las investigaciones comparadas en materia de condena de inocentes los casos de suplantación de identidad no son cuantificados, porque en aquellos sistemas, obviamente más fiables y precisos, estos problemas son resueltos con anterioridad al ejercicio de la jurisdicción. Lo mismo sucede con aquellos defectos que llevaron a la condena de aquellas 7 personas inocentes, porque también este tipo de defectos son descubiertos en las oportunidades que corresponden, y nunca, en instancias similares a la revisión.

Ahora bien, depurados los casos que hacen comparable nuestro sistema de justicia penal con sistemas comparados, aparece que la Corte Suprema de 501 acciones de revisión presentadas ha acogido sólo 4. Ciertamente es excepcional, pero en el peor de los sentidos posibles. Es decir, sólo 4 casos en 10 años, y que analizaremos con posterioridad ${ }^{64}$, han sido resueltos por la Corte Suprema en ejercicio de sus facultades jurisdiccionales, es decir, mediante el ejercicio de las facultades que caracterizan al juez: su capacidad de atender las particularidades del caso concreto ${ }^{65}$. Aparece con claridad que todavía en Chile no estamos cerca de la punta del iceberg que representa la dimensión real de la condena de inocentes. En efecto, tomando en consideración datos del derecho comparado, de un sistema con experiencia, recursos y en funcionamiento como el de Estados Unidos, resulta que la tasa esperable de sentencias condenatorias erróneas, de acuerdo con el cálculo más conservador que se ha realizado, cerca del 3.5\% de las sentencias representarían sentencias condenatorias erróneas. En comparación, pareciera que en Chile se realiza el sueño de Scalia, ¡Pues sólo el $0.79 \%$ sería el porcentaje de sentencias erróneas! Si estos fueran todos los casos reales de condenas de inocentes, entonces nuestro sistema procesal penal sería efectivamente milagroso: las víctimas y testigos no se equivocan ni mienten, la policía no emplea métodos inductivos, el Ministerio Público nunca oculta evidencia, y la defensa siempre es de excelencia, en pocas palabras, tendríamos un sistema perfecto: un verdadero milagro.

La otra hipótesis es que no hay milagro alguno, lo que parece más ajustado a la realidad. En otras palabras, que hay muchos otros casos de condena de inocentes que no han sido

\footnotetext{
${ }^{64}$ SCS Rol 5031-2007 acogido por retractación del testigo principal, SCS Rol 2827-2011 acogido por retractación de la víctima, SCS Rol 11109-2013 acogido por retractación del testigo principal, y SCS rol 27543-2016 acogido, entre otras razones, por haberse acreditado la tortura de los condenados.

${ }^{65}$ Véase ATRIA, Fernando, La Forma del Derecho, Madrid: Marcial Ponds, 2016, p. 216.
} 
FERNÁNDEZ, José Manuel; OLAVARRÍA, Malva. "Examinando de nuevo la acción de revisión”.

apropiadamente resueltos ni considerados por la Corte Suprema. Si consideramos que el porcentaje estándar de un país como Estados Unidos, donde su tradición adversarial es mucho más antigua que la nuestra, donde las policías y fiscales cuentan con amplios recursos y experiencia, ello significaría que al menos deberían existir 18 casos adicionales que deberían haberse detectado por la Corte Suprema. Desde luego, ninguno de estos debería consistir en la suplantación de identidad del verdadero culpable o deberse a errores flagrantes como los que hemos mencionado con anterioridad. La evaluación que corresponde hacer de nuestro sistema de justicia penal, es que los mecanismos a nivel jurisdiccional, como forma de detectar y solucionar los problemas de sentencias condenatorias erróneamente dictadas, no están funcionando adecuadamente. Esto reafirma lo que dijimos con anterioridad, todavía no estamos ni siquiera avizorando la punta del iceberg.

En las secciones siguientes examinaremos los problemas más relevantes y comunes que conducen al rechazo de las acciones de revisión, y los que seguramente explican la subidentificación de casos de condenas erróneas en el sistema procesal penal chileno. Sobre la base de la correcta reconstrucción racional de las normas del modelo adversarial de revisión presentaremos, nuevamente, la hipótesis que una correcta comprensión de la revisión podría incrementar la sensitividad de la Corte para detectar casos que posiblemente puedan constituir condenas erróneas, ofreciendo de esta manera espacio a aquellos casos que cuentan con evidencias suficientes de inocencia y que no merecen ser rechazados.

\section{Problemas persistentes}

En el artículo del año 2009 propusimos una interpretación novedosa y flexible de la acción de revisión con el propósito de suministrar nuevas orientaciones para los practicantes y para la jurisprudencia. La propuesta, si bien presenta diferencias importantes en relación con el entendimiento tradicional de la acción de revisión en la doctrina y jurisprudencia nacional, no es revisionista en absoluto como si lo son las propuestas de establecer procedimientos específicos para detectar la inocencia. Por el contrario, nuestra propuesta es lo que creemos corresponde a la correcta descripción de la regulación legal vigente y lo que el propio legislador previó, aseveración que respaldaremos con la historia fidedigna del establecimiento del CPP y con la mejor interpretación disponible de sus normas y disposiciones. En esta sección revisaremos y profundizaremos los aspectos de la investigación de 2009 a la luz de la jurisprudencia de la Corte Suprema anterior al año 2009 y con posterioridad hasta junio de 2017, para enfatizar los aspectos críticos de la comprensión que dicha Corte hace de la acción de revisión, los aspectos que sostenemos todavía no han sido abordados y los que todavía no han sido suficientemente comprendidos. Cuando corresponda haremos referencias al derecho comparado, lo que se justifica en que en otros países también se han producidos conflictos interpretativos semejantes, y aunque no hayan sido definitivamente zanjados por el legislador o por la jurisprudencia, el hecho de que se hayan explicitado los problemas y las argumentaciones que apuntan a su solución, aportan, en nuestra opinión, cierta claridad a los problemas que nuestra jurisprudencia enfrenta en casos semejantes.

En general, el examen de las sentencias se realizará a partir del artículo 473 letra d) del CPP porque ésta es la causal no sólo comúnmente impetrada por los recurrentes, sino que la 
Polít. crim. Vol. 13, № 26 (Diciembre 2018) Art. 15, pp. 1190 - 1285.

[http://www.politicacriminal.cl/Vol_13/n_26/Vol13N26A15.pdf]

única que ha dado lugar al acogimiento de la acción en las 501 revisiones presentadas. En la investigación de 2009 establecimos que la Corte Suprema sólo había procedido a acoger la acción cuando se hacía valer evidencia "fehaciente" de la inocencia del condenado. Esta inclinación fue confirmada 6 años después en el estudio de Mauricio Duce, y ahora nuevamente podemos confirmar dicha conclusión mediante el examen de las sentencias citadas en un período de 10 años, incluyendo junio de 2017. Puede anticiparse que no hay cambios en la doctrina de la jurisprudencia de la Corte Suprema desde el análisis que efectuáramos el año 2009. Es decir, en los últimos 10 años la Corte Suprema no ha cambiado sus criterios para acoger y rechazar las acciones de revisión. Esto obliga a considerar casi exclusivamente los casos en que se ha hecho valer la letra d), sin embargo también se examinarán los casos en que la Corte ha conocido y rechazado las acciones hechas valer por las otras causales. En particular, analizaremos distintos aspectos de la acción de revisión que han sido desarrollados por la Corte Suprema y como deben ser entendidos a la luz de la regulación nacional.

\subsection{Administrativización del proceso penal}

Uno de los aspectos problemáticos sobre los que se posiciona el modelo adversarial de revisión y que mencionáramos en la investigación de 2009, es lo que, siguiendo a Silva Sánchez, con ciertas modificaciones, podemos denominar la administrativización del derecho procesal penal ${ }^{66}$. Este fenómeno se puede caracterizar como la tendencia políticocriminal que tiene por objetivo integrar a los criterios que definen la función jurisdiccional las necesidades de operatividad del sistema. Aplicado al modelo de revisión esto significa adicionar a las consideraciones relativas al derecho al recurso, la incorporación de aspectos relativos al adecuado manejo de recursos institucionales. En principio, introducir aspectos de eficiencia en el sistema procesal penal debe ser motivo de celebración y no de rechazo, porque un sistema de justicia moderno es un sistema que cuida los recursos de los ciudadanos y provee de soluciones oportunas a los conflictos que resuelve. Sin embargo, el problema se produce cuando el cálculo de los recursos interfiere en el ejercicio de derechos individuales, específicamente, en el ejercicio del derecho al recurso, que es lo que sucede actualmente en la acción de revisión. Es en este marco evaluativo que deben entenderse las modificaciones que se incorporaron a la acción de revisión en el curso de la discusión del nuevo Código Procesal Penal, con el objeto de incorporar la posibilidad de rechazar la acción de revisión de plano cuando esta adoleciera de manifiesta falta de fundamentos y que se plasmó en el inciso tercero del actual artículo 475 del CPP:

La solicitud que no se conformare a estas prescripciones o que adolezca de manifiesta falta de fundamento será rechazada de plano, decisión que deberá tomarse por la unanimidad del tribunal.

En la investigación del año 2009 afirmamos que aquella modificación tuvo una consecuencia muy importante "La facultad de la Corte de rechazar de plano el recurso

\footnotetext{
${ }^{66}$ SILVA SÁNCHEZ, Jesus María, La Expansión del Derecho Penal: Aspectos de la Política Criminal en las Sociedades Postindustriales, Madrid: Segunda Edición, Civitas, 2001, pp. 121-122, término empleado ya por Santiago Mir Puig en los años 90, véase MIR PUIG, Santiago, "Bien jurídico y bien jurídico-penal como límites del «lus puniendi»”, Estudios Penales y Criminológicos, n 14 (1991), p. 213 y ss.
} 
FERNÁNDEZ, José Manuel; OLAVARRÍA, Malva. "Examinando de nuevo la acción de revisión”.

cuando adolece de manifiesta falta de fundamento, coincide, en la práctica, con la resolución del caso, o lo que es lo mismo, con la aplicación de la norma substantiva concurrente." ${ }^{\prime 2}$. En otras palabras, cuando describimos la práctica de la Corte Suprema durante el período 2007-2009 al conocer la acción de revisión, descubrimos que al pronunciarse sobre su admisibilidad, control que es meramente formal y superficial, la Corte resuelve el asunto controvertido. Hoy, agregando los años 2010-2017, confirmamos la misma forma de operar por parte de la Corte Suprema. Como un ejemplo véase la siguiente sentencia:

" $2^{\circ}$ Que los recurrentes fundan su petición en la circunstancia de haber interpuesto una querella criminal en contra de la supuesta víctima por falso testimonio, investigación en la que depuso una testigo que da cuenta del ardid urdido por en contra de los sentenciados, así como una copia del reportaje efectuado... donde un testigo protegido asevera lo precedentemente indicado. Agrega que de ello tuvieron conocimiento hasta después de dictada la sentencia.

$3^{\circ}$ Que, sin embargo, los antecedentes nuevos invocados no tiene la entidad suficiente para predicar la inocencia de los recurrentes." ${ }^{\circ 8}$

Queda meridianamente claro en este caso que lo que hace el recurrente al solicitar la revisión de la sentencia es que se considere nueva evidencia que podría acreditar que el condenado es inocente. Sin embargo, si en la evaluación de las evidencias destinadas a probar la inocencia la Corte ya no tiene que examinar el fondo, sino declarar a primera vista en un examen superficial y formal, equivalente a un análisis en sede de admisibilidad, entonces el control formal superficial de la admisibilidad se transforma en la resolución del asunto de fondo. En efecto, piénsese en qué debería hacer el condenado en un caso como el precedente. Pareciera que el condenado debería continuar investigando con el fin de obtener más antecedentes que acrediten que él es inocente, lo que, de lograr, implicaría poder demostrar su inocencia. Es decir, no parecen existir "casos intermedios", puesto que o se hacen valer evidencias que adolecen de evidente falta de fundamentos y que no es capaz, por lo tanto, de demostrar su inocencia, o suministra evidencia que acredite fehacientemente que es inocente. Este es el modelo disyuntivo de revisión al que nos hemos referido con anterioridad.

Ahora, dentro del universo de casos no acogidos durante 10 años de sentencias en materia de revisión, sólo unos cuantos son calificados como aquellos que no adolecen de manifiesta falta de fundamentos y son en consecuencia examinados "en el fondo". Sin embargo, ello no significa necesariamente que la Corte razone de manera diferente. Efectivamente, el razonamiento de la Corte tiende a ser el mismo, lo que se debe a cómo se describe la labor del juez de acuerdo con el modelo disyuntivo. La Corte entiende que sólo puede acoger cuando existe evidencia "fehaciente" de que el condenado es inocente, y si esta evidencia no se hace valer, entonces aparece que el caso manifiestamente no cumple con las exigencias legales, y, por lo tanto, recibe normalmente el mismo tratamiento que si adoleciera de manifiesta falta de fundamentos. En suma, en la práctica, el examen formal y

\footnotetext{
${ }^{67}$ FERNÁNDEZ y OLAVARRÍA, “Teoría y Práctica”, cit. nota n 5, p. 251.

${ }^{68}$ SCS, Rol 9349-2015.
} 
Polít. crim. Vol. 13, № 26 (Diciembre 2018) Art. 15, pp. 1190 - 1285.

[http://www.politicacriminal.cl/Vol_13/n_26/Vol13N26A15.pdf]

superficial coincide con la resolución del fondo del asunto, porque en su resolución si no se acredita de manera manifiesta la inocencia del condenado, o lo que es lo mismo, no se presenta evidencia fehaciente, aparece que el caso adolece de manifiesta falta de fundamentos, identificándose el examen de fondo con el examen de admisibilidad. Esto, como se verá posteriormente en la sección 3.4., ha tenido serias consecuencias para el estado de Chile, porque la Corte Interamericana de Derechos Humanos condenó recientemente a nuestro país por no conceder a ciertos condenados de un mecanismo eficaz y efectivo para ser escuchados en el contexto de una acción de revisión. En otras palabras, condenó a Chile por denegar el derecho al recurso, al rechazar, la Corte Suprema, una solicitud de revisión de manera escueta y sin fundamentos tal y como se ha habituado sobre la base del inciso tercero del artículo 475 del CPP, pero en un grave caso de inocencia no fáctica, sino normativa.

\subsection{Nuevas evidencias}

3.2.1. ¿Que significa la ocurrencia o descubrimiento de un hecho o documento desconocido?

El artículo 473 letra d) del CPP establece a propósito de la revisión de sentencias condenatorias firmes que la Corte Suprema anulará la sentencia: Cuando, con posterioridad a la sentencia condenatoria, ocurriere o se descubriere algún hecho o apareciere algún documento desconocido durante el proceso, que fuere de tal naturaleza que bastare para establecer la inocencia del condenado.

En la investigación del año 2009 desarrollamos la idea que se encuentra bajo esta formulación del CPP y que en el presente trabajo denominaremos como "nueva evidencia". Es decir, cuando el CPP establece que "ocurriere o se descubriere algún hecho o apareciere algún documento" a lo que se refiere es a que exista una nueva evidencia. Esta formulación, aparentemente simple, oculta la complejidad de la regulación del CPP. Procedamos entonces a separar los elementos que forman la nueva evidencia en sus unidades mínimas: (i) que ocurra o se descubra (ii) un hecho o documento (iii) desconocido durante el proceso (iv) que sea bastante para acreditar la inocencia del condenado.

(i) Asumamos por el momento que lo que debe "ocurrir" o "descubrirse" es un medio de prueba, para tener algún referente que permita entender la argumentación. Lo primero que debe distinguirse es la temporalidad del fenómeno, pues el CPP establece que con posterioridad a la sentencia condenatoria "ocurriere" o se "descubriere" un medio de prueba. Nótese que el CPP no restringe el hecho, al que el medio probatorio se refiere, a uno que haya ocurrido en un intervalo de tiempo posterior a la sentencia, pues en efecto, dispone que el hecho puede "descubrirse" con posterioridad. En otras palabras, si el hecho puede descubrirse con posterioridad ello significa que el hecho puede haber acaecido antes de la sentencia, naturalmente durante el proceso penal, pero también puede haber ocurrido antes de su inicio ${ }^{69}$. Si el legislador hubiera querido restringir la procedencia de la revisión a un determinado intervalo temporal, habría empleado sólo una forma verbal como el término "ocurre", y no adicionalmente la forma verbal "descubre". Como el legislador ha

\footnotetext{
${ }^{69}$ FERNÁNDEZ y OLAVARRÍA, “Teoría y Práctica”, cit. nota nº 5, p. 222.
} 
FERNÁNDEZ, José Manuel; OLAVARRÍA, Malva. "Examinando de nuevo la acción de revisión”.

establecido ambas formas verbales, el lapso temporal de la evidencia es razonablemente amplio, como es de esperar de un modelo flexible y amplio de revisión. Ahora bien, podría contra-argumentarse que esta interpretación no es correcta, lo que vendría respaldado en la tendencia de la Corte Suprema de seccionar esta disposición en dos normas, la norma (a) y la norma (b): la revisión procede (a) cuando ocurre o se descubre un hecho con posterioridad al juicio (b) o cuando aparece un documento desconocido durante el juicio. La Corte entiende que la norma (b) sólo admite documentos que existían al tiempo del proceso pero cuya existencia era, durante dicho intervalo temporal, desconocida. Por lo tanto, la Corte concluye, la norma (b) excluye todos aquellos documentos elaborados con posterioridad al juicio. Hay una razón, que examinamos más adelante, y que demuestra que esta interpretación es incorrecta porque se basa en una distinción insostenible entre hecho y documento. Ahora explicaremos otras tres razones por la cual la interpretación de la Corte es incorrecta.

Primero, si (b) fuera verdadero ello significaría que el sistema de revisión chileno dejaría fuera los medios de prueba más apropiados para acreditar la inocencia: la prueba de ADN. Efectivamente, un peritaje de ADN consiste en un medio de prueba escrito, y si cabe entender que este es un documento, entonces se seguiría que este tipo de pruebas estarían excluidas de la revisión si son elaborados una vez concluido el juicio. Sin embargo, no parece racional excluir pruebas que pueden acreditar la inocencia del condenado, sobre todo si son capaces de satisfacer el estándar de "prueba fehaciente". En segundo lugar, el verbo "aparecer" no excluye concluyentemente el evento que el documento sea elaborado con posterioridad al juicio. Si el legislador hubiera querido excluir dicha posibilidad habría requerido explícitamente que el documento haya sido "elaborado" con anterioridad. Esto excluiría concluyentemente documentos elaborados con posterioridad, pero el verbo "aparecer" no excluye a primera vista aquella elaboración. Y, en tercer lugar, el contraargumento adopta una comprensión amplia del término "documento" que no discrimina entre fuente de prueba y medio de prueba. En efecto, hay documentos que pueden constituir por sí mismos fuentes y medios de prueba, pero en otros casos los documentos sólo son un medio de prueba. Un caso en el que un documento es fuente y medio de prueba es el caso rol 4308-2013, en el que a través de un documento se acreditó que la licencia de conducir era auténtica, y que, por lo tanto, no había falsificación de instrumento público. Este es un documento que es medio y fuente de prueba simultáneamente. Sin embargo, los peritajes sólo son medios de prueba que se utilizan para probar una fuente de prueba. Por lo tanto, si el objetivo del legislador era evitar el uso fraudulento de prueba que podía elaborarse con posterioridad para probar un hecho que nunca existió, ello no podría producirse a través de peritajes que revelan hechos presentes al tiempo del juicio, porque ellos no son fuentes y medios de prueba, sino sólo medios de prueba. Piénsese en el rol 4308-2013, ¿que habría sucedido si el documento que comprobaba que la licencia era auténtica no había sido emitido durante el juicio? En dicho evento, si el comprobante se emite con posterioridad, de acuerdo a la interpretación de la Corte Suprema, el documento debería considerarse excluido, y el conductor, que tiene una licencia auténtica aunque elaborada con posterioridad no podría comprobar su inocencia, y la condena por uso de licencia falsa, no podría invalidarse. Esto no parece razonable. En suma, el alcance de las formas verbales previstas por el artículo 473 del CPP alcanza a los dos sustantivos "hecho" y "documento". Es decir, el hecho puede ocurrir o descubrirse con posterioridad al juicio, y el documento puede ocurrir o descubrirse con posterioridad al juicio. 
Polit. crim. Vol. 13, № 26 (Diciembre 2018) Art. 15, pp. 1190 - 1285.

[http://www.politicacriminal.cl/Vol_13/n_26/Vol13N26A15.pdf]

(ii) El legislador ha vinculado otros dos términos a las precedentes formas verbales, los sustantivos "hecho" y "documento". En la investigación de 2009 propusimos que las palabras hecho o documento debían ser consideradas como medios de prueba. Ahora explicaremos un poco más la justificación de esta tesis, lo que requiere para comenzar examinar brevemente la diferencia entre fuentes de prueba y medios de prueba, diferencia que, por lo demás, es aceptada por la doctrina tradicional y dominante, en el derecho comparado y en Chile. Fuentes de prueba son aquellos estados de hecho que se deben probar para efectos de justificar la condena o absolución, mientras que medios de prueba es la forma como las fuentes de prueba se introducen al proceso penal ${ }^{70}$, y que por lo tanto permiten al juez conocer y juzgar. En otras palabras, en el proceso penal no se prueban "fuentes de prueba" de manera directa, sino que aserciones sobre los hechos ${ }^{71}$ respaldadas mediante medios de prueba o evidencias. Es decir, las fuentes de prueba se prueban mediante medios de prueba ${ }^{72}$, que es lo que en definitiva el juez conoce durante el juicio oral y que le permite formar su convicción sobre la absolución o condena ${ }^{73}$. Ahora bien, si "hechos" y "documentos" significan lo mismo, cabe preguntarse entonces porque razón se dispuso ambos términos, ya que el legislador no habla explícitamente de medios de prueba al regular la revisión.

Hay dos pasos que conducen a aceptar la tesis sobre la equivalencia de significado de ambos términos. Primero, piénsese que por "hechos" no se entiende medios de prueba sino fuentes de prueba. Si esto es correcto, entonces el legislador sólo incluye como medios de prueba para efectos de la revisión aquellos constitutivos de "documentos", lo que excluiría fotografías, videos, audios, etc. Esta conclusión es, sin embargo, absurda. El rechazo de esta conclusión conduce a considerar que por "documento" debe entenderse cualquier "medio de prueba" en general. Segundo, si cabe diferenciar fuentes de prueba y medios de prueba, y aceptándose que lo que el juez conoce es lo último, entonces no es posible entender que por "hechos" el legislador se refiere a "fuentes de prueba", por un lado porque los hechos no se pueden probar directamente en el proceso penal y por otro porque si fueran fuentes de prueba estos ya vendrían incorporados en la referencia a los "medios de prueba", es decir, en los "documentos". Posiblemente la razón del legislador para hablar de "hechos" y "documentos" residió en el objetivo de ampliar la forma a través de la cual la Corte Suprema podía conocer y resolver sobre las solicitudes revisión, de manera que no se

\footnotetext{
${ }^{70}$ HORVITZ / LÓPEZ, Derecho, $t . I$, cit. nota ${ }^{\circ} 18$, p. 552, y en general, véanse referencias de la literatura chilena tanto en materia civil como penal en MENESES PACHECO, Claudio, "Fuentes de prueba y medios de prueba en el proceso civil", Ius Et Praxis, 2008, Vol. 14, p. 51.

${ }^{71}$ Es decir, actos de habla asertivos, FERNÁNDEZ y OLAVARRÍA, "Teoría y Práctica", cit. nota no 5, p. 222.

${ }_{72}^{72}$ FERNÁNDEZ y OLAVARRÍA, “Teoría y Práctica”, cit. nota nº 5, p. 223.

${ }^{73}$ Esto es reconocido y desarrollado en la teoría del derecho, argumentándose que para que sea válida la aserción del juez al afirmar "esta probado que $p$ " o "esta probado que X mato a Y", es necesario entenderlo como que hay suficientes medios de prueba para tener por demostrado que $\mathrm{X}$ mato a Y. Véase, por todos, TARUFFO, Michele, La Prueba de los Hechos, Madrid: Segunda Edición, Trotta, 2005, p. 122; FERRER BELTRÁN, Jordi, Prueba y Verdad en el Derecho, Madrid: Marcial Pons, Segunda Edición, 2005, pp. 35-37; Gascón Abellán, Marina, Los Hechos en el Derecho: Bases Argumentales de la Prueba, Madrid: Marcial Pons, Tercera Edición, 2010, p. 78; ACCATINO SCAGLIOTTI, Daniela, "Convicción, justificación y verdad en la valoración de la prueba”, Anuario de Filosofía Jurídica y Social, nº 26 (2006), p. 48.
} 
FERNÁNDEZ, José Manuel; OLAVARRÍA, Malva. "Examinando de nuevo la acción de revisión”.

excluyeran hechos acaecidos con posterioridad al proceso penal y documentos que si bien no existieron durante el mismo, su existencia posterior era capaz de demostrar la inocencia del condenado. En suma, cuando el legislador se refiere a hechos o documentos incluye todo medio probatorio que sea de naturaleza suficiente para establecer la inocencia del condenado. Por lo tanto, los términos "documentos" y "hechos" para efectos de la acción de revisión deben ser equiparados a medios de prueba, es decir, deben ser entendidos como evidencia.

(iii) "Desconocimiento durante el proceso", este adjetivo es el tercer elemento de la formulación de evidencia y que permite afirmar que es "nueva", y aparentemente se refiere tanto al juez como al condenado. Examinemos el caso del juez porque es el foco central de la definición de hecho nuevo. En la investigación de 2009 sostuvimos que el desconocimiento fundamental a este respecto es del juez, porque constituye un deber del juez fundamentar la sentencia de acuerdo con los medios de prueba hechos valer por las partes durante el curso del proceso penal ${ }^{74}$. Es decir, que debe entenderse que el juez "conoce" un medio de prueba sólo cuando éste se rinde en el juicio en conformidad a la ley $y$ el juez lo considera en la fundamentación de la sentencia. Esto significa que el significado de la expresión "desconocida" no se refiere a un estado subjetivo del juez, en el sentido que un determinado hecho haya sido objeto de sus creencias, sino a aquellas evidencias en las que el juez fundamentó su decisión. En rigor, si el juez pudiera fundamentar la sentencia en su conocimiento subjetivo sobre los hechos y por lo tanto exclusivamente en sus creencias, el deber de fundar el fallo con arreglo a la prueba rendida y producida durante el juicio oral sería irrelevante. En efecto, si el juez debe fundamentar su sentencia en lo que él cree, ¿cuál es el sentido de producir prueba? Esto quizás podría ser válido para un sistema de jurado, pero no en Chile donde el juez debe fundamentar su decisión. En el contexto chileno si lo que cuenta es el conocimiento subjetivo, ¿cuál sería el sentido de fundamentar la sentencia? El modelo del CPP no se corresponde con un sistema de valoración subjetivista el cual se satisface con las creencias subjetivas del juez, sino con un sistema de valoración objetivo en que la fundamentación debe basarse en las evidencias hechas valer por las partes, esto es lo que define al proceso penal adversarial. Esto conduce a una conclusión que puede aparecer controversial: si el tribunal no fundamentó su decisión con arreglo a una determinada evidencia, dicha evidencia debe considerarse "nueva" si se hace valer con posterioridad, porque en rigor la ha "desconocido" en dicha fundamentación.

Ahora bien, ¿cómo puede suceder esto, que en un momento la sentencia se encuentra justificada y que en otro intervalo de tiempo posterior deja de encontrarse justificada? Este problema teórico y práctico puede explicarse sencillamente considerando que si el juez falla con arreglo a un conocimiento disponible determinado, basado en evidencias (1), (2), y (3) presentes durante el intervalo temporal (I) la sentencia puede encontrarse perfectamente justificada. Pero, si en un intervalo de tiempo posterior (II) aparece un nuevo material probatorio (4) que por ejemplo acredita que el imputado era inocente, entonces aparece que dicha sentencia dictada en el tiempo (I), en el tiempo (II) es susceptible de ser anulada. La razón, es que el conjunto de medios probatorios que justificaban la sentencia ha cambiado del conjunto de evidencias (1), (2), y (3) durante el intervalo (I), al conjunto de evidencias

\footnotetext{
${ }^{74}$ FERNÁNDEZ y OLAVARRÍA, “Teoría y Práctica”, cit. nota no 5, pp. 226-228.
} 
Polít. crim. Vol. 13, № 26 (Diciembre 2018) Art. 15, pp. 1190 - 1285.

[http://www.politicacriminal.cl/Vol_13/n_26/Vol13N26A15.pdf]

(1), (2), (3) y (4) durante el intervalo (II). En otras palabras, en el tiempo (I) las evidencias (1), (2), y (3) fueron conocidas, pero en un tiempo posterior (II) se puede establecer que el juez no conoció la evidencia (4), y como no la conoció no pudo fundamentar su decisión en base a ella, y por lo tanto, dicha evidencia puede calificarse como "nueva". Ciertamente esto puede ocurrir porque que no se sabía de la existencia de dicha evidencia (4) o ésta por algún motivo no se encontraba disponible en el tiempo (I). En consecuencia, debe equipararse el término "desconocido" a la existencia de una "nueva" evidencia hecha valer, es decir, una evidencia no considerada por el juez al fundamentar su sentencia. Si aparece una evidencia con posterioridad a la sentencia que el juez no pudo valorar de acuerdo a las reglas de la sana crítica, entonces en rigor no conoció la evidencia. Se sigue, entonces, que el juez ha desconocido una evidencia que debió haber conocido y que por lo tanto debió haber considerado para fundamentar su decisión.

Con este concepto de "conocimiento" vinculado a un deber de fundamentación se debe entender cuándo el tribunal "conoce" los hechos "...si el tribunal fundamenta su decisión, las partes pueden suponer que éste ha conocido los estados de hecho en los que se fundan sus pretensiones y que se hacen valer a través de los medios de prueba." ${ }^{, 75}$, es decir, si la Corte fundamenta su decisión en los medios de prueba respectivos ello equivale a decir que conoció dichos medios de prueba, y por lo tanto las fuentes de prueba así incorporadas. De ello se sigue que si el tribunal ha fundamentado su decisión considerando el conjunto de evidencias (1), (2), y (3), y explica las razones por las cuales le asigna valor probatorio a algunas y porque desestima otras ${ }^{76}$, entonces queda descartada la posibilidad de acoger la acción de revisión si en ella se hacen valer todo o parte de dichas fuentes de prueba. En otras palabras, las mismas consideraciones que explican la invalidez de la sentencia condenatoria de la que puede reclamar el que recurre de revisión, explican la validez de la sentencia que no puede atacarse por dicha vía. Desde luego, si el tribunal conoció en la instancia correspondiente las fuentes de prueba a través de los medios probatorios que se hacen valer en revisión, no sería posible acogerla: en efecto, la evidencia no sería nueva. Profundicemos un poco más en este punto.

Hemos sostenido que la expresión "desconocido" debe vincularse con el deber de fundamentación del juez, en el sentido que la Corte debe rechazar la acción si la evidencia hecha valer no es nueva, es decir, fue conocida o considerada por el juez al fundamentar la sentencia. Debe precisarse un poco más que significa que la evidencia sea "nueva", porque es posible que el medio probatorio que se hace valer con posterioridad sea nuevo pero que sin embargo introduzca la misma fuente de prueba ya previamente introducida por otro medio de prueba que el juez si consideró al fundamentar la sentencia. En otras palabras, la evidencia no es nueva siempre que el nuevo medio de prueba identifique la misma "fuente de prueba" que el juez consideró, mediante ciertos medios de prueba, al fundar su sentencia. Esto implica que la identificación de la "evidencia nueva" no puede realizarse en abstracto. Por lo tanto, la Corte Suprema cuando examina los medios de prueba hechos

\footnotetext{
${ }^{75}$ FERNÁNDEZ y OLAVARRÍA, “Teoría y Práctica”, cit. nota nº 5, p. 228.

${ }^{76}$ El inciso 2 del artículo 297 establece que "El tribunal deberá hacerse cargo en su fundamentación de toda la prueba producida, incluso de aquélla que hubiere desestimado, indicando en tal caso las razones que hubiere tenido en cuenta para hacerlo."
} 
FERNÁNDEZ, José Manuel; OLAVARRÍA, Malva. "Examinando de nuevo la acción de revisión”.

valer por el recurrente debe identificar si a través de ellos se pretende incorporar la misma fuente de prueba que, incorporada por los medios de prueba al juicio, fueron consideradas por el juez al fundamentar su decisión. Si bien esto puede parecer alejado de la realidad, simplemente re-describe conceptualmente qué es lo que hace la Corte Suprema al rechazar, justificadamente, muchas acciones de revisión. De esta manera, si el recurrente hace valer un medio de prueba tratando de introducir la misma fuente de prueba que ya se incorporó el juicio mediante los medios de prueba con los que el juez fundamentó su decisión, la acción debe ser rechazada porque en rigor no hay "evidencia nueva". Cabe advertir que la razón del rechazo no es que la evidencia no sea suficientemente importante para acreditar la inocencia del condenado, sino que la evidencia no es nueva, en el sentido que ya ha sido "conocida" por el juez. Si bien el juez no ha fundamentado su decisión con arreglo al medio de prueba hecho valer por el recurrente en la revisión, sí ha considerado la misma fuente de prueba a través de los medios de prueba hechos valer en el juicio, y por lo tanto, no puede afirmarse que el juez los ha "desconocido".

Como puede verse, identificar si la evidencia es "evidencia nueva" es un asunto complejo que requiere interpretar correctamente las normas del CPP, su sistema objetivo de prueba, y la examinación detallada de lo considerado por el juez al fundamentar su decisión. Ésta es una dificultad no apreciada por la Corte Suprema. El examen de las sentencias arroja que sistemáticamente se afirma por parte de la Corte que el recurrente cuestiona la valoración de la prueba, y que por lo tanto la acción debe ser rechazada. La fundamentación sigue en general las líneas del siguiente fallo de noviembre del 2016:

" $2^{\circ}$ Que el recurrente funda su petición en supuestos facticos que no se compadecen con las exigencias de la causal alegada, toda vez que ella se hace consistir en una serie de cuestionamientos a la valoración efectuada por los jueces del fondo respecto de las pruebas rendidas en el juicio oral, a partir de las cuales se construyó su participación punible, para proponer una situación de hecho diferente de la establecida en la sentencia." 77

Ciertamente tiene razón la Corte Suprema si el recurrente no hace valer nuevos medios de prueba, e incluso también tendría razón si es que el medio de prueba es nuevo, sin embargo incorpora una fuente de prueba que puede identificarse con la fuente de prueba incorporada al juicio respectivo por los medios de prueba que el tribunal consideró para fundamentar su sentencia. No obstante, hay que tener cautela con respecto a las aserciones de la Corte, porque cuando se dispone de nuevos medios de prueba que incorporan nuevas fuentes de

\footnotetext{
${ }^{77}$ SCS, Rol 88988-2016. Los siguientes fallos se fundamentan siguiendo la misma estructura argumentativa, véase SCS, Rol 50016-2016; SCS, Rol 52863-2016; SCS, Rol 55063-2016; SCS, Rol 55068-2016; SCS, Rol 45918-2016 (antiguo CPP); SCS, Rol 45928-2016 (antiguo CPP); SCS, Rol 49691-2016 (antiguo CPP); SCS, Rol 16355-2016 (antiguo CPP); SCS, Rol 1579-2016; SCS, Rol 17032-2015; SCS, Rol 11862-2015; SCS, Rol 11372-2015; SCS, Rol 8835-2015; SCS, Rol 8837-2015; SCS, Rol 7065-2015; SCS, Rol 7065-2015; SCS, Rol 7224-2015; SCS, Rol 12920-2014 (antiguo CPP); SCS, Rol 31710-2014; SCS, Rol 29348-2014; SCS, Rol 27964-2014; SCS, Rol 21548-2014; SCS, Rol 18.019-2014; SCS, Rol 18025-2014; SCS, Rol 18026-2014; SCS, Rol 6477-2014; SCS, Rol 3194-2014; SCS, Rol 635-2014; SCS, Rol 14143-2013; SCS, Rol 10965-2013; SCS, Rol 3556-2013; SCS, Rol 4322-2013; SCS, Rol 1299-2013; SCS, Rol 5614-2012; SCS, Rol 10389-2011; SCS, Rol 5614-2012; SCS, Rol 10389-2011; SCS, Rol 10279-2011; SCS, Rol 101152010.
} 
Polít. crim. Vol. 13, № 26 (Diciembre 2018) Art. 15, pp. 1190 - 1285.

[http://www.politicacriminal.cl/Vol_13/n_26/Vol13N26A15.pdf]

prueba no consideradas por el juez al fundamentar su decisión, y que poseen una fuerza probatoria considerable, siempre existiría, incluso implícitamente, un cuestionamiento a la valoración de la prueba efectuada por el juez que dictó la sentencia que se pretende revisar. Por lo tanto, si bien es cierto que muchas veces los recurrentes no aducen nueva evidencia y efectúan solamente una nueva valoración de los medios de prueba, no por el hecho de que se efectúe una nueva valoración significa que no se han hecho valer nuevas evidencias. En rigor, y ello es especialmente cierto cuando se acoge la revisión, las nuevas evidencias siempre cuestionarán la valoración de la prueba, pues debe acreditarse que las pruebas son suficientes para acreditar la inocencia del condenado.

El último punto que cabe desarrollar a este respecto lo insinuamos en la investigación de 2009. El caso hipotético consiste en que el juez incorpora ciertas fuentes de prueba a través de ciertos medios de prueba en la parte expositiva de la sentencia, pero no estrictamente en la parte considerativa, es decir, la parte considerativa omite la asignación de valor probatorio a pruebas enumeradas o mencionadas en la parte expositiva. Si este es el caso, ello significaría que a pesar de tratarse de evidencias que el juez pudo considerar al fundamentar su sentencia, no fueron evidencias que integraron dicha fundamentación, y por lo tanto, si ellas se hacen valer en sede de revisión, constituirían "evidencia nueva". En efecto, serían evidencias que habrían sido "desconocidas" por el juez, es decir, evidencias que no formaron parte de la fundamentación del tribunal. Nótese que ésto se sigue del modelo de revisión establecido por el legislador. De acuerdo al artículo 374 del CPP constituye un motivo absoluto de nulidad "Cuando, en la sentencia, se hubiere omitido alguno de los requisitos previstos en el artículo 342, letras c), d) o e)". A su vez el artículo 342 letra c) del CPP establece como deber del juez al fundamentar su decisión que éste debe señalar "La exposición clara, lógica y completa de cada uno de los hechos y circunstancias que se dieren por probados, fueren ellos favorables o desfavorables al acusado, y de la valoración de los medios de prueba que fundamentaren dichas conclusiones de acuerdo con lo dispuesto en el artículo 297”.

Por último el inciso $2^{\circ}$ del artículo 297 del CPP establece que "El tribunal deberá hacerse cargo en su fundamentación de toda la prueba producida, incluso de aquélla que hubiere desestimado, indicando en tal caso las razones que hubiere tenido en cuenta para hacerlo.". Lo que estos artículos regulan es el deber del tribunal de valorar los medios de prueba hechos valer por las partes, lo que significa que no sólo debe mencionarlos, señalarlos o enumerarlos en la parte expositiva, sino que debe asignarles o desestimar su valor probatorio en la parte considerativa. El cumplimiento de la obligación de fundamentación es necesario para concluir que el juez ha "conocido" los hechos, y por lo tanto, si dicho deber se incumple cabe concluir, por el contrario, que el juez ha desconocido los hechos, y si estos se hacen valer con posterioridad a través de ciertos medios de prueba, dicha evidencia debería considerarse "nueva". En dicho evento, si la Corte de Apelaciones al conocer del recurso de nulidad no anula de acuerdo al artículo 374 letra e) del CPP, existiría la posibilidad de impetrar la revisión en base a que hay, conceptualmente, evidencia nueva, pues se trataría de medios prueba que no formaron parte de la fundamentación de la sentencia. 
FERNÁNDEZ, José Manuel; OLAVARRÍA, Malva. "Examinando de nuevo la acción de revisión”.

(iv) Ahora que hemos revisado casi completamente las unidades mínimas de la formulación de una "nueva evidencia" podemos agregar el último componente referido al estándar para evaluar dicha prueba, y definir la nueva evidencia como aquel medio de prueba que no fue objeto del deber de fundamentación del juez durante el proceso penal y que tiene la fuerza probatoria suficiente para establecer la inocencia del condenado ${ }^{78}$. El CPP usa la expresión "bastare" que puede interpretarse como suficiencia. Más adelante en la sección 3.3. examinaremos el alcance de dicha expresión, pero podemos adelantar aquí que no debe entenderse en el sentido técnico de "condición suficiente", sino como una alusión a la existencia de un medio probatorio lo suficientemente importante para provocar un nivel de duda mayor al de duda razonable, y que por lo tanto debería hacer procedente la anulación de la sentencia condenatoria. Denominaremos este estándar como el estándar de "prueba suficiente".

En el examen comparado que hemos hecho hasta el momento, hemos considerado la superioridad del modelo chileno, sin embargo, la comprensión del Tribunal Supremo español en lo que se refiere a lo que constituye "nueva evidencia" es claramente superior al entendimiento de nuestra Corte Suprema. Veamos como dicho tribunal formula una interpretación correcta de lo que es una nueva evidencia, haciendo alusión a la letra d) del artículo 954 del Código de Enjuiciamiento Criminal, equivalente como ya se vio en la sección 2.1 de este trabajo, a la letra d) del artículo 473 del CPP:

"Que, el citado cuarto motivo de revisión, es procedente cuando, con posterioridad a la firmeza de la sentencia condenatoria, sobrevenga el conocimiento de nuevos hechos o de nuevos elementos de prueba, debiéndose entender como nuevos, todos los hechos o medios probatorios que sobrevengan o se revelen con posterioridad a la sentencia condenatoria, sin que sea preciso que, el condenado, los desconociera durante el transcurso de la causa, bastando con que no hayan sido... producidos ante el Tribunal sentenciador ni descubiertos por la investigación judicial practicada de oficio, sin que, por consiguiente, se repute nuevo al hecho o medio de prueba que, habiéndose puesto de manifiesto durante el proceso, el Tribunal, en uso de la facultad de soberana apreciación, no le concedió valor alguno..."79

En consecuencia, no entran dentro de la categoría de "nueva evidencia" aquellas fuentes de prueba que fueron efectivamente introducidos en la instrucción y valorados en el plenario ${ }^{80}$, en otras palabras, que han sido objeto del deber de fundamentación del juez.

\subsection{2. ¿Desconocimiento del juez o del recurrente?}

En la investigación de 2009 sostuvimos que podría ser razonable exigir que el condenado sea cuidadoso y haga valer en la oportunidad procesal correspondiente todas las pruebas

\footnotetext{
${ }^{78}$ Esta formulación es coincidente con la propuesta de Daniela Accatino en el sentido que considera que cuando el juez fundamenta la sentencia no se basa en las creencias subjetivas del juez, sino en evidencias, ACCATINO, “Certezas, dudas", cit. nota n' 22, pp. 503-506.

${ }^{79}$ Sentencia del Tribunal Supremo (Sala de lo Penal), de 25 de febrero de 1985 (JUR/1985/1640), citada por VERNENGO, La Revisión, cit. nota n ${ }^{\circ}$ 17, p. 219.

${ }^{80}$ VERNENGO, La Revisión, cit. nota $n^{\circ} 17$, p. 250.
} 
Polít. crim. Vol. 13, № 26 (Diciembre 2018) Art. 15, pp. 1190 - 1285.

[http://www.politicacriminal.cl/Vol_13/n_26/Vol13N26A15.pdf]

que le favorecen, y que si no las hace valer, no podría con posterioridad interponer la acción de revisión en base a evidencia que pudo y debió haber hecho valer con anterioridad. En esa oportunidad, también consideramos que ésta es una exigencia muy poco elaborada por la Corte Suprema y que no tiene respaldo legal ${ }^{81}$, porque el artículo 473 del CPP toma como referencia el desconocimiento del juez y no del condenado. Es necesario examinar más de cerca esta exigencia. Lo que primero debe determinarse es si el término "desconocido" puede referirse, adicionalmente, al condenado. Ya hemos sostenido que esta exigencia indudablemente se dirige al juez, porque de tener como destinatario exclusivamente al condenado, la revisión no podría entenderse como un mecanismo de corrección de errores judiciales, sino como un mecanismo que se dirige a minimizar los errores del condenado. Como lo anterior es absurdo la discusión versa primeramente sobre si el término "desconocido" es una exigencia de estatus legal o no cuando tiene por destinatario al condenado. Postular que la exigencia tiene rango legal significaría considerar que la expresión es ambigua ${ }^{82}$, esto es, que tiene varios significados diferentes simultáneamente. Por una parte se dirigiría al juez disponiendo que no haya fundamentado su decisión en una nueva evidencia, y por otra, también se dirigiría al condenado disponiendo que la nueva evidencia no sea desconocida para él. Asumir que sólo porque la disposición es ambigua, es decir, porque puede tener significados distintos, no resuelve el problema. Ciertamente una expresión puede ser ambigua y tener significados diversos, pero aquí lo que se sostiene es que en base a dicha ambigüedad el legislador establece deberes distintos para distintas figuras del proceso penal. Esto parece ser aún más controversial que postular meramente que la disposición es ambigua. Como ya hemos visto, cuando el término "desconocido" tiene por destinatario al juez significa que una nueva evidencia no ha sido considerada en la fundamentación de la sentencia. Ahora, cuando la expresión se aplica al condenado el significado de la expresión no es evidentemente claro. Quizás indagando en este significado podremos concluir si el adjetivo "desconocido" es o no ambiguo.

Un primer significado del término "desconocido" podría consistir en que el condenado no debe haber conocido una evidencia que podía acreditar su inocencia como condición para hacer procedente la acción de revisión. Es decir, si el condenado conocía la existencia de una fuente de prueba y no la incorpora como medio de prueba al proceso penal, no podría con posterioridad impetrar una acción de revisión. Así formulada la norma basta para la justificación del rechazo de la acción que el condenado haya conocido la existencia de dicho medio de prueba. Es decir, independientemente que el condenado haya podido incorporar dichas fuentes de prueba a través de los medios probatorios correspondientes, basta que el condenado haya "conocido" la fuente de prueba para imposibilitarlo para solicitar la revisión. Ciertamente, si el conocimiento del condenado basta para rechazar la

\footnotetext{
${ }^{81}$ FERNÁNDEZ y OLAVARRÍA, “Teoría y Práctica”, cit. nota no 5, pp. 224.

${ }^{82}$ SCHANE, Sanford, "Ambiguity and Misunderstanding in the Law", Thomas Jefferson Law Review, n 25 (2002), pp. 169-172; ENDICOTT, Timothy, La Vaguedad en el Derecho, Madrid: Dykinson, 2006, pp. 95-97; MORESO, Josep Joan, Lógica, Argumentación, e Interpretación del Derecho, Barcelona: Editorial UOC, 2006, pp. 28-30; POSCHER, Ralf, "Ambiguity and Vagueness in Legal Interpretation", en SOLAN, Lawrence; TIERSMA, Peter (eds.), The Oxford Handbook of Language and Law, Oxford: Oxford University Press, 2012, pp. 129-130; MARMOR, Andrei, The Language of Law, Oxford: Oxford University Press, 2014, pp. 120-123.
} 
FERNÁNDEZ, José Manuel; OLAVARRÍA, Malva. "Examinando de nuevo la acción de revisión”.

acción, no sería necesario considerar si pudo o no incorporarlo en el proceso penal. Sin embargo, esta interpretación no es plausible, porque del hecho de conocer una fuente de prueba o un medio de prueba no se sigue que sea posible obtener el medio de prueba mediante el cual se puede incorporar dicha fuente de prueba al proceso penal.

Si esta primera acepción fuera plausible, entonces se excluiría de la revisión casos que evidentemente no pueden considerarse excluidos, en que por ejemplo, el fiscal o la policía ocultan medios de prueba exculpatorios a la defensa que, no obstante el condenado sabe de su existencia, no los puede hacer valer en el proceso penal. Tampoco parece prudente excluir de la revisión los casos en que la prestación de defensa ha sido gravemente deficitaria. En efecto, en estos casos el no haberse hecho valer el medio de prueba en la oportunidad correspondiente no se debe normalmente a la negligencia o pasividad del condenado, y no parece razonable que se rechace la revisión sólo porque éste ha conocido el medio o fuente de prueba que en definitiva no pudo hacer valer. Excluir todos estos casos o bien imposibilitaría al condenado acreditar su inocencia, o en el mejor de los casos se colocaría todo el peso de corregir una sentencia condenatoria errónea en el conocimiento del condenado, apartándose del propósito del legislador de establecer un medio flexible "...porque se trata de reparar eventuales errores judiciales que pueden producirse." 83 . Ciertamente, cuando el legislador establece en el artículo 473 del CPP los requisitos de procedencia para que la Corte acoja la acción, este considera los requisitos que debe cumplir la evidencia disponiendo que esta debe haber sido desconocida para el juez porque el error que se pretende corregir es un error "judicial", no un error del condenado. Interpretar la carga exclusivamente en el condenado implicaría entender la revisión como un procedimiento destinado a minimizar los errores del condenado, y ello se aparta completamente del propósito de la revisión. Todas estas razones refuerzan la posición que el término "desconocido" no puede interpretarse como una exigencia legal, sino más bien jurisprudencial.

Ahora bien, siendo una creación jurisprudencial vale la pena preguntarse cual podría ser la racionalidad de considerar que existe el deber del condenado de hacer valer toda la evidencia que le favorece en la oportunidad que corresponde, considerando que el mismo legislador consideró que la acción debía ser interpretada en sentido amplio porque era consciente de que esta acción estaba precisamente destinada a corregir errores judiciales, y que por lo tanto, no podía aplicarse de manera tan estricta ${ }^{84}$. En un fallo muy reciente, y que examinaremos en la última sección de esta investigación, la Corte consideró cuales son sus temores, y señaló que el legislador, al regular la revisión, persigue

“...evitar que el imputado o su defensa, reserven elementos de prueba exculpatorios que pudiendo invocar en el juicio para, de esa manera, hacerse de mala fe, de un medio

\footnotetext{
${ }^{83}$ Historia de la Ley No 19.696 Establece Código Procesal Penal, Segundo Informe Comisión de Constitución, Senado, p. 1515.

84 “....se señaló que el riesgo de incorporarlo como recurso ordinario es que se abuse de él, considerando que la mayor parte de los recursos de revisión que se presentan carecen de fundamentos reales, sería conveniente revisar su admisibilidad. No obstante, debe tener cierta amplitud porque se trata de reparar eventuales errores judiciales que pueden producirse.”, Historia de la Ley No 19.696 Establece Código Procesal Penal, Segundo Informe Comisión de Constitución, Senado, p. 1515.
} 
Polít. crim. Vol. 13, № 26 (Diciembre 2018) Art. 15, pp. 1190 - 1285.

[http://www.politicacriminal.cl/Vol_13/n_26/Vol13N26A15.pdf]

para invalidarlo posteriormente en caso de obtener un pronunciamiento desfavorable. En último término se busca evitar el uso de la acción de revisión de forma fraudulenta." ${ }^{85}$

Primeramente debe señalarse que no hay evidencia que de razón a la creencia que esto puede suceder. Si el temor de la Corte Suprema es que el imputado puede ocultar evidencia que le favorece para utilizarla con posterioridad con el propósito de anular la sentencia, debería existir al menos algún dato empírico que justifique que este es un problema real y cual son sus dimensiones en términos cuantitativos. Sin embargo, no hay investigaciones empíricas ni en Chile ni en el derecho comparado que ilustren sobre este fenómeno, o bien porque no ha sido investigado, o bien porque es un temor sin fundamento plausible. A continuación, se verá que esto último es el caso.

En segundo lugar, aún de no existir información empírica disponible podemos conjeturar, asumiendo que el condenado es una persona racional que selecciona ciertos medios apropiados en atención a conseguir ciertos fines, qué razones podrían llevarlo a ocultar evidencia en su favor. A primera vista nada hay de racional en ocultar evidencia que favorece al condenado si se considera los estándares con arreglo a los cuales el juez debe fallar en el juicio oral y al conocer de una acción de revisión. En el primer caso, la evidencia sólo debe provocar dudas razonables que al acusado le ha cabido una participación culpable en el delito imputado por el Ministerio Público, es decir, la evidencia no debe acreditar la inocencia del imputado, sino que sólo crear dudas razonables. Sin embargo, si el imputado hace valer dichas evidencias en el procedimiento de revisión, debe demostrar que es inocente, es decir, que las evidencias que hace valer deben ser capaces de establecer, al menos, de manera suficiente que el condenado es inocente. Ahora bien, en atención a esta diferencia de estándares cabe preguntarse si es racional que el acusado elija ocultar evidencias en su favor con el propósito de hacerlas valer en el procedimiento de revisión, porque en él disminuyen sustancialmente sus opciones de obtener una sentencia favorable. En tercer lugar, incluso asumiendo que el condenado es irracional y persigue dicho propósito fraudulento, y asumiendo que la Corte anule la sentencia, la Corte ignora, como se verá posteriormente, que no hay nada que impida al Ministerio Público reiniciar la investigación, formalizar, acusar y llevar a juicio oral al condenado por los mismos hechos. Por último, en este evento, debe considerarse que a diferencia de otros modelos de nuevo juicio, como el Alemán, el Ministerio Público no se encuentra limitado para solicitar la misma pena. Es decir, el Ministerio Público podría eventualmente solicitar una pena superior. En suma, no existen razones para creer que el condenado ocultaría evidencia en su favor, porque ni aún asumiendo que es irracional hacerlo, el condenado no obtendría ninguna ventaja, por el contrario, podría verse condenado a una pena mayor, en un nuevo juicio donde la prueba con que obtuvo la anulación del juicio en sede de revisión, posiblemente no tendría el mismo peso que de haberla hecho valer con anterioridad.

Ahora bien, si nuestra línea de razonamiento es correcta, cabe preguntarse, si se considera excluida la alternativa del ocultamiento intencional de evidencia que le favorece al imputado, qué razones existen para sostener que debe responder de la infracción de un

\footnotetext{
${ }^{85}$ SCS, Rol 27543-2016.
} 
FERNÁNDEZ, José Manuel; OLAVARRÍA, Malva. "Examinando de nuevo la acción de revisión”.

supuesto deber de hacer valer todas las pruebas que le favorecen. Uno podría sostener que hay razones de economía procesal, es decir, que el imputado debe hacer valer todas las pruebas que le favorecen en la oportunidad que corresponde para evitar un gasto innecesario de recursos. Bajo esta comprensión el condenado no respondería de un ocultamiento intencional sino que respondería por un ocultamiento negligente. Es decir, el condenado debería haber hecho valer las evidencias que le favorecían y si no lo hizo, incluso si se trata de evidencias importantes, no podrían hacerse valer con posterioridad. Sin embargo, la economía procesal no parece ser un argumento de peso, puesto que de lo que se trata es de corregir errores judiciales. Por lo demás, si la sentencia es errónea y el condenado debe ir a la cárcel, esto generaría muchísimos más costos sociales e individuales que someter la evidencia a un nuevo examen ante la Corte Suprema o en un nuevo juicio. No debe olvidarse además, que el principio de economía procesal ya se encuentra vigente en el modelo de revisión, como hemos aludido con anterioridad al describir la administrativización del proceso penal. Con ello, se agotan las razones para considerar plausible la existencia de una norma jurisprudencial que imponga el deber al condenado de haber desconocido la evidencia como condición para acoger la acción de revisión.

Es el momento de examinar la jurisprudencia de la Corte Suprema, la que ha sostenido consistentemente que sí existe el deber de hacer valer la evidencia que favorece al condenado, y que si éste ha sido de alguna manera negligente en hacerla valer, la acción debe ser rechazada. La Corte Suprema normalmente formula el deber del imputado de incorporar prueba en su favor de forma objetiva, pues basta que se trate de nuevas evidencias que "pudieron aportarse" para concluir que el condenado las ha conocido, sin indagar las reales posibilidades que el condenado tuvo para poder incorporarlas. Cabe advertir que esta formulación evidentemente va más allá de lo que la misma Corte Suprema tiene en mente al considerar este deber, puesto que al asumir que se trata de pruebas que "han podido aportarse" no atiende a si el condenado tuvo conocimiento de ellas. Es decir, incluso considerando que existe una norma jurisprudencial que exige que el condenado haya "desconocido" la prueba, la Corte entiende incumplida la condición sin probar que el condenado la "conoció" si constata que la prueba "pudo" aportarse al proceso penal. Veamos el siguiente fallo:

"Que sin embargo, de la lectura del libelo se advierte que no se invoca algún antecedente nuevo o desconocido durante el proceso, sino que se adjuntan declaraciones juradas y fotos que pudieron aportarse, por lo que se propone una nueva valoración de las evidencias de cargo, argumento que no se ajusta a la causal que se esgrime." $\$ 86$

En este reciente caso del 2017 fallado en conformidad a las reglas del CPP la Corte presume que se trataban de evidencias que pudieron aportarse y que por lo tanto no pueden ser consideradas "nuevas", y no pueden ser consideradas nuevas porque al haber "podido aportarse" concluye que el condenado las ha conocido. Al formular el deber de manera objetiva, y al ser innecesario determinar el efectivo conocimiento del condenado, la revisión se transforma en un procedimiento que persigue minimizar errores del condenado, lo que niega que ésta esté destinada a la corrección de errores judiciales:

\footnotetext{
${ }^{86}$ SCS, Rol 10300-2017.
} 
Polit. crim. Vol. 13, № 26 (Diciembre 2018) Art. 15, pp. 1190 - 1285.

[http://www.politicacriminal.cl/Vol_13/n_26/Vol13N26A15.pdf]

"Que se ha solicitado la revisión de la sentencia dictada por el Tribunal de Juicio Oral en lo Penal de Talca que condena a M. V. G. por el delito de homicidio frustrado, invocando la causal de la letra d) del artículo 473 del Código Procesal Penal, por existir documentos que acreditan que a la época de los hechos sancionados la encartada sufría de epilepsia y, aludiendo dichos documentos a afecciones de salud de la propia sentenciada, su existencia no podía ser desconocida por ésta, no cumpliéndose entonces los extremos de la causal invocada.

" $2^{\circ}$ Que, sin embargo, el antecedente que se invoca como nuevo o desconocido durante el proceso no tiene tal característica, puesto que se trata de una condición conocida del imputado al momento de la investigación y de la cual debió hacerse cargo su defensa en su oportunidad, por lo que no se ajusta a la causal que se esgrime." ${ }^{\prime 8}$

Nótese que al sancionar lo que para la Corte son negligencias inexcusables del condenado, ya no se trata de prevenir el fraude, sino de delimitar el correcto comportamiento del imputado, porque si el condenado hubiera tenido un comportamiento correcto dichas pruebas habrían sido incorporadas al proceso penal. Sin embargo, y esto es lo relevante, la Corte se niega a precisar las razones que impidieron que el condenado hiciera valer dichas evidencias durante el juicio. La Corte parece adoptar la posición que aún cuando dichas sentencias constituyan errores, en el sentido que condenan erróneamente a un inocente, el inocente aparece responsable de su propia condena, porque dichos documentos no pudieron ser desconocidos por el condenado. Lo mismo ocurre en el siguiente caso del antiguo CPP:

" $2{ }^{\circ}$ Que la solicitud de revisión se sostiene en la causal 4a del artículo 657 del Código de Procedimiento Penal, invocándose al efecto una copia certificada de la hoja de vida institucional del encartado, que da cuenta de sus vacaciones, permisos y licencias médicas, la que le fue entregada al peticionario el 7 de abril de 2014, y que acreditaría que los actos de formalización de adquisición y financiamiento que integran la conducta sancionada, no fueron ejecutados por el encartado, al encontrarse éste a la sazón de vacaciones. Asimismo, se arguye que, advirtiendo el inculpado una falta de transparencia en las gestiones de la empresa Textiles Ponpadour S.A., informó tales hechos al Subdirector Administrativo del Hospital de Carabineros, remitiendo Oficio $\mathrm{N}^{\circ} 323$, de 9 de octubre de 2003, cuya copia certificada notarialmente acompaña.

$3^{\circ}$ Que como resulta de claridad manifiesta, los documentos enunciados no son de aquellos a que alude la causal invocada, a saber, que apareciendo con posterioridad a la sentencia, sean desconocidos durante el proceso, pues por la naturaleza de los instrumentos en cuestión, su existencia no pudo ser ignorada por el encartado H. J. A.. En efecto, su hoja de vida institucional en Carabineros de Chile corresponde a un registro común en cualquier organismo público, más aún en la institución indicada, y cuya confección y conservación no podía ser preterida, lo cual le permitía haberla recabado y presentado al juicio de estimarla relevante para sus descargos. Por otra parte, huelga explicar que, al haber sido suscrito el Oficio $\mathrm{N}^{\circ} 323$ por el propio peticionario, su existencia tampoco podía ser desconocida para éste".

${ }_{88}^{87}$ SCS, Rol 9587-14.

${ }^{88}$ SCS, Rol 5143-13. 
FERNÁNDEZ, José Manuel; OLAVARRÍA, Malva. "Examinando de nuevo la acción de revisión”.

Por lo anterior, no es posible dar por satisfechas las exigencias previstas en el artículo 659, incisos $1^{\circ}$ y $2^{\circ}$, del Código de Procedimiento Penal, esto es, que la solicitud de revisión exprese con precisión su fundamento legal en relación a la causal invocada, descuido del peticionario que autoriza a esta Corte para desestimar de plano la petición en examen." ${ }^{\text {, }}$

En este caso parece obvio, para la Corte Suprema, que el condenado infringió su deber de incorporar evidencia que le favorecía. Sin embargo, como hemos visto, en ningún momento examina si efectivamente el condenado es responsable de haber infringido su deber. Es posible que las fichas clínicas y las hojas de vida institucional no hayan podido obtenerse hasta antes de la dictación del fallo, es posible que éstas hayan sido emitidas sólo con posterioridad, y tampoco puede descartarse que el defensor haya prestado una asesoría legal considerablemente defectuosa. Sin embargo, la Corte considera que como "era posible" incorporar dichas pruebas, el condenado las "conocía", y por lo tanto, aún de tratarse de condenas erróneas, dicha evidencia ya no podía hacerse valer por la vía de la revisión. Nótese además que todos estos casos son rechazados de manera preliminar en sede de admisibilidad, porque el argumento de la Corte para rechazar el recurso no pasa por un examen del fondo de la evidencia hecha valer para determinar su peso probatorio, sino que presume que el condenado fue negligente, haciéndolo en consecuencia, responsable de su propia condena sin antes acreditar que el condenado fue, efectivamente, negligente. Es decir, incluso considerando que el adjetivo "desconocido" establece un deber de cuidado en relación a la incorporación oportuna de pruebas que favorecen al condenado, la Corte debería al menos acreditar que el condenado es realmente negligente, lo que no es posible si la Corte considera que consistió en evidencia que el condenado "pudo conocer". De este problema la Corte está claramente consciente, es decir, la Corte sabe que el condenado no siempre es responsable de lo que aparentemente es una instancia de negligencia, porque en ciertos casos acoge la revisión a pesar de que se trata de un documento que era "conocido": "Agrega que, si bien es cierto el documento que sirve de sustento a la presente acción de revisión, existía y era conocido de su parte, incluso con anterioridad al juicio, no es menos cierto que el Ministerio Público no llevó adelante la investigación de este ilícito con la diligencia debida y que el Defensor Privado tampoco actuó con diligencia, toda vez que C.A.J.C. se encontraba sujeto a cautelar de prisión preventiva desde el mismo día 25 de octubre de 2008.

CUARTO:... $4^{\circ}$ ) Que, por último, se acreditó que la pistola Taurus serie $\mathrm{N}^{\circ}$ TZK39619 además de estar inscrita a nombre del condenado, registraba autorización para ser mantenida en el domicilio donde fue encontrada e incautada, esto es, el de Pasaje Lautaro Yancas $\mathrm{N}^{\circ}$... Villa El Rosario de la comuna de San Pedro de la Paz, no constituyendo los hechos pertinentes descritos en la acusación, el delito de tenencia ilegal de arma de fuego, careciendo de responsabilidad en tales hechos C.A.J.C. En consecuencia, el condenado en el procedimiento ordinario originado por los hechos antes señalados, esto es, la supuesta tenencia de un arma de fuego en un determinado domicilio sin autorización, lo fue en forma errónea." 90

\footnotetext{
${ }^{89}$ SCS, Rol 8542-2014.
}

${ }^{90}$ SCS, Rol 1558-2011. 
Polít. crim. Vol. 13, № 26 (Diciembre 2018) Art. 15, pp. 1190 - 1285.

[http://www.politicacriminal.cl/Vol_13/n_26/Vol13N26A15.pdf]

Lo que es relevante de este caso es que a pesar que es el mismo recurrente el que indica que la nueva evidencia era "conocida", la Corte accede a la solicitud de revisión. Es decir, la Corte considera probado que el condenado conocía la existencia del medio de prueba, sin embargo lamentablemente no fundamenta porqué en este caso dicha exigencia de conocimiento no era aplicable. Si efectivamente el adjetivo "desconocido" establece un deber para el condenado, la Corte debería haber fundamentado su decisión señalando porqué en este caso la acción debía ser acogida. Lo que parece estar operando en el trasfondo de la decisión de la Corte es el modelo inquisitivo de revisión, es decir, la idea del juez mecánico que es capaz de identificar, sin evaluar la prueba, los casos de manifiesta injusticia. Si la Corte está en frente de dicho prototipo de casos ya ninguna exigencia legal parece importar, es decir, ya no parece importar si la evidencia es o no nueva, si fue forjada con posterioridad o no, o si el condenado conocía su existencia o no, porque para este modelo, lo único que interesa es si la Corte conoce de un caso de "manifiesta injusticia". Ciertamente es admirable la flexibilidad de la Corte para acoger estos casos, pero el problema que genera es qué sucede con los casos "intermedios" como los precedentes, porque si los organismos de investigación mejoran sus mecanismos de identificación y la mecánica se vuelve más precisa, entonces la Corte ya no conocerá casos de "manifiesta injusticia". Y este es precisamente el escenario en que muchas veces se encuentra la Corte, porque si bien todavía se presentan casos de "manifiesta injusticia", porque siguen existiendo casos de suplantación de identidad y otros semejantes, muchos otros son casos intermedios en que la prueba es "suficiente" pero no "fehaciente".

Ciertamente la posición institucional de la Corte Suprema le permite, entre otras cosas, crear seguridad jurídica a través de la previsibilidad de sus decisiones, y es desde luego de lamentar el que no confronte sus propias normas jurisprudenciales, guardando silencio respecto de las explicaciones que justifican su proceder. En el universo de acciones acogidas existen numerosos casos en que la Corte Suprema acepta que el condenado conocía el medio probatorio. En el caso que considera que no había giro doloso de cheques porque el condenado había pagado íntegramente la deuda ${ }^{91}$; en el caso que acoge porque la gestión preparatoria de notificación del protesto era nula ${ }^{92}$; en el caso que el arma se encontraba debidamente inscrita ${ }^{93}$ y que por lo tanto no había delito de tenencia ilegal; en el caso que se había decretado con anterioridad el sobreseimiento definitivo de la causa ${ }^{94}$; el caso del delito de uso de licencia de conducir falsa ${ }^{95}$; en el caso del delito de desacato ${ }^{96} \mathrm{el}$ condenado conocía que dicha medida no se encontraba vigente. Todos estos casos demuestran que esta norma jurisprudencial que no tiene asidero legal y que como hemos visto no esta soportada en razones, es innecesaria. Ello parece confirmado por 9 de los 10 casos acogidos por la Corte ${ }^{97}$ en que ésta ni siquiera se pronuncia sobre si dicha exigencia concurre o no.

\footnotetext{
${ }^{91}$ SCS, Rol 5546-2007.

${ }^{92}$ SCS, Rol 8884-2012.

${ }^{93}$ SCS, Rol 1558-2011.

${ }^{94}$ SCS, Rol 2227-2011.

95 SCS, Rol 4308-2013.

${ }^{96}$ SCS, Rol 6720-2013.

${ }^{97}$ En ninguno de estos casos consideramos los casos de suplantación de identidad.
} 
FERNÁNDEZ, José Manuel; OLAVARRÍA, Malva. "Examinando de nuevo la acción de revisión”.

Podemos concluir que el término "desconocido" no constituye una norma de rango legal cuando tiene por destinatario al condenado, y que en cuanto norma de rango jurisprudencial no existen razones que la justifiquen. Queda preguntarse porqué dicha norma todavía continúa siendo aplicada por la Corte Suprema. Al parecer esta norma no constituye nada más que una expresión de la discreción de la Corte Suprema para conocer de la acción de revisión, y que tal como se utiliza en los casos que hemos analizado se aplica de manera impredecible. Esta conclusión no debería causar sorpresa, porque como hemos visto la Corte no explica como el artículo 473 del CPP puede tener como destinatario al condenado, tampoco cuando dicha norma es aplicable y cuando no, y cuando parece ser claramente aplicable omite todo pronunciamiento sobre su alcance y las razones que sostienen su decisión de no aplicarla. Una mejor práctica de la acción de revisión pasa entonces por una adecuada interpretación del término "desconocido", el que tiene como destinatario únicamente al juez. Y para alcanzar una mejor práctica, parece fundamental que la Corte abandone la comprensión de la revisión de acuerdo con el modelo inquisitivo y adopte definitivamente el modelo previsto por el legislador, el modelo adversarial.

3.2.3. La determinación de una evidencia nueva, ¿corresponde ser examinada como un asunto de admisibilidad o de fondo?

Como se puede advertir, determinar si los antecedentes hechos valer por el recurrente constituyen "evidencia nueva" difícilmente puede ser evaluado en sede de admisibilidad. Esto es correcto aseverarlo hoy, sin embargo, es posible que una vez que exista claridad conceptual sobre lo que debe entenderse por evidencia nueva, ello sí pueda ser identificado en el control de admisibilidad. Hoy, parece indiscutible de acuerdo a lo examinado en las secciones precedentes, que en muchos casos determinar si el recurrente hace valer una nueva evidencia o no es una tarea que requiere interpretar y destilar los principios y normas de la escueta regulación del CPP. Lo anterior no excluye al día de hoy que hay casos en que la Corte efectivamente se encuentra justificada en rechazar la acción "de plano", porque dependiendo del caso, no es necesario un examen detallado de los antecedentes hechos valer. En atención a estos últimos casos pareciera tener una buena explicación la reforma para hacer más eficiente el conocimiento de las acciones de revisión. Sin embargo, debido a una insuficiente atención por parte de la doctrina y la jurisprudencia, muchos de los aspectos más complejos del modelo adversarial de revisión han sido pasados por alto, y en consecuencia casos que merecían una discusión y examen detallado han sido fallados incorrectamente como adoleciendo manifiesta falta de fundamentos. En al menos un caso, la Corte Suprema ha reconocido la complejidad del problema, sosteniendo que no era posible determinar en sede de admisibilidad si la evidencia era o no nueva. Aunque se trata de una sentencia del antiguo CPP su análisis tiene importancia dado que la regulación a este respecto en el nuevo CPP es la misma. Antes de examinar la sentencia compárese de la siguiente manera el antiguo y el nuevo modelo de revisión:

Artículo 475 inciso 2 CPP: “...y si fuere la de la letra d), indicará el hecho o el documento desconocido durante el proceso, expresará los medios con que se pretendiere acreditar el hecho y se acompañará, en su caso, el documento o, si no fuere posible, se manifestará al menos su naturaleza y el lugar y archivo en que se encuentra." 
Polít. crim. Vol. 13, № 26 (Diciembre 2018) Art. 15, pp. 1190 - 1285.

[http://www.politicacriminal.cl/Vol_13/n_26/Vol13N26A15.pdf]

Artículo 475 inciso 3 CPP: “...La solicitud que no se conformare a estas prescripciones o que adolezca de manifiesta falta de fundamento será rechazada de plano, decisión que deberá tomarse por la unanimidad del tribunal.”

Artículo 659 inciso 2 antiguo CPP: “...y si fuere la del numero $4^{\circ}$ indicará el hecho o el documento desconocido durante el proceso, expresará los medios con que se pretenda acreditar el hecho y se acompañará, en su caso, el documento o, si no fuere posible, se manifestará al menos su naturaleza y el lugar y archivo en que se encuentra."

Artículo 659 inciso 2 antiguo CPP: El recurso que no se conformare a estas prescripciones será desechado de plano.

Como puede notarse, bajo ambas regulaciones si el recurrente no indica la nueva evidencia la acción debe ser rechazada de plano, es decir, no requiere de un examen de fondo determinar si la evidencia es o no nueva. Una diferencia importante prevista por el nuevo CPP es que si el asunto es potencialmente complejo, un solo voto basta para que se niegue dicha determinación en sede de admisibilidad. Es decir, la Corte tiene los recursos procedimentales para, cuando lo requiera, examinar el asunto de forma más detallada. Ello abona la tesis de que el nuevo modelo no puede ser caracterizado como el anterior, aunque no obstante ello, la regulación sea similar. Veamos ahora la sentencia de la Corte Suprema, que es muy breve, pero ilustrativa:

" $2^{\circ}$ Que, sin embargo, en la especie el recurrente se limita a analizar los mismos antecedentes en cuya virtud se dictó la sentencia condenatoria, reclamando de una serie de situaciones procesales y de merito probatorio de la evidencia rendida en el proceso, sin invocar algún hecho o documento realmente nuevo desde los cuales se pueda predicar su inocencia, razones por las cuales el recurso de autos no será admitido a tramitación.

Y visto además, lo dispuesto en el articulo 659 del Código de Procedimiento Penal, se desecha de plano, el recurso de revisión deducido...

Acordado con el voto en contra del Ministro Sr. Segura, quien fue del parecer de acoger a tramitación el recurso de revisión intentado a fojas 8 , por estimar que la decisión sobre si el hecho o documento desconocido alegado en el arbitrio constituye una circunstancia nueva, corresponde sea resuelta al conocer el fondo del asunto." ${ }^{98}$

Si bien sólo el voto minoritario considera que la determinación de lo hecho valer por el recurrente, es decir, si es o no evidencia nueva, debe ser parte de un análisis de fondo, es interesante notar que la Corte ha reflexionado en lo complejo de este aspecto de la revisión, al menos en una oportunidad. Del examen de las sentencias en el período 2007-2017 uno de los problemas más comunes que pueden detectarse es la poca claridad en la identificación de lo que es una evidencia nueva. En un primer tipo de casos, como ya hemos visto, la Corte Suprema considera que todo aquello que se pueda inferir del conocimiento que el

\footnotetext{
${ }^{98}$ SCS, Rol 3449-2011.
} 
FERNÁNDEZ, José Manuel; OLAVARRÍA, Malva. "Examinando de nuevo la acción de revisión”.

propio condenado pudo haber tenido de los hechos es "conocido" por él, y por ende, hace improcedente la revisión. No enfatizaremos lo erróneo de este proceder en atención a que ya se ha examinado anteriormente, pero corresponde ahora demostrar las implicancias de concebir que la expresión "desconocido" se aplica al condenado. El siguiente caso es muy semejante a lo que vimos en la sección precedente:

" $2^{\circ}$ Que, en el presente caso, lo que se pretende hacer valer como hecho o antecedente nuevo, sería la circunstancia de no saber conducir el acusado, cuestión que claramente no tiene el carácter de nuevo ni descubierto, sino que conocido siempre por el imputado, de modo que no satisface la exigencia de la causal invocada." $" 99$

Ya hemos descrito los errores con esta forma de proceder de la Corte, pero es interesante notar como ésta concluye que la evidencia no es nueva, y por lo tanto, debe ser rechazada de plano. En este caso la Corte confunde lo que constituye una fuente de prueba con lo que constituye un medio de prueba, porque aún sin conocer con detalle los hechos del caso, el hecho relativo a si el condenado conocía que tenía o no las certificaciones legales para manejar no es, naturalmente, un medio de prueba. El conocimiento que alguien pueda tener respecto de un hecho nunca puede ser un medio de prueba, a menos que se incorpore como tal de acuerdo a las reglas del CPP. Si lo que se pretendía probar era si el condenado sabía manejar o no, la fuente de prueba, habría sido necesario incorporar dicha fuente a través de un medio de prueba, como un certificado legítimamente expedido que acreditara que el condenado sabía conducir, incluso, dependiendo de lo que se pretendía probar, podría bastar la declaración de testigos. Debe advertirse que identificar que $\mathrm{X}$ es una nueva evidencia todavía no implica la existencia de un medio de prueba que demuestra suficientemente o fehacientemente que el condenado es inocente. Es decir, constituye un segundo paso resolver si dicha evidencia, en este caso, la circunstancia de no saber conducir el acusado, es de relevancia para efectos de acoger el recurso. Pero, sin duda, antes de resolver sobre su peso en cuanto evidencia, es necesario determinar si la evidencia es nueva, y apelando exclusivamente a lo que el condenado sabía o debía saber no puede determinarse si la evidencia era o no nueva. Veamos otro caso:

" $2^{\circ}$ Que sin embargo, en el presente caso se desechará la revisión, pues los hechos y antecedentes en que se hace consistir la causal no son nuevos ni tienen la entidad suficiente para configurarla. En efecto, el testimonio de J.S.S., que según el recurrente sería el verdadero autor del delito, fue ofrecido para el juicio oral y, por ende, a esa época ya se sabía de su existencia."

Este caso es un poco más complejo que el anterior. Asúmase, como asevera la Corte, que el testimonio de J.S.S sí fue ofrecido durante el juicio oral, pero que por algún motivo dicho testimonio no fue escuchado, o porque no concurrió al juicio oral, o porque no fue encontrado, o porque guardó silencio. En estas tres hipótesis, si el condenado ha logrado obtener una confesión o declaración de J.S.S. con posterioridad al juicio oral, suponiendo adicionalmente que dicha evidencia exculpa al condenado, efectivamente se trataría de evidencia nueva, pues dicho testimonio, si bien fue ofrecido como medio de prueba el

\footnotetext{
${ }^{99}$ SCS, Rol 6847-2007.

${ }^{100}$ SCS, Rol 4702-2007.
} 
Polít. crim. Vol. 13, № 26 (Diciembre 2018) Art. 15, pp. 1190 - 1285.

[http://www.politicacriminal.cl/Vol_13/n_26/Vol13N26A15.pdf]

tribunal no habría justificado la sentencia en base a él. Ahora bien, aquí el término "desconocido" parece haber mutado nuevamente, no ya cuando toma como destinatario al condenado, sino ahora teniendo como destinatario al juez. La Corte Suprema parece suponer que basta para que el hecho no sea desconocido el mero conocimiento que se tuvo en el juicio oral respecto del posible testimonio de una persona. Es decir, la Corte adopta nuevamente el modelo subjetivista de valoración de la prueba, para el que como vimos en la sección 3.2.1., basta como fundamentación las creencias subjetivas del juez, siendo innecesario atender a los medios probatorios hechos valer por las partes en el juicio. Obsérvese que podría ser verdadero que se ofreció un determinado testigo, que incluso el condenado y el fiscal podrían haber conocido los puntos sobre los que iba a declarar, asumamos que incluso el juez conocía sobre lo que iba a declarar. Aún de ser verdadero lo anterior, esto no podría constituir "conocimiento" en el sentido del modelo objetivo de valoración de la prueba del CPP. En efecto, solamente el testimonio ofrecido y prestado en conformidad a las normas legales durante el juicio oral habría constituido un medio de prueba, porque sólo entonces el juez habría tenido la oportunidad para justificar su sentencia en base a él, y habría, en otras palabras, conocido la evidencia. Como aparentemente esto no sucedió, lo hecho valer por el recurrente parece efectivamente constituir "nueva evidencia".

En suma, es desafortunado que la Corte Suprema aplique respecto del juez el modelo subjetivista de valoración de la prueba, bastando sus meras creencias subjetivas sobre una fuente de prueba para aceptar que el hecho o documento no es "desconocido", modelo que aplica injustificadamente respecto del condenado, como hemos podido ver. Concluimos esta sección enfatizando que si bien en algunos casos la Corte puede efectivamente identificar si la evidencia es o no nueva en sede de admisibilidad, en muchos otros el examen de la Corte ha sido menos que satisfactorio, constatando un sólo caso, de los más de 500, en que la Corte estimó que el asunto debía haber sido examinado con mayor detalle. Sin embargo, como ya hemos visto, dado que la Corte rechaza en base al estándar de prueba fehaciente, en general, no hay diferencias cualitativas entre el examen que hace en admisibilidad y cuando falla en el fondo. Esto sugiere que se requiere algo más que mayor disponibilidad para examinar los hechos con detalle: se requiere un cambio sustantivo el que pasa por adoptar el modelo adversarial de revisión, el que suministra una tercera alternativa a cómo puede proceder la Corte.

\subsubsection{Discapacidad mental}

Existen dificultades adicionales a las ya mencionadas, y que se exacerban al enmarcarse en la posibilidad de rechazo de plano cuando la acción de revisión adolece de manifiesta falta de fundamento. Estas dificultades dicen relación con un grupo de casos que también pueden ser problemáticos a nivel de juicio oral; aquellos casos en que el imputado tiene una discapacidad mental. Nótese que no se trata aquí de evidencia respecto de un condenado que cae en enajenación mental durante el cumplimiento de la condena, porque existen procedimientos específicos previstos por el CPP para manejar dicha eventualidad. Se trata de casos en que la evidencia es relevante al momento del juicio oral, y por lo tanto, se vincula directamente con los casos de revisión de sentencias firmes. Veamos algunos datos del derecho comparado para apreciar cuantitativamente, más o menos, la población que sufre de discapacidad mental. En Estados Unidos si bien alrededor del 2\% de la población 
FERNÁNDEZ, José Manuel; OLAVARRÍA, Malva. "Examinando de nuevo la acción de revisión”.

tiene un grado de discapacidad mental ${ }^{101}$, cerca del $10 \%$ de la población penal tiene una discapacidad mental considerable ${ }^{102}$. Es decir, la tasa de población penal con discapacidad mental es 5 veces superior a la de personas sin discapacidad mental. En Inglaterra se considera una base más amplia para la cuantificación de casos de discapacidad mental, y se ha demostrado, en base a ello, que la cifra bordea el 32\% de la población penal ${ }^{103}$. En Chile un estudio del año 2015 demostró que el $26.8 \%$ de todos los condenados sufre algún tipo de trastorno mental $^{104}$, y el censo de 2012 reveló que el $12 \%$ de las personas tienen al menos una discapacidad. Todos estos datos avalan la posición que caracteriza a la población de discapacitados como una población en riesgo. Es decir, que es más probable que una persona que se encuentre dentro de la población con discapacidad mental sea criminalizada, en comparación a una persona que se encuentra fuera de dicha población. En el derecho comparado ello naturalmente impacta en la generación de sentencias condenatorias erradas. Efectivamente, en Estados Unidos las personas con discapacidad mental representan el 15\% de los casos de sentencias condenatorias erróneas ${ }^{105}$.

Ahora bien, estos datos deberían generar y generan preocupación para los operadores del sistema de justicia criminal. Un primer problema para hacer efectiva la evidencia sobre discapacidad mental es poder identificar que el imputado tiene discapacidad mental. Desde el punto de vista de la asistencia jurídica del imputado, si bien para el abogado defensor identificar que el imputado padece alguna enfermedad o discapacidad mental puede ser relativamente sencillo y evidente en algunos casos, en muchos otros sin entrenamiento médico especial no es fácil identificar si aquél tiene algún tipo de discapacidad. En segundo lugar, incluso conociendo que el imputado tiene alguna discapacidad no siempre es evidente el impacto que ello tiene para determinar su capacidad de culpabilidad. En tercer

${ }^{101}$ BLUME, John; JOHNSON, Sheri Lynn, MILLOR, Susan, “Convicting Lennie: Mental Retardation, Wrongful Convictions, and the Right to a Fair Trial”, New York Law School Law Review, n 56 (2012), pp. 949. Nótese sin embargo que para el cálculo cuantitativo sólo se consideran aquellos que tienen una discapacidad de desarrollo ontogenético o de desarrollo (en ingles "developmental disability"), pues estos son los estándares utilizados por la American Association on Intellectual and Developmental Disabilities (AAIDD), y la American Psychiatric Association (APA), que son los que la jurisprudencia considera válidos.

102 BLUME y JOHNSON y MILLOR, “Convicting Lennie", p. 949.

${ }^{103}$ En Estados Unidos, siguiendo los estándares de la AAIDD y la APA, en la cuantificación de casos con discapacidad mental se excluyen aquellos en que la causa de la discapacidad se debe a un traumatismo encéfalo craneano ocurrido después de los 18 años, y también los casos menos graves de dificultad de aprendizaje. Ahora bien, si estos casos se incluyen entonces la cantidad de discapacitados se eleva al $32 \%$ de la población penal, datos a junio del 2016 en Inglaterra y Gales, véase www.prisonreformtrust.org.uk/ (visto en Junio del 2017).

${ }^{104}$ En Chile los estudios sobre la discapacidad se han centrado mayoritariamente en trastornos mentales, lo que naturalmente hace muy difícil la comparación, sin embargo los datos son ilustrativos del problema. En un estudio de Rubén Alvarado del año 2015, de la Escuela de Salud Pública de la Facultad de Medicina de la Universidad de Chile, denominado "Prevalencia de trastornos mentales en personas recluidas en cárceles en Chile y necesidades de atención”, tomó como muestra 1008 personas privadas de libertad en las regiones Quinta y Metropolitana, constatando un $26.8 \%$ de presos con trastornos mentales en el último año. Es interesante señalar que Alvarado demuestra las dificultades de identificar a la población con trastornos mentales, aseverando que se logra identificar exitosamente 1 de cada 4 casos, y ello considerando que se trata de una población "cautiva", en comparación con aquellos que no se encuentran privados de libertad, véase http://www.uchile.cl/noticias/117216/la-salud-mental-prende-alertas-en-las-carceles-chilenas (visto en Junio del 2017).

${ }^{105}$ Blume y JOHNSON y Millor, “Convicting Lennie”, cit. nota nº 103, p. 950. 
Polít. crim. Vol. 13, № 26 (Diciembre 2018) Art. 15, pp. 1190 - 1285.

[http://www.politicacriminal.cl/Vol_13/n_26/Vol13N26A15.pdf]

lugar, aún cuando el abogado haya logrado identificar que la persona tiene algún grado de discapacidad mental, y ésta parece ser relevante para determinar su capacidad de culpabilidad, obtener evidencia para probar dicha discapacidad también puede presentar dificultades prácticas. $\mathrm{O}$ bien los registros no se encuentran disponibles, o bien no existen registros porque la persona nunca ha sido sometida a un examen médico para determinar su discapacidad mental. Veamos ahora algunos casos en que se ha hecho valer esta evidencia en sede de revisión:

“...fundándose esta solicitud en la enfermedad mental congénita que sufriría el encargado, la que le habría impedido participar en los delitos atribuidos.

$2^{\circ}$ Que la naturaleza de la enfermedad a que alude el recurrente - congénito-, impide considerarla un hecho nuevo y posterior al juicio, menos aún cuando su existencia fue objeto de debate en esa oportunidad, y además materia de pericias psiquiátricas elaboradas durante el procedimiento."

Como ya hemos podido ver con anterioridad, esta sentencia pareciera estar correctamente fundamentada, incluso a pesar de su brevedad. Efectivamente, de ser correcto que se realizaron pericias psiquiátricas para determinar la enfermedad mental y que ellas fueron objeto de debate y discusión durante el juicio oral, y que no arrojaron de manera concluyente que el condenado tenía una enfermedad mental para hacer procedente una medida de seguridad, se trataría de una evidencia que ya fue "conocida" por el tribunal, en el sentido que hemos asignado a dicha expresión. Ahora bien, sin perjuicio de lo anterior, podría argumentarse que se trata de una "evidencia nueva" porque existe un nuevo informe psiquiátrico del que no tuvo conocimiento el tribunal al momento del juicio, y que acredita que al tiempo del juicio el condenado debía haber sido objeto de una medida de seguridad. Como hemos visto, esto sólo sería correcto si la fuente de prueba incorporada a través del medio de prueba hecho valer por el recurrente, no se identifica con la fuente de prueba considerada por el juez al fundamentar la sentencia en los medios probatorios hechos valer en el juicio. Véase, sin embargo, el siguiente caso:

" $2{ }^{\circ}$ Que, sin embargo, el antecedente que se invoca como nuevo o desconocido durante el proceso no tiene tal característica, puesto que se alega un estado de enajenación mental irrecuperable que, de ser efectivo, ya presentaba al momento de llevarse a cabo el juicio oral tal como admite al afirmar que debió ser sometido a pericias psiquiátricas, por lo que las alegaciones no se ajustan a la causal que se esgrime."107

En este caso se hace presente algo que ya parecía sugerirse en el anterior, puesto que la Corte ya señalaba que la enfermedad, como antecedente hecho valer "...impide considerarla un hecho nuevo y posterior al juicio, menos aún...", es decir, que antes de determinar si la fuente de prueba había sido introducida por algún medio de prueba, para la Corte ya se demostraba que ya había sido "conocida", no por el juez, sino por el recurrente, y por lo tanto el "menos aún" opera como confirmación de una hipótesis ya completamente formada por la Corte. El problema que esto revela, es que antes de examinar la

\footnotetext{
${ }^{106}$ SCS, Rol 22945-2014.

${ }^{107}$ SCS, Rol 5011-2014.
} 
FERNÁNDEZ, José Manuel; OLAVARRÍA, Malva. "Examinando de nuevo la acción de revisión”.

comparabilidad de la fuentes de prueba, la Corte considera que el hecho no es desconocido si por algún motivo puede concluirse que el recurrente ya lo conocía. Ahora en este nuevo caso esto es precisamente lo que la Corte infiere, es decir, del conocimiento privado del imputado sobre su propia condición mental que la evidencia no es nueva. Del texto de la sentencia pareciera que la condición mental del condenado ya estaba presente al momento del juicio. Asumamos que dicha aserción es verdadera. De ser verdadera, posiblemente la condición de discapacidad mental se encontraba presente con anterioridad a los hechos investigados y por los que fue condenado, pues de lo contrario se podría haber solicitado el procedimiento del artículo 488 del CPP. Sin embargo, como hemos enfatizado en este trabajo, no basta que una persona haya conocido un medio de prueba, en el sentido de tener acceso a una fuente de prueba a través de sus creencias subjetivas, para afirmar que se trata de un hecho desconocido. Para constatar si se trata de una evidencia nueva o no debe verificarse una cierta identidad entre las fuentes de prueba hechas valer a través del medio de prueba considerado por el juez al fundamentar su decisión, y el medio de prueba hecho valer por el recurrente en sede de revisión. Aparece entonces, con meridiana claridad, que la Corte puede haber rechazado una acción en la que el que el recurrente sí estaba incorporando una nueva evidencia, y por lo tanto, la Corte debió evaluar su fuerza probatoria, lo que sin embargo, no hizo por haberlo rechazado de plano.

\subsubsection{Nuevos peritajes}

En esta sección revisaremos otro tipo de casos, no ya relacionados con las creencias del recurrente en cuestión, o con su conocimiento al tiempo del proceso, sino con la determinación de si el medio de prueba, en este caso un peritaje, puede considerarse una nueva evidencia, véase el siguiente fallo:

“...con respecto a lo alegado por la letra d) del precepto en referencia, cabe consignar que las pruebas usadas en otro proceso y que consisten en nuevos peritajes a las grabaciones hechas valer en un juicio diverso, así como las declaraciones acompañadas y meta peritaje, no tienen tal característica, sino que han sido forjados con posterioridad al juicio oral, por lo que no se ajusta a la causal que se esgrime, circunstancias que no se corresponden con ninguna de las causales esgrimidas."108

Esta sentencia representa el patrón común de la Corte Suprema en la evaluación de la nueva evidencia cuando esta consiste en un peritaje, la que confunde por un lado, fuente y medio de prueba, y por otro, interpreta incorrectamente los intervalos temporales relevantes en que puede descubrirse u ocurrir la nueva evidencia. Ambos problemas ya han sido examinados en la sección 3.2.1., formulándose la interpretación correcta de lo que es un "documento" y los intervalos temporales cubiertos por la acción de revisión. Ahora puede verse concretamente en estas sentencias que la Corte Suprema no logra identificar lo relevante, esto es, que pudo tratarse de fuentes de prueba no previamente incorporadas al juicio oral y consideradas por el juez al fundamentar la sentencia. Ciertamente un meta-peritaje y declaraciones vertidas por testigos en juicio distintos efectivamente pueden contribuir a esclarecer la participación culpable del condenado que recurre de revisión. Algo semejante ocurre en el siguiente caso:

\footnotetext{
${ }^{108}$ SCS, Rol 14778-2015.
} 
Polit. crim. Vol. 13, № 26 (Diciembre 2018) Art. 15, pp. 1190 - 1285.

[http://www.politicacriminal.cl/Vol_13/n_26/Vol13N26A15.pdf]

" $2{ }^{\circ}$ Que el documento que se invoca como nuevo o desconocido durante el proceso no tiene tal característica, puesto que corresponde a un informe evacuado con posterioridad al juicio y confeccionado, tal como lo admite la solicitante, a raíz de la declaración de la perito del Instituto Médico Legal de Valparaíso en el que se expresan las razones por las cuáles, en concepto del médico que lo suscribe, la perito oficial habría equivocado su análisis, de modo tal que no se trata, en consecuencia, de un documento desconocido durante el proceso y que tenga la entidad que exige la disposición legal invocada." 109

Si bien es ciertamente posible que este meta-peritaje se refiera a aspectos del informe pericial que sí consideró el juez al fundamentar la sentencia, también es posible que se hayan vuelto defectuosos a la luz de nueva evidencia que el recurrente ha logrado descubrir, o debido a nuevos conocimientos disponibles en el ámbito de la investigación científica. Sin embargo, la Corte asume sin demostrar que dicha fuente de prueba sí fue considerada por el juez, para lo cual recurre nuevamente al paradigma de valoración subjetiva. Nótese que tal como en el caso precedente, existen otras razones por la que posiblemente dichas acciones de revisión podrían haber sido rechazadas. Es posible, por ejemplo, que ambos meta-peritajes se refieran a fuentes de prueba ya consideradas por el juez al fundamentar su decisión. Es decir, podría tratarse de medios de prueba, si bien diferentes de los considerados por el juez en su oportunidad, que en todo caso introducen las mismas fuentes de prueba, es decir, los mismos hechos que el juez consideró para fundamentar su decisión. Si este fuera el caso, no se trataría de evidencias nuevas. Adicionalmente, incluso de tratarse de evidencias nuevas si éstas no son lo suficientemente importantes no se cumpliría con el estándar del artículo 473 letra d) del CPP. Ahora, y esto debe enfatizarse, es tremendamente problemático que la Corte Suprema entienda que por el sólo hecho de "forjarse" un medio probatorio con posterioridad a la sentencia la acción deba rechazarse. Como ya hemos visto esta interpretación es errada y el riesgo que representa es relevante, porque eventualmente puede llegar a rechazar una acción en que se hace valer a través de un nuevo peritaje prueba de ADN que es capaz de demostrar que el condenado es inocente. Puede pensarse que ésto constituye una exageración, en el sentido que todos confiamos que la Corte Suprema, llegado el caso en que se haga valer prueba de ADN, será lo suficientemente sensible para acoger la revisión. Sin embargo, el hecho que la Corte entienda excluido medios de prueba elaborados con posterioridad al juicio oral hace pensar que llegado el caso de un peritaje de ADN elaborado con posterioridad, éste quedaría excluido de la revisión. Lo realmente serio, es que ésto ya ha ocurrido, véase el siguiente fallo:

" $2^{\circ}$...el recurrente apoya su solicitud señalado que existen tres peritaje en los que se ha descartado la participación del condenado, toda vez, que la sangre encontrada en la lata de cerveza con que la víctima golpea a su agresor no pertenece al recurrente. En ellos precisamente hace consistir la causal invocada, pues, en su opinión, se trata de antecedentes nuevos que eran desconocidos.

${ }^{109}$ SCS, Rol 3623-2011. 
FERNÁNDEZ, José Manuel; OLAVARRÍA, Malva. "Examinando de nuevo la acción de revisión”.

$3^{\circ}$ Que, los hechos relatados y los documentos en que se sustenta la revisión no configuran la causal invocada, pues no se trata de elementos nuevos y desconocidos al momento de producirse el juzgamiento, puesto que los peritajes acompañados, no pueden ser considerados como documentos desconocidos durante la sustanciación del proceso en los términos que exige la causal invocada, desde que, los mismos han sido forjados con posterioridad.", 110

De las más de 550 sentencias en materia de revisión dictadas durante los últimos 10 años este es el único caso que hemos podido identificar en que el recurrente ha hecho valer prueba de $\mathrm{ADN}$ para demostrar su inocencia. Como ya anticipáramos en el párrafo anterior, el argumento de la Corte para rechazar el recurso no es que se trata de una evidencia que ya fue valorada por el juez porque, por ejemplo, también durante el juicio oral se realizó una prueba de ADN que debatida entre las partes no quedó duda de su poca fiabilidad o falsedad. Tampoco el argumento es que existen otras pruebas de mayor valor que fueron acreditadas durante el juicio, sino que se repite el mismo patrón argumentativo que hemos venido examinando: es un medio de prueba forjado con posterioridad.

En la experiencia comparada la prueba de ADN en muchos casos acredita de forma fehaciente que el condenado es inocente, especialmente en delitos de violación y homicidio en que a la fecha del juicio no se disponía de dicha prueba pero en que se demuestra con posterioridad que el ADN no correspondía al acusado. Naturalmente esta prueba no es necesariamente concluyente en todos los casos, como señala Gascón Abellán "No es lo mismo que la prueba guarde una relación directa con el hecho principal que se pretende probar o que la prueba proporcione tan sólo un indicio más para probar ese hecho principal." 111 .

Es decir, si se trata por ejemplo de un delito de violación y la prueba de ADN arroja que el semen no es del condenado, entonces pareciera evidente que éste es inocente a título de autoría directa de violación. Sin embargo, en otros casos la prueba de ADN constituye sólo una razón para dudar de su participación, si por ejemplo, si estando condenado como cómplice en dicho delito de violación, por haber sostenido a la víctima por la fuerza, dicha prueba arroja que en la habitación donde se produjo la violación el condenado no estaba presente, ello contribuiría a probar que él nunca estuvo allí y que posiblemente no sea ni siquiera cómplice. Dependiendo del caso el valor probatorio que puede tener el ADN puede variar, sin embargo, la Corte no examina la nueva evidencia hecha valer como debería haberlo hecho, es decir, determinando su peso probatorio vis a vis la prueba hecha valer en el juicio, sino que rechaza la acción por una razón que no es legalmente admisible. Simultáneamente, la Corte aparece rechazando en general la admisibilidad de la prueba de $\mathrm{ADN}$, porque en cualquier caso en que ésta se haga valer será necesariamente un medio de prueba elaborado o "forjado" con posterioridad al juicio, salvo que se trate de un peritaje que se realizó durante el juicio pero era "desconocido" para las partes. En suma, para el

\footnotetext{
${ }^{110}$ SCS, Rol 28364-2016.

111 GASCÓN ABELLÁN, Marina, "Validez y Valor de las Pruebas Científicas: La Prueba del ADN", Cuadernos Electrónicos de Filosofía del Derecho, no 15 (2007), http://www.uv.es/cefd/15/gascon.pdf, p. 11 (visto en Junio del 2017).
} 
Polít. crim. Vol. 13, № 26 (Diciembre 2018) Art. 15, pp. 1190 - 1285.

[http://www.politicacriminal.cl/Vol_13/n_26/Vol13N26A15.pdf]

condenado que hace valer la prueba de ADN sea como indicio o como prueba principal, parece imposible demostrar su inocencia.

\subsubsection{Testigos que se retractan}

En esta sección se examinan los casos de retractación de testigos. La existencia de testigos que se retractan no es un evento novedoso para la Corte Suprema. Es habitual en las acciones de revisión examinadas que el recurrente haga valer una declaración jurada y a veces firmada ante notario, afirmando que las declaraciones de los testigos vertidas durante el juicio no fueron correctas. Como ya se adelantara, las investigaciones empíricas en materia de retractación de testigos y su impacto en la condena errónea de inocentes se encuentra en sus fases iniciales, por lo que no se dispone de mucha información sobre lo generalizado de este fenómeno. En Chile, si bien no existen investigaciones empíricas sobre este tema específico, es posible hacer algunos comentarios al respecto basados en los casos en que los recurrentes hacen valer declaraciones juradas de testigos y/o de co-imputados. Uno de los problemas más importantes que presenta al hacer valer este tipo de evidencia, es que la Corte Suprema tiende a considerar que si se trata de testigos que posiblemente mintieron en juicio ello obligaría a entregar como antecedente la sentencia condenatoria por falso testimonio, condición que en el período examinado ninguno de los recurrentes ha podido satisfacer. Esta exigencia, como veremos a continuación, genera lo que llamaremos la "paradoja del testigo cooperador".

Piénsese por el momento que el recurrente dispone de un testigo de buena voluntad, un testigo que o por presiones de los órganos de investigación o por sus prácticas inductivas declaró que el condenado era culpable ${ }^{112}$, pero que con posterioridad acepta que cometió un error y está dispuesto a declarar a favor del condenado declarando lo anterior. Es decir, el testigo cooperador es aquel que le informa al recurrente que, o ha mentido en su declaración en el juicio, o ha cometido un error en su identificación como culpable. Si el condenado erróneamente dispone de dicho testigo parece muy difícil continuar teniendo su colaboración para la presentación de una acción de revisión en atención a la exigencia de la Corte Suprema. Desde luego, una vez que el testigo adquiera conciencia que puede ser condenado por revelar la verdad con posterioridad al juicio, parece muy difícil poder continuar contando con su colaboración si todavía no ha sido condenado. Se produce entonces la paradoja, porque si se cuenta con un testigo que puede decir la verdad, no se le debería revelar el riesgo de la posible sentencia condenatoria para continuar contando con su colaboración, puesto que una vez que adquiera conciencia de dicho riesgo, que es lo que la Corte Suprema exige, difícilmente podría contarse con su colaboración para que el condenado acredite su inocencia. En pocas palabras, acreditar la inocencia del condenado requiere la condena del testigo colaborador, lo que hace o imposible o muy difícil contar con su colaboración. Examinemos ahora como se extienden los efectos de la paradoja.

\footnotetext{
${ }^{112}$ Véase el examen de Mauricio duce al respecto, en que explica que en algunos casos de exoneración, las policías han utilizado mecanismos de identificación que inducen al testigo a la creencia que cierta persona es culpable, DUCE, “Algunas Lecciones”, cit. nota n 6, p. 175-176.
} 
FERNÁNDEZ, José Manuel; OLAVARRÍA, Malva. "Examinando de nuevo la acción de revisión”.

La mayor cantidad de casos en que víctimas o testigos se han retractado de sus declaraciones éstos insisten que se ha tratado de errores, lo que si bien por un lado los deja protegidos de la posible condena por falso testimonio, por otro lado imposibilita hacer valer dicho testimonio por la vía de la letra a), porque el delito de falso testimonio no es un delito que pueda cometerse de manera negligente. Este es un problema importante, puesto que si la finalidad que se persigue es la corrección de una sentencia condenatoria errónea, contar con un testigo colaborador parece imprescindible y lo que difícilmente podría obtenerse en el caso que el testigo crea, y con razón, que puede ser sancionado penalmente precisamente en el caso en que se haga efectiva dicha colaboración, es decir, por decir la verdad. En efecto, es paradójico que una vez que se dispone de un testigo colaborador dispuesto a decir la verdad que corrija una sentencia condenatoria errónea, dicho testigo pueda verse válidamente amenazado de castigo penal si efectivamente colabora, es decir, si dice la verdad permitiendo liberar al inocente. Véase el siguiente caso:

"1 Que la solicitud de revisión de fs. 4, se sostiene en la declaración de los coimputados J. Ch. V., F. L. V., M. C. B., y C. M. So., una de las víctimas, A. Ll. E., y de las testigos extrajudiciales A. M. H. (vecina del condenado) y B. G. G. (prima del condenado).

Sin embargo, el artículo 476 del Código Procesal Penal prescribe que no podrá probarse por testigos los hechos en que se funda la solicitud de revisión, proscripción perentoria que se mantiene vigente aunque se escriture tal testimonio, y en esa forma se presente a esta Corte, tal como ha ocurrido en estos autos.

$2^{\circ}$ Que sin perjuicio de lo anterior, salvo los testigos A. M. H. y B. G. G., todos los demás eran conocidos en el juicio, del que formaron parte como co-acusados o víctima; y en lo que respecta a la testigo B. G. G., al informar haber compartido en su domicilio con el G. R. al momento de los hechos juzgados en estos autos -según se lee a fs. 1-, igualmente se evidencia que su testimonio no podía ser desconocido para el condenado a la época del juicio. Por último, los dichos de A. M. H -señala ser testigo presencial del delito sin que en éste haya participado el condenado G. R.- no revisten una naturaleza tal, de manera que por sí solos basten para establecer la inocencia del encartado, pues, se desconoce en esta sede la objetividad e imparcialidad de dicha deponente, así como las circunstancias que rodearon las declaraciones juradas acompañadas a fs. 2 y 3 , las que, además, por la forma documental de su presentación, no han sido sometidas al escrutinio directo del Ministerio Público ni del órgano jurisdiccional, por lo que no es posible estimarlas de mayor peso, y excluyentes de la prueba de cargo incorporada y conocida en el juicio oral que formó la convicción sancionatoria del Tribunal."

\footnotetext{
${ }^{113}$ SCS Rol N 6678-14. Existen, desde luego, otros casos de retractaciones, sin embargo, mucho menos fundamentadas, como la siguiente: "1 Que la revisión de las sentencias firmes procede en los casos taxativamente señalados en el articulo 473 del Código Procesal Penal, que en su literal d) dispone que la Corte Suprema podrá rever extraordinariamente las sentencias firmes en que se hubiere condenado a alguien por crimen o simple delito, para anularlas, cuando con posterioridad a la sentencia condenatoria, ocurriere o se descubriere algún hecho o apareciere algún documento desconocido durante el proceso, que fuere de tal naturaleza que bastare para establecer la inocencia del condenado.

$2^{\circ}$ Que, sin embargo, el antecedente que se invoca como nuevo o desconocido durante el proceso no tiene tal característica, puesto que corresponde a una declaración jurada en que un testigo del juicio se retracta del reconocimiento efectuado en dicha sede, el que no se ajusta a la causal que se esgrime.", SCS, Rol 1150-2013.
} 
Polit. crim. Vol. 13, № 26 (Diciembre 2018) Art. 15, pp. 1190 - 1285.

[http://www.politicacriminal.cl/Vol_13/n_26/Vol13N26A15.pdf]

Como hemos visto con anterioridad, la Corte no examina con detalle el contenido de dichas las declaraciones por considerar que no eran "desconocidas" para el condenado, lo que como se ha visto es incorrecto. La sentencia es confusa, porque la Corte por un lado parece considerar respecto de algunas declaraciones que se trata de evidencias nuevas y simultáneamente que no pueden estimarse como "desconocidas", y ello aunque se trate de declaraciones posteriores referidas a hechos nuevos, esto es, que el condenado no era culpable. Respecto de los otros testimonios, nuevos al parecer, la Corte indica que no se trata de evidencias suficientes. No obstante, la Corte señala que estas últimas declaraciones deberían haber sido sometidas al escrutinio del Ministerio Público puesto que de otro modo no puede establecerse su peso. Ahora, si la Corte realmente considera que se trata de evidencias de peso considerables, lo que debería haber hecho es anular la sentencia y permitir la realización de un nuevo juicio, como veremos con detalle en la sección 3.3. Ciertamente, no es sólo una declaración la que parece acreditar que el condenado es inocente, sino varias declaraciones de varios testigos y co-imputados. La forma más adecuada de poder examinar su validez y peso sería efectivamente a través de un nuevo juicio, pero como la Corte rechaza exclusivamente en atención a que no se cumple con el estándar de prueba fehaciente, termina exigiendo que el condenado presente más evidencias que acrediten su inocencia, evidencias que seguramente no existen. Este caso es el caso paradigmático del modelo inquisitivo de revisión que no da espacio a los casos que hemos denominado "intermedios". Antes de explicar la alternativa del nuevo juicio veamos ahora algunos de los casos más interesantes que le ha tocado conocer a la Corte Suprema, casos de retractación de víctimas, porque la Corte ha acogido la revisión en tres casos en atención a este tipo de evidencias, y que revelan tanto en el antiguo CPP como en el nuevo, que la Corte nunca ha podido ser descrita como mera boca de la ley.

\subsubsection{Víctimas que se retractan}

El siguiente es uno de los casos posiblemente más interesantes de los últimos 10 años en materia de revisión de sentencias condenatorias penales, el caso de Julio Robles Vergara condenado erróneamente por el delito de robo con violencia. Este caso es analizado pormenorizadamente por Mauricio Duce en lo que se refiere a las causas que lo llevaron a ser condenado ${ }^{114}$. La prueba clave para la condena de Robles fue el testimonio de la víctima, la que inducida por varias actuaciones de los cuerpos de investigación identificó erróneamente al condenado como el autor del delito. Examinemos sólo una parte de la sentencia:

"TERCERO...2 $2^{\circ}$. Que con posterioridad a esos hechos, meses después del juicio, encontrándose el fallo condenatorio firme y ejecutoriado, la víctima, H.H.R., o H.H.R., mientras trabajaba en un supermercado de la ciudad de Copiapó, vio en uno de los pasillos a la persona que lo asaltó, el que estaba robando bebidas alcohólicas, percatándose que en las diligencias de reconocimiento efectuadas con ocasión del procedimiento que se originó por el robo de que fue víctima, se equivocó de persona, pues sindicó erróneamente como culpable a un inocente.

\footnotetext{
${ }^{114}$ DuCE, “Algunas Lecciones”, cit. nota no 6, p. 173-175.
} 
FERNÁNDEZ, José Manuel; OLAVARRÍA, Malva. "Examinando de nuevo la acción de revisión”.

QUINTO: Que de todo lo anterior fluye que los elementos en que se ha fundado la presente acción de revisión constituyen hechos nuevos, desconocidos durante el pleito, que se descubrieron con posterioridad al pronunciamiento condenatorio, medios todos que son bastantes para comprobar la inocencia de Julio César Robles Vergara.

Es así como aparece demostrado, con las probanzas referidas en el motivo segundo de esta resolución, que ...con posterioridad a la ejecutoriedad de dicho fallo, se determinó que la víctima H.H.R., desde fines de 2012 y durante el curso del año 2013, en diversas instancias -radio, televisión y prensa escrita, ante el Ministerio Público y la familia del condenado, por escrito en carta dirigida al Presidente de esta Corte, don Rubén Ballesteros Cárcamo, y frente al propio sentenciado- ha reconocido el error en que incurrió en el reconocimiento del autor del delito que le afectó, el 4 de agosto de 2010, imputándoselo a una persona diversa de la que lo cometió, a quien reconoció con posterioridad, mientras prestaba labores en un supermercado de Copiapó. Si tales antecedentes hubiesen sido ponderados por el sentenciador de primer grado, no habría llegado a la certeza condenatoria que legitimó en su momento la dictación de la sentencia cuya revisión se ha pedido, dictando por el contrario sentencia de absolución.

SEXTO: Que en relación a las circunstancias en que la víctima reconoció al verdadero autor del delito, momento en que el sentenciado Robles Vergara se encontraba privado de libertad - lo que excluye toda posibilidad de confusión - hacen más comprensibles los argumentos contenidos en el recurso que descartan el móvil del robo, por cuanto el condenado a la fecha de los hechos, contaba con buen trabajo y sueldo estable, lo que habría arriesgado por sustraer $\$ 30.000$. Por último, también es decidor el rechazó al juicio abreviado propuesto por el Ministerio Público, y el apoyo familiar y de la comunidad que lo conoce, que no cree posible la conducta que se le reprocha, de todo lo cual se desprenden presunciones que justifican aún más las nuevas declaraciones de la víctima." 115

Cabe notar que la Corte rechaza la interpretación del Ministerio Público que sostuvo que la acción debía ser rechazada, porque si lo que se pretendía era la retractación del testimonio de la víctima, previamente debía dicho testimonio ser declarado falso y penado como falso testimonio. Es decir, al parecer la Corte se aparta del patrón de evaluación examinado en la sección precedente cuando quien se retracta es la propia víctima. Nótese que en este caso la víctima no reconoce haber faltado a la verdad, sino que reconoce haber cometido un error, por lo que en rigor, la Corte no se distancia de sus propios precedentes. En efecto, ya que no se trata de un testimonio intencionalmente falso, no podría exigirse la causal letra a) del artículo 473 del CPP. Esto parece correcto. Sería, en efecto, un despropósito del legislador requerir la existencia de una sentencia por falso testimonio cuando de lo que se trata no es de un testimonio intencionalmente falso, sino de un testimonio erróneo en que la víctima reconoce que ha cometido un error. Ello deja en evidencia que las reclamaciones del Ministerio Público no tenían asidero legal alguno.

Otro aspecto interesante que cabe resaltar, y relacionado con la exigencia infundada que sostiene el Ministerio Público, es que el caso Robles da cuenta de un testigo colaborador que reconoce abiertamente, incluso por medios de comunicación públicos, que ha cometido

\footnotetext{
${ }^{115}$ SCS, Rol 11.109-2013.
} 
Polít. crim. Vol. 13, № 26 (Diciembre 2018) Art. 15, pp. 1190 - 1285.

[http://www.politicacriminal.cl/Vol_13/n_26/Vol13N26A15.pdf]

un grave error y que el condenado es inocente. Cabe preguntarnos que habría ocurrido si, en un caso hipotético, la víctima no hubiera reconocido la existencia de un error, sino que presionada por los organismos de persecución, reconoce que mintió. Ciertamente, de los casos de revisión examinados, pareciera que nuestro proceso penal es milagroso, no sólo porque casi nadie se equivoca, sino porque además nadie miente. La experiencia comparada en Estados Unidos demuestra que del total de exonerados por retractación de víctimas en casos de delitos de violación el 16\% de las acusaciones fueron retractadas por las víctimas, y no por error, como en el caso de Robles, sino que reconocen haber mentido durante el proceso penal ${ }^{116}$. No existen razones fundadas para creer que estas mentiras son naturalmente explicables como expresiones particulares de la cultura de Estados Unidos, así como tampoco hay razones fundadas para creer que la razón porque aparentemente no se han identificado mentiras proferidas por víctimas y testigos en el proceso penal, se explican en las particularidades de la cultura chilena. De hecho, lo más probable a este respecto es que la ausencia de identificación se debe a que es muy difícil distinguir entre quien miente y quien dice la verdad. En efecto, la literatura científica ha demostrado que las habilidades de una persona para discriminar entre quien miente y quien no, superan mínimamente las posibilidades de predecir entre el cara y sello si se lanza una moneda al aire ${ }^{117}$. No es una sorpresa que no se identifique una mentira, es que es muy difícil lograrlo. En otras palabras, no es que nadie mienta en el proceso penal chileno, es que es muy difícil determinar quien lo hace.

Por último, y para cerrar con la sección de las nuevas evidencias, es interesante comparar dos sentencias respecto de una clase semejante de delitos, una ocurrida en Chile y que fue acogida, y otra en España que fue rechazada. Antes de examinarlas vale mencionar algunas evidencias que informa Gross en su estudio preliminar sobre la retractación de víctimas y testigos. Primero, Gross determinó de un total de 1068 casos de exoneración que 250 involucraron retractaciones efectuadas después de la sentencia condenatoria ${ }^{118}$, es decir un poco menos del $25 \%$ de todas las exoneraciones involucraron retractaciones. Segundo, el estudio indica que del $100 \%$ de las exoneraciones explicadas en base a retractaciones el $82 \%$ se dieron en delitos de homicidio (132 casos) y violación/abuso sexual de menores (67). Nos enfocaremos en esta última categoría, porque esta es la clase de delitos objeto de las sentencias de revisión que examinaremos. Gross concluye que las:

"Exoneraciones en casos de delitos sexuales contra menores de edad a menudo siguen un patrón común: el testimonio falso de la supuesta víctima o víctimas es la única o principal fuente de evidencia que demuestra la culpabilidad del ofensor, y las retractaciones de los acusadores son consideradas creíbles por la corte, suscitando la exoneración del ofensor." 119 .

Veamos primero la sentencia del Tribunal Supremo Español:

\footnotetext{
${ }^{116}$ Gross y Gross, "Witness Recantation", cit. nota n' 42, p. 7.

117 SIMON, Dan, In Doubt: the Psychology of the Criminal Justice Process, Cambridge Massachusetts: Harvard University Press, 2012, p. 125.

118 GROSS y GROSS, "Witness Recantation”, cit. nota no 42, p. 2.

119 GROSS y Gross, “Witness Recantation”, cit. nota no 42, p. 10.
} 
FERNÁNDEZ, José Manuel; OLAVARRÍA, Malva. "Examinando de nuevo la acción de revisión”.

“...en el caso que nos ocupa, tenemos a un condenado en prisión cumpliendo condena, cuyo principal testigo de cargo resulta ahora que se retracta de sus imputaciones iniciales, relata que está sufriendo un proceso de ansiedad con manifestaciones depresivas y trastornos de sueño, y que dentro de ese cuadro, ha logrado reconstruir su historia de abusos sexuales en su infancia y adolescencia, pudiendo poco a poco rememorar las circunstancias que le condujeron a señalar como autor de esos abusos al fue pareja de su madre, que es a la vez el padre de su hermano menor, y tomando en consideración a su conciencia, reconoce que esta acusación era falsa, y que fue objeto de una manipulación por parte de su madre, que le indujo a acusar a quien era su marido, y precisamente en trance de separación matrimonial. Y además, que ha solicitado ayuda a profesionales "para hacer llegar esta información a las autoridades competentes", en el Centro que le presta apoyo psicológico, aportándose un completo Informe pericial suscrito por profesionales psicológicos y especialistas en psiquiatría..." $" 120$

El Tribunal Supremo desestima sin mayor fundamento la acción presentada, la que en todo caso contó con un voto disidente. Nótese que los antecedentes parecen ser nuevos y suficientes, porque se trata de una retractación de la testigo principal, la que no sólo hace valer su testimonio reconociendo que mintió, sino que adicionalmente ofrece prueba para acreditar su estado mental y emocional actual, como consecuencia directa de haber mentido en el juicio, y lo que constituiría evidencia adicional. Ello se ajusta al patrón ilustrado por Gross; hay una prueba principal que demuestra la culpabilidad del ofensor, y a esa prueba es ofrecida una contra-prueba que le resta su valor probatorio, la retractación de la víctima, el testigo principal. Ahora, el caso chileno es un caso del año 2011. Así como el caso Español, se trató de un delito sexual, específicamente un delito de violación. Así como el caso Español, la víctima reconoce con posterioridad haber mentido. La víctima ahora es mayor de edad, pues han transcurrido más de 10 años, y asevera que cuando declaró contra su padre a los 9 años de edad mintió porque no quería que su padre se fuera con otra mujer, separando a la familia. Declara así mismo que todo lo que dijo a su madre fue mentira, y lo mismo lo que declaró a las terapeutas que la examinaron. Declara que tuvo miedo de confesar haber mentido porque, en su desconocimiento, pensaba que podría ir a la cárcel. Así como en el caso español, la víctima presenta evidencia adicional concerniente a un peritaje psiquiátrico que demuestra que presenta un cuadro de trastorno mental severo, manifestado en instancias de auto-flagelación y otras que de acuerdo a los profesionales tiene su origen en los hechos que ha revelado en terapia. Efectivamente, durante el proceso de terapia la supuesta víctima reveló que existe un hecho pendiente en su vida y que no ha sido capaz de superar; el no haber dicho la verdad respecto de un tema importante y el no haberlo confrontado apropiadamente. Habiendo tomado en consideración que todos estos son medios de prueba nuevos y fehacientes, la Corte Suprema acoge la acción, aseverando que la declaración de la víctima aparece:

"CONSIDERANDO 6:... como veraz y concordante con los antecedentes que obran en la causa principal que se tiene a la vista, en la cual consta que interrogada que fuera, no incrimino a su padre y el enjuiciado durante el transcurso del proceso negó su

\footnotetext{
${ }^{120}$ Sentencia del Tribunal Supremo 949/2010 (Sala de lo Penal), de 1 de octubre del 2010.
} 
Polit. crim. Vol. 13, № 26 (Diciembre 2018) Art. 15, pp. 1190 - 1285.

[http://www.politicacriminal.cl/Vol_13/n_26/Vol13N26A15.pdf]

participación en el delito, no existiendo mas prueba de cargo que la inculpación de la madre... [la] que no fue testigo presencial de los supuestos hechos..."121.

Lamentablemente la Corte Suprema no menciona nada sobre los otros medios probatorios tomados en consideración por el tribunal de la instancia, como las declaraciones de la menor que constan en el proceso, y en los que declara que su padre la violó y abuso de ella sexualmente, y lo dicho por la madre y los terapeutas que la examinaron. La Corte considera: (i) la declaración de la recurrente que "...se aprecia consistente y exenta de presiones, hecha por una persona mayor de edad, en la que se advierte la madurez. necesaria para tomar conciencia acerca de sus actos y ponderar las consecuencias que su denuncia provoco." (ii) una corroboración de la declaración realizada por un profesional que emite un informe pericial al respecto confirmando los hechos y que el estado mental y psiquiátrico de la víctima se corresponde con el hecho de haber mentido años atrás, un informe que es de notar, fue forjado con posterioridad al juicio (iii) que dicho informe además, como meta-peritaje, demuestra que la infección vaginal no estuvo vinculado a un supuesto abuso sexual, lo que excluye el contagio por parte de su padre. La Corte Suprema concluye que estos antecedentes:

"CONSIDERANDO 7:... de haber sido dichos nuevos antecedentes debidamente ponderados por el sentenciador de primer grado y los jueces de alzada, no habían llegado a la certeza condenatoria que legitimó en su momento de la dictación de la sentencia cuya revisión se intenta, dictando por el contario, sentencia de absolución." 122

Este fallo es muy inusual, y es el único a la fecha en un delito de carácter sexual en que el Corte ha considerado fehacientemente demostrado que el condenado era inocente. Sin embargo, hay otros casos en que si bien no se presentan ante la Corte antecedentes con el mismo valor probatorio, posiblemente porque variando el tipo de delitos varían también el tipo de pruebas que pueden acreditar la inocencia, si se presentan antecedentes que parecen suficientes para demostrar la inocencia del condenado, véase el siguiente caso como ejemplo:

" $2^{\circ}$ Que, el recurrente argumentando sobre las causales expone que la decisión de condena se basó en la declaración de la supuesta víctima, quien tiempo después tomó contacto con el condenado y le expresó que lo que declaró en el juicio oral no era verdad y que en su oportunidad no se retractó por temor, haciéndolo en septiembre del presente año por medio de una declaración jurada prestada ante notario.

$3^{\circ}$ Que, la declaración del testigo A.A.J.Ch., no tiene la entidad y naturaleza necesarias para configurar la primera de las causales invocadas y tampoco se puede predicar la falsedad respecto de los dichos del reseñado testigo pues no ha sido declarada judicialmente la misma, motivos por los cuales no será admitido a tramitación."123

\footnotetext{
${ }^{121}$ SCS, Rol 2827-2011.

122 SCS, Rol 2827-2011.

${ }^{123}$ SCS, Rol 10756-2013.
} 
FERNÁNDEZ, José Manuel; OLAVARRÍA, Malva. "Examinando de nuevo la acción de revisión”.

En este caso, resuelto dos años después de haber acogido el caso de la retractación de la víctima en el delito de violación, y tres meses antes de acoger el caso del condenado Robles, la Corte considera que el testimonio del testigo, para ser considerado como antecedente para evaluar la procedencia de la acción de revisión, debe haber sido condenado por falso testimonio, variando claramente su posición al respecto, porque ahora la Corte considera que también la retractación de la víctima debe ser confirmada mediante una sentencia que la declare culpable de falso testimonio. Aparece entonces confirmado lo que afirmáramos anteriormente, y que ahora podemos aseverar de manera más general. Que la Corte Suprema interpreta con absoluta discreción sin ofrecer claridad cuando concurren o no los requisitos para que la acción sea acogida, imposibilitando el conocimiento que los recurrentes necesitan para saber qué es lo que deben probar y con qué medios probatorios la inocencia que se persigue que se declare. Esta falta de predictibilidad afecta sin duda precisamente lo que la Corte pretende resguardar, la seguridad jurídica, pues no justifica sus decisiones en razones ${ }^{124}$ sino atendiendo al resultado que quiere alcanzar y que se predefine de acuerdo a si la evidencia es fehaciente o no, tal como lo requiere el modelo inquisitivo de revisión.

\subsection{Nuevo juicio}

\subsection{1. ¿Es posible que se realice un nuevo juicio al fallar la acción de revisión?}

Posiblemente el aspecto más controversial que desarrollamos y expusimos en la investigación del año 2009 fue el aparente olvido de la Corte Suprema de la posibilidad, prevista por el CPP, de proceder a un nuevo juicio. Han transcurrido más 8 años desde nuestra investigación y nuevamente creemos necesario hacer énfasis en esta posibilidad, precisando las normas legales que la justifican, los problemas que se generan de no reconocerla, y explicando el estándar de prueba que la hace procedente. La propuesta no pasa en este caso por una modificación legal porque la eventualidad de un nuevo juicio ya esta prevista por el CPP, sino por una interpretación más flexible por parte de la Corte Suprema de las normas correspondientes. Nótese que hablamos aquí de "nuevo juicio" en sentido amplio, esto es, entendiéndose como una nueva investigación del Ministerio Público que eventualmente puede conducir a un nuevo juicio oral. En lo que sigue cuando hablemos de "nuevo juicio" lo entendemos en este sentido amplio. Parece notable, y por lo demás, desastroso, que en las últimas 550 instancias de revisión no hay ningún sólo caso de nuevo juicio. Con ello, en la práctica, la Corte ha eliminado del ordenamiento jurídico ciertas normas que el legislador estructuró como parte del mecanismo de revisión. Vale la pena preguntarse porque razón la Corte Suprema ha eliminado las normas que hacen

\footnotetext{
${ }^{124}$ En general el que los tribunales cuenten con discreción no parece necesariamente un problema. Lo que sí constituye un problema ocurre cuando los tribunales ofrecen decisiones no razonadas, porque entonces parece difícil separar lo que constituye un nivel admisible de discreción y cuando se produce arbitrariedad. Sobre la discreción justificada en razones véase, RAZ, Joseph, "Legal Principles and the Limits of Law", Yale Law Journal, no 81 (1972), pp. 847-848, HART, H. L. A., "Post Scriptum”, Estudios Públicos, n 65 (1997), p. 261. Sobre la diferencia entre discreción justificada y la arbitrariedad véase, ENDICOTT, Timothy, "Arbitrariness", Canadian Journal of Law and Jurisprudence, n 27 (2014), pp. 49-71. Para una visión panorámica acerca de la discreción y la arbitrariedad, véase ETCHEVERRY, Juan, "Discrecionalidad Judicial”, en ZAMORA FABRA, Jorge Luis; NÚÑEZ VAQUERO Álvaro (eds.), Enciclopedia de Filosofía y Teoría del Derecho, México: Vol. 2, Universidad Nacional Autónoma de México, 2015, pp. 1389-1418.
} 
Polit. crim. Vol. 13, № 26 (Diciembre 2018) Art. 15, pp. 1190 - 1285.

[http://www.politicacriminal.cl/Vol_13/n_26/Vol13N26A15.pdf]

procedente, bajo ciertas condiciones, la realización de un nuevo juicio y que dan forma al modelo adversarial, reviviendo, con ello, el fenecido modelo inquisitivo.

La explicación es en ciertos aspectos simple pero en otros aspectos compleja. Veamos primero la explicación simple. Cuando el recurrente interpone la acción de revisión la Corte Suprema interpreta sus facultades jurisdiccionales de forma disyuntiva; o rechaza o acoge. Cuando rechaza, la sentencia del Tribunal Oral o del Juez de Garantía mantiene su validez, y obviamente el Ministerio Público se ve imposibilitado para iniciar una nueva investigación respecto del mismo imputado y por los mismos hechos. Cuando la Corte acoge, sin excepción procede a dictar sentencia de reemplazo absolutoria, por lo que el Ministerio Público nuevamente se encuentra imposibilitado de iniciar una investigación respecto del mismo imputado y por los mismos hechos. Si bien la sentencia de la instancia fue anulada, ahora existe otra sentencia válida que es absolutoria. Es decir, la explicación simple a la pregunta porque no han habido nuevos juicios se explica en el propio proceder de la Corte Suprema que entiende que las únicas alternativas que tiene al conocer la revisión son acoger o rechazar. Veamos ahora la explicación compleja.

La explicación compleja requiere tres pasos, veamos el primero. El primer paso consiste en justificar la aserción que el CPP no regula con detalle la diferencia entre las dos alternativas que tiene la Corte Suprema dentro de la opción de acoger. Estas dos alternativas son las siguientes: la primera consiste en que la Corte acoja la acción de revisión y dicte sentencia de reemplazo absolutoria impidiendo la realización de un nuevo juicio; la segunda consiste en que la Corte acoja la acción de revisión pero no dicte sentencia de reemplazo absolutoria, permitiendo, entonces, la realización de un nuevo juicio. La inhabilidad de la Corte de distinguir estas dos alternativas se basa en que el CPP aparentemente regula a través de un único estándar la evaluación de la prueba hecha valer por el recurrente. Como veremos no hay un único estándar, sino dos estándares de evaluación de la prueba. Antes de examinar con mayor detalle estos estándares, debemos justificar la posibilidad que la Corte pueda permitir la realización de nuevo juicio. Comencemos con la historia legislativa del $\mathrm{CPP}$, porque la posibilidad de un nuevo juicio es parte integrante del modelo previsto por el legislador para la revisión. Si bien el CPP no establece expresamente la posibilidad de un nuevo juicio hay al menos dos disposiciones que se refieren directamente a ella:

Artículo 479 inciso primero:

"Efectos de la sentencia. Si la sentencia de la Corte Suprema o, en caso de que hubiere nuevo juicio, la que pronunciare el tribunal que conociere de él, comprobare la completa inocencia del condenado por la sentencia anulada, éste podrá exigir que dicha sentencia se publique en el Diario Oficial a costa del Fisco y que se devuelvan por quien las hubiere percibido las sumas que hubiere pagado en razón de multas, costas e indemnización de perjuicios en cumplimiento de la sentencia anulada."

Artículo 480: "Información de la revisión en un nuevo juicio. Si el ministerio público resolviere formalizar investigación por los mismos hechos sobre los cuales recayó la sentencia anulada, el fiscal acompañará en la audiencia respectiva copia fiel del fallo que acogió la revisión solicitada". 
FERNÁNDEZ, José Manuel; OLAVARRÍA, Malva. "Examinando de nuevo la acción de revisión”.

Si bien claramente ambas disposiciones regulan eventos que toman como referencia un nuevo juicio permitido por la Corte Suprema, en cuanto regulación, es muy poco detallada, sobre todo en comparación a la regulación pre-existente del antiguo CPP. En efecto, en el antiguo CPP si concurría el supuesto número $1^{\circ}$ del artículo 657 (hoy letra a) artículo 473 del CPP) el legislador le ordenaba al juez declarar la contradicción entre las sentencias "... anulará una y otra y mandará instruir de nuevo el proceso por el juez que corresponda." (artículo 662 del antiguo CPP); si concurría el supuesto número $2^{\circ}$ del artículo 657 (hoy letra b) del artículo 473 del CPP) el legislador le ordenaba al juez si no encontraba mérito para un nuevo procedimiento a poner en libertad al condenado, pero si "...encontrare mérito, mandará seguir causa por el juez correspondiente." (inciso 2 artículo 663 del antiguo CPP); si concurría el supuesto número $3^{\circ}$ del artículo 657 del antiguo CPP (hoy letra c) del artículo 473 del CPP) el legislador le ordenaba al juez anular la sentencia y mandar "...que el juez competente instruya nuevo proceso en la forma ordinaria." (inciso 1 artículo 664 del antiguo CPP). Curiosamente, no se disponía lo mismo en caso que concurriera el supuesto número $4^{\circ}$ del antiguo CPP el que establecía "Cuando, con posterioridad a la sentencia condenatoria, ocurriere o se descubriere algún hecho o apareciere algún documento desconocido durante el proceso, que sean de tal naturaleza que basten para establecer la inocencia del condenado". La razón parecía ser que si la evidencia "bastaba" para acreditar la inocencia no era necesaria la procedencia de un nuevo juicio. Ahora bien, podría pensarse que ésto es lo que ocurre con la letra d) del artículo 473 del CPP, es decir, que lo que regula este precepto es el caso en que la prueba "fehacientemente" demuestra que el condenado es inocente, y por lo tanto, no regula a través de un estándar de valoración diverso la posibilidad de un nuevo juicio. Esta conclusión es, sin embargo, equivocada porque asigna el mismo significado al término "bastar" en dos contextos institucionales completamente distintos. Profundicemos en las razones de la equivocación.

En primer lugar, el supuesto del número $4^{\circ}$ del antiguo CPP se traslada al nuevo artículo 478 del CPP, el que establece una de las alternativas posibles para la Corte Suprema si es que acoge la acción:

Si de los antecedentes resultare fehacientemente acreditada la inocencia del condenado, el tribunal además dictará, acto seguido y sin nueva vista pero separadamente, la sentencia de reemplazo que corresponda.

La segunda alternativa está establecida en el artículo 473 letra d) del CPP, el que establece: Cuando, con posterioridad a la sentencia condenatoria, ocurriere o se descubriere algún hecho o apareciere algún documento desconocido durante el proceso, que fuere de tal naturaleza que bastare para establecer la inocencia del condenado.

En otras palabras el supuesto $4^{\circ}$ del antiguo CPP no se puede identificar con la letra d) del artículo 473 del CPP. Ello implica que el término "bastar" del supuesto $4^{\circ}$ significa "fehaciente", y por lo tanto, una vez trasladado al artículo 478 del CPP, el término bastar en el artículo 473 letra d) del CPP no puede significar lo mismo. En segundo lugar, aparece que sólo en el nuevo CPP el legislador distingue entre dictar sentencia de reemplazo absolutoria y permitir un nuevo juicio de acuerdo a diferentes estándares de evaluación de la prueba, modelo que hemos denominado adversarial. En tercer lugar, como ya hemos 
Polit. crim. Vol. 13, № 26 (Diciembre 2018) Art. 15, pp. 1190 - 1285.

[http://www.politicacriminal.cl/Vol_13/n_26/Vol13N26A15.pdf]

aseverado en la sección 2.1, el supuesto $4^{\circ}$ del antiguo CPP era parte de un modelo inquisitivo de revisión, y por ende, expresaba una cierta idea de estado de derecho que hoy ya no corresponde a la descripción del proceso penal ni al estado de derecho del que aquél es parte. Dicho supuesto integraba un modelo inquisitivo de justicia penal que reducía la jurisdicción a una aplicación mecánica de la ley, lo que explicaba la detallada regulación de cómo debía proceder el juez y que fue descrita en el párrafo precedente. También afirmamos que una de las expresiones más claras del modelo inquisitivo se plasmaba en la prueba tasada. Dentro de este modelo el término "bastar" significaba que la prueba debía establecer "fehacientemente" la inocencia del condenado, en otras palabras, significaba que la prueba debía ser tan concluyente que la Corte Suprema, como aplicador mecánico de la ley, pudiera sin necesidad de evaluar su peso probatorio establecer la inocencia.

Naturalmente, en un sistema adversarial de justicia penal la jurisdicción ocupa una nueva posición institucional, lo que implica caracterizar la revisión de manera diferente, en otras palabras, como modelo adversarial. Por esta razón al modelo de revisión no se incorporaron los artículos 662, 663, y 664 del antiguo CPP. Su ausencia se debe no sólo a que la valoración legislativa de los medios de prueba resulta inaplicable en el nuevo CPP, sino también a que la titularidad de la acción penal no reside en el juez, sino en el Ministerio Público. La actual letra d) del artículo 473 del CPP integra un nuevo modelo de estado de derecho, un modelo estructurado de acuerdo al principio de distribución de poderes y en que la jurisdicción no puede ser reducida a una mera "boca de la ley". En consecuencia, el término "bastar" no tiene el mismo significado que bajo la regulación precedente. Como se puede ver a continuación, el legislador tenía presente este nuevo modelo de revisión en la discusión del nuevo modelo de justicia penal:

"Señala que el tribunal, al pronunciarse sobre la revisión, lo rechazará o acogerá, anulando la sentencia.

Añade que si anulare la sentencia, dispondrá la realización de un nuevo juicio cuando el caso lo requiriere o pronunciará directamente la sentencia definitiva.

La Comisión estimó que la resolución sólo producirá efectos si la Corte anula el fallo, y en este evento solamente podría dictar sentencia de reemplazo para absolver al condenado pero no para condenar por [1519] otro delito, tampoco puede determinar por ese solo hecho la realización de un nuevo juicio, porque esa decisión la debe tomar el ministerio público, a quien le corresponde el ejercicio de la acción penal.

El ministerio público podrá iniciar o no otra acción, según la prueba de que disponga, salvo por el delito específico por el que ha sido absuelto.

Acordó también incorporar un inciso tercero recogiendo la norma que se propone en el inciso segundo del artículo 443, en el sentido que, cuando hubiere mérito para ello y así lo hubiere recabado quien solicitó la revisión, la Corte podrá pronunciarse de inmediato sobre la procedencia de la indemnización a que se refiere el artículo 19, No 7, letra i), de la Constitución Política. 
FERNÁNDEZ, José Manuel; OLAVARRÍA, Malva. "Examinando de nuevo la acción de revisión”.

Las modificaciones se acordaron por unanimidad con los votos de los HH. Senadores Aburto, Díez y Viera-Gallo.",125

Esta discusión es relevante porque para el legislador la decisión sobre si procede un nuevo juicio ya no corresponde al juez o al legislador a través de un modelo de prueba tasada, sino al Ministerio Público. Efectivamente, de anularse la sentencia condenatoria pero de abstenerse la Corte de dictar una de reemplazo absolutoria, el Ministerio Público se encuentra, en el nuevo CPP, en condiciones de decidir si procede una nueva investigación o no, lo que debe decidir de acuerdo a los nuevos antecedentes de que dispone. En el nuevo modelo de revisión la decisión sobre si procede o no un nuevo juicio no corresponde a los tribunales, y ello en atención a que el condenado ha hecho valer nueva evidencia que el juez no tuvo a su disposición para en base a ella justificar la sentencia. Lo que la Corte sí puede hacer es permitir la realización de un nuevo juicio cuando la prueba si bien no establece "fehacientemente" la inocencia del condenado, si es "suficiente" para acreditar que es inocente. Este es el elemento clave del modelo adversarial. Naturalmente, quien se encuentra en condiciones de determinar si habrá o no un nuevo juicio es una decisión que corresponde al Ministerio Público en atención a la nueva prueba que dispone. Ahora bien, la evaluación de la nueva evidencia ocurrirá en la instancia jurisdiccional correspondiente, y ello nuevamente contrasta el modelo adversarial de revisión con el modelo inquisitivo. En lo concerniente a la prueba, en el antiguo CPP se disponía que en el nuevo juicio el testigo condenado por falso testimonio no podría rendir nuevamente prueba testimonial (inciso 2 artículo 664 del antiguo CPP), y adicionalmente que: "Ninguno de los jueces que hubieren intervenido en el pronunciamiento de la sentencia que se declare nula en virtud de las disposiciones del presente título, podrá tomar parte en el nuevo juicio que la Corte Suprema mandare instruir con arreglo a los tres artículos que preceden" (artículo 665 del antiguo CPP).

Al respecto se dejó constancia de lo siguiente en la historia del CPP:

"Excluye los elementos fundantes de la revisión en el nuevo juicio, indicando que no se podrán incorporar elementos de prueba cuyo cuestionamiento hubiere dado lugar a la revisión.

La Comisión estimó que esta norma es muy amplia e innecesaria porque por el sistema de libertad probatoria es muy difícil que se le de valor a una prueba objetada.

La Comisión estimó innecesario este artículo por entender que debe quedar sometida a las reglas generales. Sin embargo, causó preocupación de que en este caso, si hay un nuevo juicio el fiscal debiera exhibir la sentencia recaída en la revisión.

La Comisión, por razones de transparencia, reemplazó la norma propuesta por una disposición, como norma final, en cuya virtud, si con posterioridad al fallo de revisión el ministerio público formaliza investigación por los mismos hechos a los que se

\footnotetext{
125 Historia de la Ley No 19.696 Establece Código Procesal Penal, Segundo Informe Comisión de Constitución, Senado, p. 1520.
} 
Polít. crim. Vol. 13, № 26 (Diciembre 2018) Art. 15, pp. 1190 - 1285.

[http://www.politicacriminal.cl/Vol_13/n_26/Vol13N26A15.pdf]

refiere la sentencia anulada por la revisión, deberá acompañar copia del fallo respectivo." 126

Ciertamente, en un sistema de valoración fundado en la sana crítica, no existen testigos inhábiles o prueba que quede en principio excluida en toda circunstancia del juicio oral. En relación a los modelos comparados, en lo que se refiere a la procedencia de un nuevo juicio, el modelo chileno es excepcional, y ahora, en el buen sentido de la expresión. En Estados Unidos, Canadá, Inglaterra, Escocia y Alemania es el juez, normalmente de una instancia superior, el que decide si debe o no proceder un nuevo juicio oral. Sin embargo, cabe preguntarse si hay alguna razón que justifique que, en estos sistemas bastante más adversariales que el nuestro, la decisión sobre un nuevo juicio corresponda al juez, y no naturalmente al fiscal. Efectivamente, como afirman James Chalmers y Fiona Leverick, es el fiscal quien se encuentra en la mejor situación para determinar el curso a tomar en relación a la investigación de los hechos desde el punto de vista del interés público ${ }^{127}$. A lo que cabe agregar que el Ministerio Público, atendiendo a su capacidad organizacional y posición institucional, está colocado en una situación superior desde un punto de vista epistémico para evaluar la prueba disponible: este es el órgano llamado a determinar si se debe o no dar curso a dicha investigación, y por lo tanto, al eventual juicio oral. También parece excepcional, en el mejor de los sentidos, que en principio no sea aplicable ninguna causal de implicancia o recusación para que el juez conozca de los hechos una vez más. En efecto, no es aplicable la causal de implicancia establecida en el artículo 195 del Código Orgánico de Tribunales " $8^{\circ}$ Haber el juez manifestado su dictamen sobre la cuestión pendiente con conocimiento de los antecedentes necesarios para pronunciar sentencia", si en el caso, como es obvio, hay evidencia adicional que apunta a la inocencia y la cual no fue considerada por el juez. Tampoco parece aplicable la causal de recusación prevista en el artículo 196 del Código Orgánico de Tribunales "10. Haber el juez manifestado de cualquier modo su dictamen sobre la cuestión pendiente, siempre que lo hubiere hecho con conocimiento de ella", porque el caso ya fue resuelto con anterioridad y respecto de la nueva evidencia que se hace valer el juez no necesariamente puede haber manifestado su dictamen. La razón por la que es conveniente que estas causales de implicancia y recusación no sean aplicables se basa en que, como señala Mary Brennan, dicho juez es el que se encuentra en la mejor posición, luego de haber observado a los acusados y evaluado la evidencia hecha valer, para determinar si la evidencia exculpatoria es suficiente o no en el nuevo juicio ${ }^{128}$. Es decir, es el mismo tribunal juez quien se encuentra en la mejor condición para determinar el impacto de la prueba que la Corte Suprema ha calificado de suficiente para acreditar la inocencia del condenado.

Con esto el primer paso en la argumentación compleja ya se ha completado, pues queda claro de la historia fidedigna del establecimiento del CPP, así como de la regulación del

\footnotetext{
126 Historia de la Ley No 19.696 Establece Código Procesal Penal, Segundo Informe Comisión de Constitución, Senado, p. 1520.

${ }^{127}$ CHALMERS, James y LEVERICK, Fiona, "When Should a Retrial be Permitted After a Conviction is Quashed on Appeal?", Modern Law Review, no 74 (2011), p. 745.

${ }^{128}$ BRENNAN, Mary Ellen, "Interpreting the Phrase "Newly Discovered Evidence": May Previously Unavailable Exculpatory Testimony Serve as the Basis for a Motion for a New Trial Under Rule 33?”, Fordham Law Review, no 77 (2008), p. 1138.
} 
FERNÁNDEZ, José Manuel; OLAVARRÍA, Malva. "Examinando de nuevo la acción de revisión”.

antiguo CPP que también establecía dicha posibilidad, que es posible que a consecuencia de la acción de revisión se anule la sentencia pero no se dicte la de reemplazo absolutoria, permitiéndole al Ministerio Público resolver si debe o no proceder a una nueva investigación, y eventualmente arribar a un nuevo juicio oral. El segundo paso es precisar cuál puede ser la razón que justifica esta eventualidad, es decir, cual podría ser la justificación de la posibilidad de un nuevo juicio como tercera alternativa para la Corte Suprema. Como ya hemos visto en la primera sección de esta investigación, y como queda más o menos en evidencia de los fallos que hemos analizado hasta el momento, el colocar a la Corte Suprema en la disyuntiva de rechazar o acoger, cuando conoce de casos de errores judiciales en perjuicio del condenado, la ha llevado a interpretar las normas del CPP con excesivo rigor y sin generar un mínimo de predictibilidad. La consecuencia de este estado de cosas, es que tenemos en Chile una tasa de inocentes al menos 5 veces inferior a la tasa esperable de errores judiciales en perjuicio del condenado. Es correcto que muchas veces se presentan acciones de revisión sin justificación, pero como se ha visto, en muchos casos también se presentan evidencias que parecen introducir dudas más que razonables sobre la culpabilidad del condenado. Piénsese al respecto el caso del ADN, en que la evidencia si bien no acredita fehacientemente la inocencia del condenado, si se trata de una prueba que de haberse tenido en consideración por el juez habría provocado serias dudas de la participación punible del condenado.

Parece razonable afirmar que del conjunto de 550 casos fallados por la Corte Suprema hay muchos "casos intermedios", es decir, que si bien no parece correcto que se rechacen por insuficiencia probatoria tampoco parece prudente que se acojan porque no acreditan de manera fehaciente la inocencia del condenado. Nótese que aquí es clave como se interprete el sistema de revisión. Como afirmamos al comienzo de este trabajo, en un sistema inquisitivo como el Español que no contempla la posibilidad de un nuevo juicio, no resulta adecuado caracterizarlo como comprometido con la justicia, puesto que al no contemplar dicha posibilidad, los casos intermedios no pasan la barrera del acogimiento, y que sin embargo habrían llevado a la duda razonable en la instancia correspondiente. El sistema adversarial chileno, por el contrario, se encuentra mejor comprometido con la justicia porque contempla la posibilidad de un nuevo juicio, incorporando aquellos casos en que existe una nueva evidencia suficiente y en que hay buenas razones para creer que el condenado es inocente, concediendo la posibilidad de un nuevo juicio. De lo contrario, de describir el sistema de revisión excluyendo la posibilidad de un nuevo juicio no sólo se presentaría una falsa descripción del sistema, sino que se admitiría que aquellos casos en que se hace valer nueva evidencia suficiente que demuestra que el condenado es inocente quedarían sin solución. En otras palabras, al dejar estos casos intermedios fuera del alcance del sistema de revisión, al no concederles la posibilidad de un nuevo juicio, el sistema quedaría comprometido con claras violaciones de justicia material, tal y como el sistema Español.

\subsubsection{Aclarando el terreno para el nuevo juicio}

El tercer paso en la explicación compleja consiste en defender la propuesta refutando ciertos argumentos escépticos respecto de la posibilidad de un nuevo juicio. En esta sección revisaremos ciertos argumentos que reducen la plausibilidad de esta alternativa, los refutaremos y aclararemos ciertas dudas que parecen suscitarse una vez que, 
Polít. crim. Vol. 13, № 26 (Diciembre 2018) Art. 15, pp. 1190 - 1285.

[http://www.politicacriminal.cl/Vol_13/n_26/Vol13N26A15.pdf]

eventualmente, se proceda a nuevo juicio. La primera dificultad que parece presentarse parece devastadora, porque el condenado cuya sentencia ha sido declarada nula, podría oponer, eventualmente, una excepción de cosa juzgada basada en que el condenado ya fue objeto de una investigación y juicio por los mismos hechos. La dificultad apunta a algo relevante, pues en el tipo de casos en que procedería el nuevo juicio es de aquellos en que la inocencia del condenado no es fehaciente, esto es, se trata de casos en que existen antecedentes que apuntan a establecer la inocencia del condenado pero que no excluyen que éste sea en definitiva culpable. En la historia fidedigna como vimos se dijo, entre otras cosas, que "El ministerio público podrá iniciar o no otra acción, según la prueba de que disponga, salvo por el delito específico por el que ha sido absuelto." 129

Esto debe interpretarse con cautela. El legislador se está refiriendo al caso en que el condenado sea absuelto pero que el Ministerio Público decida abrir una investigación para efectos de determinar al verdadero culpable. Evidentemente, si se trata de un solo condenado y queda acreditado que es inocente, el verdadero culpable todavía puede encontrarse con libertad, o preso, pero no formalizado ni juzgado por estos hechos. El legislador entonces no está considerando el caso en que la sentencia condenatoria es anulada y no se dicta la de reemplazo absolutoria. Es decir, el legislador está considerando que se ha dictado sentencia absolutoria de reemplazo de inmediato, y evidentemente, aquí esta resolución si genera cosa juzgada. En otras palabras, el legislador no está pensando aquí en los casos intermedios. Ahora bien, es precisamente en los casos intermedios donde existe el temor que el condenado, que puede ser culpable pero también inocente, pueda impetrar una excepción de cosa juzgada de forma de imposibilitar la investigación, y eventualmente, la existencia de un nuevo juicio sobre de los mismos hechos. Este es más o menos el mismo temor de la Corte Suprema sobre los posibles casos de interposición fraudulenta de la acción de revisión. Sin embargo, este temor no tiene fundamento alguno.

En efecto, la posible oposición de la excepción de cosa juzgada descansa sobre el hecho que existe una sentencia condenatoria válida, es decir, no anulada. Es decir, esta excepción procede sólo en el caso que exista una sentencia condenatoria, porque sólo dicha sentencia proscribiría que el Ministerio Público pueda reiniciar la investigación sobre los mismos hechos y respecto del mismo condenado. Lo mismo ocurre con una sentencia absolutoria. Específicamente, esto haría procedente la excepción de previo y especial pronunciamiento prevista por el artículo 264 letra c) del CPP. De acuerdo a María Inés Horvitz y Julián López hay cosa juzgada cuando hay "...identidad en la persona perseguida (eadem persona), en el objeto de la persecución (eadem res) y en la causa de la persecución (eadem causa petendi.)" 130 , pero esto supone adicionalmente que la "cosa", el hecho, ha sido juzgado porque la cosa juzgada es una propiedad de una resolución firme, y en el evento que la Corte Suprema anule la sentencia condenatoria, no existiría dicha resolución. Efectivamente, lo que hace procedente la posibilidad de un nuevo juicio es precisamente la premisa que hace imposible que el Ministerio Público pueda reiniciar la investigación; que

\footnotetext{
${ }^{129}$ Historia de la Ley No 19.696 Establece Código Procesal Penal, Segundo Informe Comisión de Constitución, Senado, p. 1520.

${ }^{130}$ HORVITZ / LÓPEZ, Derecho, t. II, cit. nota no 18, p. 39; COUTURE, Eduardo, Fundamentos de Derecho Procesal Civil, Buenos Aires: Tercera Edición, Depalma, 1958, p. 399 y ss.
} 
FERNÁNDEZ, José Manuel; OLAVARRÍA, Malva. "Examinando de nuevo la acción de revisión”.

exista una sentencia condenatoria firme. Naturalmente, si la Corte Suprema no dicta la sentencia de reemplazo entonces no sería posible oponer dicha excepción, porque no existiría la sentencia condenatoria que la hace procedente. De esta forma, el Ministerio Público puede reiniciar dicha investigación y el juez, en el eventual juicio oral, será libre para valorar las pruebas, tal como se dejó constancia en la historia fidedigna del establecimiento del CPP.

Semejante al argumento precedente podría pensarse que cuando la Corte Suprema declara anulada la sentencia y no dicta absolutoria de reemplazo el Ministerio Público no podría reiniciar la investigación por concurrir una causal de sobreseimiento definitivo, específicamente la letra f) del artículo 250 del CPP "f) Cuando el hecho de que se tratare hubiere sido materia de un procedimiento penal en el que hubiere recaído sentencia firme respecto del imputado". Sin embargo, al igual que en el caso de la cosa juzgada, la premisa que hace procedente esta causal de sobreseimiento definitivo no concurre, pues esta requiere la existencia de una sentencia firme, y este no sería el caso pues la sentencia habría sido anulada. Nótese, finalmente, que la posibilidad de hacer procedente un nuevo juicio está establecida a favor del condenado, por lo que curiosamente en todos estos casos nos hallamos en circunstancias más favorables para el imputado. El escenario en que se admite un nuevo juicio, para aquellos casos en que no se cuenta con evidencia para demostrar fehacientemente la inocencia del condenado, es ciertamente más beneficioso que aquel en que éstos son rechazados de plano. Una variación de este argumento se sostiene en el artículo $1^{\circ}$ del CPP que establece a nivel de principio la existencia de una "única persecución". Sin embargo, si dicho principio fuera realmente exigible, si fuera una regla categórica, habría una seria inconsistencia con lo que dispone el CPP a propósito del recurso de nulidad. En efecto, el artículo 386 del CPP, establece que, cumpliéndose ciertas condiciones, procede un nuevo juicio, por lo que la existencia de un nuevo juicio luego de la revisión, no hace más inconsistente al sistema previsto por el CPP.

Antes de avanzar a la siguiente sección quisiéramos examinar algunas sentencias que claramente, a nuestro juicio, se revelan como casos "intermedios", es decir, casos en que el recurrente hace valer antecedentes suficientes que si bien no acreditan fehacientemente la inocencia del condenado, si se trata de evidencias nuevas que contribuyen a demostrar que el condenado es inocente. Uno de los casos a este respecto, y que ya mencionáramos anteriormente, es el caso del ADN (SCS Rol N²8364-16), en donde la Corte rechaza sin considerar el peso probatorio de la evidencia. En los casos que siguen la Corte, por el contrario, considera el valor probatorio de la nueva evidencia hecha valer, esto es, considera que lo hecho valer por el recurrente es "evidencia nueva":

"Que se ha solicitado la revisión de la sentencia dictada por el Tribunal de Juicio Oral en lo Penal de Talca el 17 de septiembre de 2013, que condena a A.A.V. por el delito de robo con intimidación y violencia, invocando la causal de la letra d) del artículo 473 del Código Procesal Penal, basándose en la declaración jurada de 28 de abril de 2014, prestada por la víctima de los hechos sancionados, G.A.M., en la que precisa que el encartado "no tubo (sic.) participación alguna en la rencilla y en los actos de violencia que se produjeron en el interior del taxi (...) sin tener participación del delito por el cual se encuentra condenado", sin embargo, al final de su atestado manifiesta que "mi declaración no tiene por finalidad retractarme de ninguna declaración que haya emitido 
Polít. crim. Vol. 13, № 26 (Diciembre 2018) Art. 15, pp. 1190 - 1285.

[http://www.politicacriminal.cl/Vol_13/n_26/Vol13N26A15.pdf]

en el transcurso del proceso" y, al respecto, según se lee en el motivo octavo del fallo cuya revisión se persigue, G.A.M. señaló en el juicio oral que "el chico le dijo al otro [A.V.] que se bajara para registrarlo, abrió la puerta del chofer, lo registró y le sacó su billetera (...) el sujeto que se bajó, se quedó con la billetera y $\$ 16.000$ (...) Los reconoció en la sala de audiencia, el más alto fue el que lo registró y le sacó la plata y el otro fue quien le disparó y corresponden a A.A.V. y M.P., respectivamente". De esa manera, al no retractarse el testigo G.A.M. de sus dichos prestados en el juicio, y siendo esa versión contraria a la que ahora refiere, no es posible estimar que el documento invocado revista tal naturaleza que bastare para establecer la inocencia del condenado, como exige la causal invocada."131

La evidencia hecha valer por el condenado en este caso parece ser de mucho peso, pues se trata de la víctima que se retracta de su testimonio prestado durante el juicio oral. Curiosamente, la víctima asevera que no se está retractando, lo que para determinar, y esto es más que curioso, la Corte considera la declaración de la víctima efectuada en el juicio oral. Es decir, contrasta, para determinar si hay retractación o no, no lo aseverado por la víctima como evidencia nueva, sino lo dicho por la víctima en cuanto a que lo aseverado en la nueva evidencia no constituye retractación y su declaración durante el juicio oral. Naturalmente, la Corte concluye que no hay retractación. Ahora bien, si efectivamente no hay retractación, entonces no sería necesario considerar el valor probatorio de la nueva evidencia. Después de todo, si no hay retractación, ello significa que la evidencia no es nueva, es decir, en rigor no es desconocida, porque el juez fundamentó su decisión con arreglo a la declaración no retractada de la víctima. Sin embargo, la Corte evalúa el peso probatorio de la nueva evidencia, concluyendo que la prueba no tiene valor suficiente para acreditar la inocencia del condenado. La aserción de la víctima respecto de cómo califica lo que hace es sugerente, en el sentido que parece explicarse en la amenaza penal si se determina en definitiva que mintió en el juicio, de otra manera, ¿por qué retractarse de lo aseverado en el juicio y afirmar al mismo tiempo que lo que dice no constituye una retractación? Una explicación plausible es la paradoja del testigo colaborador que ya examináramos con anterioridad. Ahora, independiente de esta paradoja, el hecho es que se trata de una evidencia muy importante, de una retractación de la víctima, lo que si bien posiblemente no acredita fehacientemente la inocencia del condenado, ciertamente si contribuye suficientemente a demostrar su inocencia. Si dicha evidencia hubiera sido incorporada y rendida en el juicio oral, probablemente el resultado habría sido diferente.

Algo semejante ocurre en el siguiente caso:

“...primero se acompaña informe pericial sonido y audiovisual de la PDI de 22 de mayo de $2014 \ldots$ en el cual se transcribe un diálogo entre dos personas de género femenino (no las individualiza) donde una de las voces señala que "yo no los había reconocido", "claro...alteraron...la declaración yo no la leí, si a mí no me la quisieron mostrármela...". Sin embargo, la víctima en su declaración de fs. 83, de 11 de septiembre de 2013, prestada ante la Fiscalía Militar, refiere que lo señalado en el video "fue solamente porque me encontró en un mal momento y por temor a que me hicieran algo, ya que los padres de J.M. y A.Y. fueron en varias oportunidades a mi casa pero siempre conversaron con mi papá, por lo que me dijo mi papá la primera vez

\footnotetext{
${ }^{131}$ SCS, Rol 10847-2014.
} 
FERNÁNDEZ, José Manuel; OLAVARRÍA, Malva. "Examinando de nuevo la acción de revisión”.

que fue la mamá de estos jóvenes lo hizo en forma prepotente diciendo que quería conversar conmigo", agregando que "los carabineros en ningún momento me indujeron a que culpara a las dos personas que resultaron detenidos".

En cuanto a la declaración de 20 de abril de 2014 de fs. 116, prestada también ante la Fiscalía Militar, la víctima expresa que en las fotos que le muestran los funcionarios de la SIP "no reconocí a nadie ya que no les había visto la cara... el funcionario me dice que tiene dos hombres que se caracterizan por Robo con Intimidación, y me muestra a uno de ellos, señalándome además que éste tenía un tatuaje, le dije al funcionario que no le había visto el tatuaje pero éste insiste que ese era un delincuente que había salido hacía poco de la cárcel y que tenía un hermano con el que andaba siempre. Y deduje por lo que el Sargento me decía que ellos habían sido los que habían asaltado". Al finalizar indica que "en algún momento pensé que no fueran los jóvenes que me habían asaltado pero no se lo dije al Sargento Moya, me dejé llevar por los antecedentes que dicho funcionario me aportaba y ya al día siguiente al ver a estos jóvenes con la misma ropa asumí que habían sido ellos.

En relación a esta declaración, sin perjuicio de la relevancia de los antecedentes que da a conocer la víctima, no puede pasarse por alto su notoria contradicción con todas sus declaraciones previas, tanto las prestadas instantes después del robo ante la policía, como durante la investigación ante el Ministerio Público, y finalmente en el juicio oral ante los magistrados sentenciadores, ocasión en que manifestó que al ser abordada por sus agresores procede "a darse vuelta y notar el rostro de estos [esto lo reitera en el parte policial y en declaración policial según se lee a fs. 18 y 27 "a ambos les vi bien el rostro ya que me volteé cuando estaban sacando el dinero", y en su declaración en Fiscalía de fs. 42 "yo me di vuelta quedando de frente a ellos, pudiendo verles la cara a los dos

$3^{\circ}$ Que, por otra parte, el solicitante nada ha dicho del estado del proceso instruido ante la Fiscalía Militar, ni tampoco pide que éste sea traído a la vista, por lo cual se desconoce si la víctima ha prestado alguna otra declaración, o si se han efectuado otras diligencias y, principalmente, si se ha adoptado alguna resolución judicial sobre los hechos que aquí interesan, esto es, la supuesta inducción de los funcionarios policiales a la víctima en la diligencia de reconocimiento fotográfico o la alteración de su declaración policial. Esto último, sumado a que en el juicio oral, instancia donde la víctima se encontraba en libertad para declarar, pues no se ha insinuado que hubiese sido presionada o intimidada de alguna manera a faltar a la verdad en su deposición, además sometiéndose al contraexamen de la defensa así como a las preguntas de los jueces, dio un relato claro y contundente sobre la autoría de los sentenciados, tal como ya se ha expuesto, conjunto de elementos que impide desde ya considerar que los antecedentes en que se apoya la solicitud de revisión puedan bastar para establecer la inocencia de los condenados.

$4^{\circ}$ Que así las cosas, atendido que la Fiscalía Local de Angol archivó la investigación iniciada por el delito de obstrucción a la investigación en lo que dice relación a M.J.S, como se lee a fs. 77, y no existiendo certeza sobre el resultado de la investigación llevada por la justicia militar por el mismo ilícito pero en lo que respecta a la supuesta participación de funcionarios de carabineros, ni tampoco un conocimiento acabado de todas las actuaciones recabadas en virtud de dicha instrucción -de la cual sólo se acompaña copia simple-, la revisión impetrada no puede ser admitida a tramitación, pues los nuevos hechos y documentos, por ahora no resultan bastantes para establecer 
Polít. crim. Vol. 13, № 26 (Diciembre 2018) Art. 15, pp. 1190 - 1285.

[http://www.politicacriminal.cl/Vol_13/n_26/Vol13N26A15.pdf]

la inocencia de los condenados, lo cual importaría necesariamente, afirmar que las declaraciones prestadas por la víctima y los funcionarios policiales que depusieron en el juicio oral, se apartaron deliberadamente de la verdad, conclusión que, en este contexto actual, no resultaría posible alcanzar."132

Al igual que en el caso precedente el recurrente hace valer una evidencia cuyo valor probatorio parece ser muy importante, sin embargo, dado que la Corte auto-describe su labor disyuntivamente, se ve obligada a rechazar la acción, porque si bien la nueva evidencia es importante parecieran existir otras evidencias que apuntan en la dirección contraria. A diferencia del caso precedente, la víctima hace presente ciertas irregularidades en el proceso de identificación volviéndolo, como ella misma sugiere, inductivo. Desde este punto de vista, la nueva evidencia no sólo consiste en la retractación, sino que describe algunas de las posibles causas que la explican. Por último, la Corte indica que "por ahora" los elementos "no resultan bastantes" para acreditar la inocencia del condenado, implícitamente atribuyendo el deber de evidenciar "fehacientemente" la inocencia a la actividad probatoria del condenado. Ciertamente el condenado esta una posición muy vulnerable, pues encontrándose privado de libertad, no hay mucho que pueda investigar por cuenta propia, sin considerar además los recursos para investigar y las restricciones normales a que se ve sujeta una persona particular para encontrar evidencias. Como lo resaltáramos anteriormente, en este tipo de casos en que el condenado ha logrado, gracias a testigos y víctimas, hacer valer evidencia nueva en la acción de revisión y que contribuye de manera suficiente a demostrar su inocencia, el condenado persiste obligado a continuar su actividad probatoria hasta demostrarla fehacientemente. Naturalmente, si la Corte hubiera anulado la sentencia, no sería el condenado sino el órgano encargado especialmente destinado a dirigir la investigación, contando con amplias facultades investigativas y recursos, y su actividad no se iniciaría sin fundamento o por mero capricho, sino en base a una sentencia de la Corte Suprema que evaluando la nueva evidencia hecha valer, ha considerado que la sentencia debe ser anulada por haberse hecho valer prueba suficiente y que, por lo tanto, debe permitirse una nueva investigación.

\subsubsection{Estándar nuevo juicio}

En esta sección revisaremos otro de los aspectos controversiales de la propuesta interpretativa del CPP relativa al eventual nuevo juicio y que es clave para hacerla operativa. Como hemos podido ver, lo que elimina la posibilidad del nuevo juicio es la aplicación disyuntiva de acoger o rechazar, y esto, a su vez, se debe a una causa muy particular, y en la que el CPP claramente contribuye al actual estado de la situación. Lo que obliga a la Corte a entender su labor disyuntivamente cuando conoce de una acción de revisión, o dicho de otra manera, lo que imposibilita visualizar la alternativa de un nuevo juicio, es que, aparentemente, o la Corte considera que la nueva evidencia no acredita fehacientemente la inocencia del condenado o considera que sí. En el primer caso rechaza, y en el segundo acoge, y, aparentemente, no hay más alternativas. Entendido desde este punto de vista, el problema parece residir en la forma como la Corte valora la prueba, es decir, el estándar que gobierna la decisión de la Corte para acoger o rechazar.

\footnotetext{
${ }^{132}$ SCS, Rol 24210-2014.
} 
FERNÁNDEZ, José Manuel; OLAVARRÍA, Malva. "Examinando de nuevo la acción de revisión”.

Ciertamente, si fuera posible distinguir al menos 3 estándares distintos para la valoración de la prueba no aparecería inevitable la disyuntiva entre acoger y rechazar, porque entonces, dependiendo del valor probatorio de la nueva evidencia hecha valer, la Corte podría o rechazar, si la prueba es insuficiente, o acoger pero no dictar sentencia de reemplazo absolutoria cuando es suficiente, o acoger y dictar sentencia de reemplazo absolutoria cuando se acredita fehacientemente la inocencia del condenado. Sin embargo, la Corte, como hemos visto, interpreta erradamente; primero, los presupuestos para examinar la evidencia, es decir, si la evidencia es o no evidencia; segundo, si la evidencia es o no nueva; y tercero, no discrimina entre los casos en que debe rechazar/acoger y los casos en que debe permitir un nuevo juicio. Sobre la interpretación disyuntiva de su labor la Corte Suprema condiciona el acogimiento de la revisión a la satisfacción de un estándar extraordinariamente estricto, aplicación que aparece facilitada y reforzada por el discurso doctrinario tradicional que entiende la revisión como parte de un modelo inquisitivo exclusivamente enfocado en casos de manifiesta injusticia. Como consecuencia, todos los casos que no cumplen dicho estándar son rechazados, incluso aquellos en que se hace valer evidencia suficiente que apunta a acreditar la inocencia del condenado. Ahora bien, ya que parece relativamente identificado el problema, ¿existe alguna solución?

Como hemos propuesto e identificado previamente hay "casos intermedios" que deberían ser objeto, si la Corte Suprema lo permite, de la posibilidad de un nuevo juicio. Esto implica afirmar que se pueden identificar tres tipos de casos. Dos de ellos se encuentran, por así decirlo, en limites opuestos: aquellos en que la Corte Suprema debe rechazar (el extremo inferior), y aquellos que debe acoger y dictar sentencia de reemplazo absolutoria (el extremo superior). Esto sugiere que lo primero que se debe establecer es dichos extremos. Veamos primero los casos en que la Corte Suprema debe acoger porque aquí el CPP es relativamente claro. Podría pensarse que la letra d) del artículo 473 del CPP establece un estándar especial que le indica al juez cuando debe acoger, ya que dispone de prueba "que bastare" para establecer la inocencia del condenado, estándar que hemos denominado "prueba suficiente". Sin embargo, para arribar a esta conclusión se asume que, por ejemplo, en el caso de la letra b) "Cuando alguno estuviere sufriendo condena como autor, cómplice o encubridor del homicidio de una persona cuya existencia se comprobare después de la condena" la Corte necesariamente debe dictar sentencia absolutoria de reemplazo, pero esto es un error. Podría darse el caso en que el condenado no cometió homicidio, naturalmente si la víctima se encuentra con vida ciertamente el homicidio se vuelve imposible, pero ¿sucede lo mismo con calificar la conducta como homicidio frustrado? Dependiendo de la nueva evidencia hecha valer, ciertamente podría darse el caso en que la Corte deba dictar sentencia de reemplazo absolutoria, sin embargo la evidencia también podría demostrar solamente que la víctima se encuentra con vida, y no adicionalmente demostrar de manera fehaciente que el condenado no ha tenido ninguna participación culpable en un delito en contra de ella. Lo mismo sucede con las letras a), c) y e), incluso si uno de los testigos es condenado por falso testimonio (letra c) o si el juez es condenado por prevaricación o cohecho (letra e), dependiendo de la evidencia hecha valer, ello no necesariamente acredita fehacientemente la inocencia del condenado, pues puede existir prueba adicional que contribuya a probar lo contrario. Esto es correcto incluso en el supuesto de la letra a), porque del hecho que una persona $X$ haya sido condenado por un delito $\mathrm{A}$, y una persona $\mathrm{Z}$ haya sido condenado por el mismo delito $\mathrm{A}$, en circunstancias 
Polít. crim. Vol. 13, № 26 (Diciembre 2018) Art. 15, pp. 1190 - 1285.

[http://www.politicacriminal.cl/Vol_13/n_26/Vol13N26A15.pdf]

que sólo una persona pudo cometerlo, ello no significa que $\mathrm{X}$ y $\mathrm{Z}$ sean necesariamente ambos inocentes. Si esta interpretación es correcta entonces, ¿qué orientación le entrega el CPP a la Corte Suprema para evaluar la prueba y acoger? La solución se encuentra en el inciso 2 del artículo 478 del CPP: Si de los antecedentes resultare fehacientemente acreditada la inocencia del condenado, el tribunal además dictará, acto seguido y sin nueva vista pero separadamente, la sentencia de reemplazo que corresponda.

El CPP dispone entonces, aun respecto de la letra d) del artículo 473, y desde luego respecto de todas las otras causales, que la Corte Suprema puede acoger y dictar sentencia de reemplazo proscribiendo la realización de un nuevo juicio, sólo cuando la nueva evidencia hecha valer demuestre "fehacientemente" la inocencia del condenado, estándar de evaluación de la prueba que hemos denominado "prueba fehaciente". Debe enfatizarse esta conclusión, porque ésto indica expresamente el estándar con arreglo al cual la Corte Suprema debe evaluar para proceder de acuerdo al extremo superior, y porque dicho estándar que debe guiar a la Corte Suprema en su proceder está establecido legalmente. Ahora, desde el punto de vista del peso de la nueva evidencia hecha valer, ello significa, primeramente, que debe tratarse de evidencia específicamente destinada a acreditar la inocencia del condenado. Evidencia destinada a acreditar que el condenado debió recibir una pena menor de la que en derecho correspondía no hace procedente la revisión. En segundo lugar, esta evidencia debe ser tal que acredita la inocencia de manera fehaciente. Esto pareciera sugerir que la nueva evidencia no debe dejar lugar a dudas que el condenado es inocente. Es de notar que en estos casos la Corte Suprema efectivamente no valora sustantivamente la prueba, pues efectivamente, si se trata de evidencia que acredita de manera fehaciente ello permite concluir por sí misma que el condenado es inocente. Nótese así mismo que esto no es problemático en la medida que la Corte acoja aquellos casos en que dicha evidencia no es "fehaciente" sino "suficiente", porque entonces estos casos no serían rechazados de plano sino que podrían ser objeto de una nueva investigación y eventualmente un nuevo juicio. Es decir, los casos intermedios tendrían cabida en el sistema de revisión.

En cuanto al extremo inferior, corresponden a aquellos casos en que la Corte debe rechazar. Los requisitos formales están claramente previstos en el artículo 475 y artículo 476 del CPP, pero lo que nos interesa es el estándar con arreglo al cual la Corte puede rechazar la acción una vez declarada admisible. En esto el CPP no establece aparentemente ninguna norma o principio. Negativamente uno podría afirmar que cabe rechazar aquellas acciones que hacen valer nueva evidencia y que no logran acreditar fehacientemente la inocencia del condenado. Sin embargo, esto conduciría al mismo problema que se pretende evitar, porque si éste fuera el estándar, entonces no podrían discriminarse aquellos casos intermedios que estamos tratando de identificar. Efectivamente, si la nueva evidencia hecha valer no acredita fehacientemente la inocencia del condenado, entonces parece que no hay más alternativa que rechazar la acción. En consecuencia, se incluirían en aquellos casos que deben ser razonablemente rechazados, casos en que se hace valer nueva evidencia suficiente para acreditar la inocencia, con lo que estaríamos al igual que al comienzo de la sección, incapaces de dar espacio, con justicia, a aquellos casos intermedios que la requieren. Si bien, como solución, podría pensarse aplicable el estándar de duda razonable, es decir, aquella regla de distribución del riesgo de error a favor del acusado y que ha sido 
FERNÁNDEZ, José Manuel; OLAVARRÍA, Malva. "Examinando de nuevo la acción de revisión”.

institucionalizada por el legislador a propósito del juicio oral. En cambio, la respuesta debe ser negativa, en atención a las siguientes razones. El primer problema de hacer aplicable este estándar es que el CPP no lo adopta explícitamente. Por el contrario, la letra d) del artículo 473 del CPP dispone que la prueba "bastare" para establecer la inocencia del condenado, es decir, adopta otro estándar más estricto para evaluar la prueba, el de "evidencia suficiente". No parece plausible interpretar "evidencia suficiente" como aquella prueba que causa una "duda razonable", precisamente porque el legislador entiende que dichos estándares son diferentes.

El segundo problema, es que aun si se admitiera dicho estándar para la evaluación de la nueva evidencia, en revisión no se trata de evaluar, al menos directamente, la posible culpabilidad del condenado porque ésta está previamente establecida, sino el impacto que tiene en dicha sentencia no cualquier evidencia nueva, sino una evidencia nueva suficiente que apunta a establecer que el condenado es inocente. Es decir, el estándar de duda razonable se aplica a pruebas que apuntan a establecer la culpabilidad del condenado, y no a pruebas hechas valer en una instancia diferente del juicio oral y en que la evidencia esta destinada no a determinar la culpabilidad del acusado, sino la inocencia del condenado. El tercer problema está directamente conectado con el segundo, porque la evaluación de la prueba bajo el estándar de duda razonable supone que el juez ha examinado todas las pruebas relevantes bajo los principios de oralidad e inmediación ${ }^{133}$, principios que no son aplicables en sede de revisión. Es decir, los presupuestos epistémicos que hacen aplicable la duda razonable no están presentes cuando la Corte se pronuncia sobre la nueva evidencia, por lo que no parece justificado la adopción de dicho estándar si no concurren las condiciones que se esperaría que estuvieran presentes para hacerlo procedente. Posiblemente, las cosas serían diferentes de poder rendirse toda la prueba nuevamente ante la Corte Suprema, pero por diseño institucional, dicha Corte está primariamente avocada a resolver controversias de derecho, y no está diseñada para suplir al juicio oral.

En la investigación del año 2009 sostuvimos que hay un criterio para discriminar entre los casos que la Corte debe rechazar y aquellos en que debe permitir la realización de un nuevo juicio

“...lo que la Corte Suprema debe hacer para acoger la acción de revisión y permitir la procedencia del nuevo juicio... en el caso que las pruebas no acrediten fehacientemente la inocencia del condenado, es determinar si los medios de prueba hechos valer parecen ser suficientes para modificar la parte resolutiva de la sentencia condenatoria." 134 .

Aparece necesario ahora explicar este estándar con mayor profundidad. Debe notarse que en esta formulación hay dos aspectos que considerar. Uno es de carácter negativo y al que ya hemos aludido, es decir que la prueba no acredite de manera fehaciente la inocencia del condenado. El criterio negativo si bien permite discriminar los casos intermedios del extremo superior, porque la evidencia nueva no demuestra fehacientemente la inocencia del condenado, no permite por sí mismo discriminar los del extremo inferior. No obstante,

\footnotetext{
${ }^{133}$ HORVITZ / LÓPEZ, Derecho, $t$. II, cit. nota n ${ }^{\circ}$ 18, p. 233-240.

${ }^{134}$ FERNÁNDEZ y OLAVARRÍA, “Teoría y Práctica”, cit. nota nº 5, p. 244.
} 
Polít. crim. Vol. 13, № 26 (Diciembre 2018) Art. 15, pp. 1190 - 1285.

[http://www.politicacriminal.cl/Vol_13/n_26/Vol13N26A15.pdf]

afortunadamente tenemos cierta orientación del CPP en la letra d) del artículo 473 del CPP, el dispone que la prueba "bastare", es decir, que sea "suficiente" para establecer la inocencia del condenado. Este criterio cumple dos funciones, por un lado diferencia los casos intermedios de los casos en que la Corte Suprema debe rechazar, y por otro, de los casos en que la Corte debe acoger y dictar sentencia de reemplazo absolutoria. Si bien esta función doble del término "suficiencia" parece claro, todavía necesitamos más orientación para especificar su significado en el contexto de la revisión, lo que podemos conseguir considerando los aspectos mínimos que deberían ser reconocidos por la Corte como aspectos de relevancia al momento de acoger la acción. En otras palabras, lo que la Corte no puede ignorar en los casos intermedios puede ilustrarse con arreglo al artículo 375 del CPP, el que a propósito del recurso de nulidad, establece el impacto de aquellos aspectos mínimos que la Corte está obligada a considerar: Defectos no esenciales. No causan nulidad los errores de la sentencia recurrida que no influyeren en su parte dispositiva, sin perjuicio de lo cual la Corte podrá corregir los que advirtiere durante el conocimiento del recurso.

La idea que este precepto ilustra es el tipo de errores que no deberían dar lugar al recurso de nulidad, pero más en general, ilustra sobre aquellos errores que no tendría sentido corregir. En este sentido, este precepto describe aquello que sí debería considerarse como un error relevante: aquellos errores susceptibles de influir en la parte dispositiva de la sentencia. Es decir, el principio que se establece aquí, es que para hacer procedente el examen jurisdiccional por un tribunal de jerarquía superior el error debe haber podido influir sobre la decisión del tribunal, lo que en el contexto de la revisión, significa que la nueva evidencia debe haber podido influir en la decisión condenatoria. Efectivamente, si la nueva evidencia no es susceptible de provocar una decisión diferente, entonces la acción debe ser rechazada. Por el contrario, si la nueva evidencia tiene esa virtud, eso significa que el condenado, de haber hecho valer dicha evidencia con anterioridad, posiblemente habría sido declarado inocente. Esto es, finalmente tenemos la orientación que buscábamos para interpretar que es lo que debe entenderse por suficiencia: es aquella evidencia nueva que de haberse incorporado al juicio oral habría influido en la decisión condenatoria.

Aparece entonces que este estándar es diferente al de duda razonable, porque en éste lo que se evalúa necesariamente son los antecedentes que demuestran que a una persona le ha correspondido una participación culpable en un delito. En cambio, en el de prueba suficiente lo que se evalúa necesariamente es el impacto que la nueva evidencia exculpatoria debería haber tenido en la decisión condenatoria. Aparece así mismo, que esta opción legislativa es coherente con el sistema de la revisión, porque ésta tiene lugar con posterioridad a un juicio donde se ha acreditado más allá de duda razonable que al acusado le ha correspondido una participación culpable en un delito, y por lo mismo, la nueva evidencia hecha valer apunta a acreditar que si la prueba hubiera sido hecha valer con anterioridad, el condenado posiblemente habría sido declarado inocente. Es decir, la razón para la mayor exigencia probatoria tratándose de la acción de revisión, se explica en que ya se ha aplicado la regla de distribución de riesgo de error y que ya ha operado, sin éxito, a favor del condenado. Por ende, aparece razonable que el estándar de prueba que sujeta a los casos intermedios sea superior al del juicio oral. 
FERNÁNDEZ, José Manuel; OLAVARRÍA, Malva. "Examinando de nuevo la acción de revisión”.

Finalmente, examinemos un posible contra-argumento a la tesis defendida en esta sección sobre la posibilidad de nuevo juicio basada en la existencia de diferentes estándares de valoración de la prueba. El contra-argumento procede considerando que el estándar de prueba fehaciente no es aplicable al decidir los casos en que la Corte puede acoger la revisión, por lo tanto no existirían tres estándares diferentes, sino sólo dos, uno para acoger, y uno negativo para rechazar, y por lo tanto, no existiría la posibilidad de un nuevo juicio. El contra-argumento sostiene que el estándar de prueba fehaciente no se aplica a la decisión de acoger la acción de revisión, sino para efectos de determinar cuando procede y cuando no la indemnización por error judicial. Es decir, que sólo cuando se acredite fehacientemente la inocencia del condenado se podría obtener una indemnización, y cuando no es fehaciente, si bien procede dictar una sentencia de reemplazo absolutoria, no procedería la indemnización. Aunque a primera vista parece plausible, el argumento no es correcto. Hay tres razones que descartan el contra-argumento.

La primera razón, es que el estándar de prueba fehaciente esta explícitamente dispuesto en el inciso 2 del artículo 478 del CPP que trata sobre los casos en que es procedente el acogimiento de la acción y la dictación de la sentencia de reemplazo absolutoria. Lo relativo a la indemnización no está regulado en dicho inciso 2, sino en el inciso 3 del mismo artículo. Esta posición sistemática del estándar de prueba fehaciente sugiere que no está establecido para determinar si la indemnización procede o no, sino para que la Corte identifique los casos en que debe acoger y dictar sentencia absolutoria de reemplazo. Ciertamente, no debería sujetarse la procedencia de la indemnización al hecho de que la nueva evidencia es capaz de establecer de manera fehaciente la inocencia del condenado. En efecto, debe tenerse presente que esta indemnización es de carácter reparatorio, es decir, está destinada a reparar el daño causado a una persona a consecuencia de haber sido condenada injustamente. Para evaluar dicha indemnización debe atenderse al tipo de daño producido y no naturalmente, al tipo de evidencia hecha valer. A saber, es irrelevante si la evidencia es o no fehaciente para determinar el daño que debe ser objeto de reparación, y por lo tanto, un estándar de prueba diferente no puede justificarse si no tiene conexión alguna con lo que pretende distinguir.

La segunda razón es que parece evidente que el estándar de prueba fehaciente no es adoptado por el legislador sólo para efectos de la procedencia de la indemnización, porque ello obligaría a postular dos estándares diversos respecto de un mismo procedimiento de revisión; uno para determinar si está completamente acreditada la inocencia, y uno más exigente para la indemnización de perjuicios, lo que no parece razonable. Ciertamente, ¿porqué debe haber un estándar más exigente sólo para la obtención de una indemnización de perjuicios? Como ya hemos visto, la reparación no tiene ninguna conexión con el estándar que debe cumplir la evidencia que se hace valer, sino con el daño causado. La tercera razón, incluso aceptando que tal estándar es aplicable, si se ha demostrado la inocencia del condenado, como en un caso de suplantación de identidad, lo que no puede ser más fehaciente, ¿cuál sería el criterio en virtud del cual el estado podría negarse a la indemnización? Efectivamente, en los casos de suplantación de identidad aparece fehaciente la inocencia del condenado, pero ¿significa esto que siempre debe proceder la indemnización independientemente del daño causado al inocente? La evidencia nueva fehaciente no parece, a fin de cuentas, relevante para la procedencia de la indemnización. En suma, la mejor interpretación consiste en aceptar la posibilidad de un nuevo juicio, y en 
Polít. crim. Vol. 13, № 26 (Diciembre 2018) Art. 15, pp. 1190 - 1285.

[http://www.politicacriminal.cl/Vol_13/n_26/Vol13N26A15.pdf]

consecuencia, negar que el estándar de evidencia nueva fehaciente es aplicable a la decisión si procede o no la indemnización.

Por último, y como ya lo hemos mencionado, la propuesta interpretativa es completamente coherente con el sistema de valoración de la prueba actual, en el que la Corte Suprema es más que un mero aplicador mecánico de la ley, especialmente cuando debe considerar si hay casos intermedios para permitir la realización de un nuevo juicio. Esto es lo que constituye al nuevo modelo de revisión como un modelo adversarial, porque la Corte ya no examina solamente los casos de manifiesta injusticia, sino también, casos en que se hace valer evidencia nueva suficiente. En la inhabilidad para discriminar estos estándares para las tres alternativas que puede adoptar la Corte Suprema durante el procedimiento de revisión la doctrina ha cumplido un papel importante. En efecto, la comprensión disyuntiva entre acoger y rechazar se sostiene en el discurso de la doctrina que entiende la revisión como un mecanismo que vulnera la seguridad jurídica, y que en consecuencia "hacer justicia" sólo cabe en aquellos casos de manifiesta injusticia. A pesar que, la jurisdicción en el nuevo proceso penal no puede caracterizarse como un aplicador mecánico, como una mera boca de la ley, puesto que para hacer permisible un nuevo juicio la Corte debe examinar y ser sensible al caso concreto, específicamente, a la cuestión de si la nueva evidencia hecha valer es suficiente, es decir, si hubiera sido capaz de influir en la decisión condenatoria del juez.

El modelo adversarial de revisión tiene otras ventajas adicionales. Primero, la posibilidad del nuevo juicio evita que el mecanismo de revisión se traduzca en una "nueva instancia", porque al permitir un nuevo juicio la Corte Suprema no examinaría de manera concluyente el peso de la nueva evidencia. Ciertamente, corresponderá al juez, en el nuevo juicio, determinar si en consideración a la nueva evidencia hecha valer, se satisface el estándar de duda razonable. Segundo, admitiendo la posibilidad de un nuevo juicio fundada en evidencia nueva, existiría una nueva oportunidad para corrección de errores judiciales en perjuicio del condenado, lo que es especialmente importante considerando que los estudios empíricos revelan que las causas sobre condenas injustas se deben a errores de hecho, y a este respecto la Corte Suprema, por diseño institucional, no está en las mejores condiciones de revisar cuestiones de hecho de manera concluyente, sino los Juzgados de Garantía y Tribunales de Juicio Oral en lo Penal. Probablemente, esto debería contribuir a elevar la tasa injustificadamente baja que hoy tenemos en materia de reconocimiento de sentencias condenatorias erróneas. Tercero, debe considerarse que la consecuencia de identificar con mayor precisión las condenas erróneas es que abre la posibilidad de perseguir al verdadero culpable, lo que no es una consideración irrelevante. De acuerdo a James Acker, en Estados Unidos como consecuencia de las exoneraciones de los inocentes se ha podido identificar correctamente a los verdaderos culpables en más o menos la mitad de los casos, los que cometieron desde el momento del arresto del inocente 123 crímenes: 32 asesinatos y 68 violaciones ${ }^{135}$. Maximizar la precisión en la identificación de los posibles inocentes, que es lo que persigue el modelo adversarial de revisión, permitiría al Ministerio Público perseguir

${ }^{135}$ ACKER, James, "The Flipside Injustice of Wrongful Convictions: When the Guilty Go Free”, Albany Law Review, $\mathrm{n}^{\circ} 76$ (2013), pp. 1629-1712. 
FERNÁNDEZ, José Manuel; OLAVARRÍA, Malva. "Examinando de nuevo la acción de revisión”.

a los verdaderos culpables, y evitar, que ciertos delitos importantes para la comunidad queden sin sanción.

Estimamos necesario resumir la dinámica del mecanismo de revisión en el modelo adversarial de la siguiente manera cuando el recurrente hace valer evidencia nueva:

(i) La Corte Suprema debe rechazar la acción de revisión interpuesta si la nueva evidencia de haberse incluido en el juicio oral no parece suficiente para haber influido en la decisión condenatoria del juez.

(ii) La Corte Suprema debe acoger la acción de revisión si la nueva evidencia de haberse incluido en el juicio oral si parece suficiente para haber influido en la decisión condenatoria del juez, por lo que debe proceder a anular la sentencia, permitiendo la realización de un nuevo juicio.

(iii) La Corte Suprema debe acoger la acción de revisión si la nueva evidencia acredita de manera fehaciente la inocencia del condenado, por lo que debe proceder a anular la sentencia y dictar sentencia de reemplazo absolutoria.

\subsubsection{Casos que posiblemente debería haber requerido un nuevo juicio}

Hay varios casos en que el recurrente ha hecho valer medios de prueba que sí parecen suficientes para haber influido en la decisión condenatoria del juez. Ya hemos visto el caso del ADN, pero existen otros que identificamos en la nota al pie 137, lista a la que cabe agregar el siguiente:

"QUINTO:... 1.- Las afirmaciones de la Directora Técnica de la Comunidad Terapéutica Cape Diem... conducen a que P.A.L.P estuvo en su Centro en tratamiento por policonsumo de drogas particularmente entre el 24 de julio al 05 de agosto de 2005, con programa de modalidad "Residencial" que implica vivir en el Centro las 24 horas del día, sin permiso de salida o con salidas restringidas a casos por especiales y siempre acompañado de su apoderado. En el caso de ausencia sin autorización el Equipo de Trabajo lo visualizaría fácilmente, y termina sosteniendo que el usuario no salió del centro durante el régimen de residencia.

De lo anterior se desprende con meridiana claridad que esta persona, no obstante el énfasis que pone en afirmar que P.A.L.P. no salió del Centro durante sus periodos de permanencia en él, no pasa ello de ser una mera afirmación sin sustento en hechos concretos, serios y graves, fácilmente destruibles si se tiene en consideración que ella misma abre la posibilidad de que se produzcan ausencias no autorizadas, las que confía serían visualizadas fácilmente por un equipo, quedando en la duda si esa constatación lo sería al mismo momento de la fuga o con posterioridad.

Pero lo que es más grave aún, en el propio libelo de formalización del Ministerio Público a fs. 30 , párrafo $2^{\circ}$, se dice que "Sobre este punto hago presente la existencia de un documento escrito, extendido por el Director Técnico de la Comunidad Terapéutica Carpe Diem el 21 de agosto de 2005, en el que se indica que P.A.L.P. estuvo internado dos semanas en su institución y que hizo abandono sin previo aviso, sin embargo, dicho documento no expresa el periodo de internación cumplido por el 
Polit. crim. Vol. 13, № 26 (Diciembre 2018) Art. 15, pp. 1190 - 1285.

[http://www.politicacriminal.cl/Vol_13/n_26/Vol13N26A15.pdf]

sentenciado y el régimen a que estuvo sujeto". Con esto no puede dejar de observar el tribunal que se refuerza muchísimo más la debilidad de estos antecedentes, advirtiendo que esta denunciada fuga de que conoció la actora lo fue precisamente en el mismo mes y año de ocurrencia de los hechos de la sentencia condenatoria...

En definitiva, la prueba de la actora está muy distante de reunir los requisitos y estándares que la ley exige en la revisión, como se ha expresado con anterioridad, consiguientemente, en modo alguno es capaz de revertir las pruebas de cargo tenidas en cuenta y valor por la sentencia condenatoria para llegar a determinar la responsabilidad de autor que le reprocha al condenado, consistentes en expresos reconocimientos de las víctimas, corroboradas por dichos de funcionarios de Carabineros y de Gendarmería que participaron en reconocimientos en rueda de detenidos.

Por lo demás, el hecho en cuestión no podía ser ignorado por el propio encausado y la defensa que lo asistió en el desarrollo del proceso en que terminó condenado, y de la sentencia resulta que no se hizo alusión a él en ningún momento, limitándose a cuestionar los distintos hechos punibles y alegar modificatorias de responsabilidad...

SEXTO.- Que, en cuanto la solicitud de revisión se pretende argumentando que han aparecido documentos bastantes para establecer la inocencia del condenado.

Este capítulo de la acción también deberá ser rechazado y en razón del simple fundamento que sigue:

Se trata de los mismos documentos acompañados por la solicitante ya referidos latamente en las consideraciones previas, pero para los efectos de esta causal no cumplen la exigencia legal de que su origen debe remontarse al período de duración del proceso y haber sido desconocidos en esa etapa. Como se ha evidenciado antes, y así también lo ha reconocido implícitamente la solicitante, han sido emitidos todos con posterioridad al 4 de marzo de $2008 . . . " 136$

Esta sentencia tiene varios aspectos interesantes. Primero, de todos los casos en que el Ministerio Público solicitó se acogiera la acción de revisión este es el único en que la Corte Suprema decidió no acogerlo, acción que adicionalmente fue sostenida por la Defensoría Penal Pública. Segundo, la Corte continúa siguiendo el mismo patrón de adscribir al condenado el deber de incorporar la evidencia que le favorece rechazando la acción si éste "debía haber" conocido la evidencia. Tercero, la Corte también continúa siguiendo el mismo patrón de considerar que la nueva evidencia "forjada" con posterioridad a la sentencia no es admisible en la acción de revisión. Cuarto, y en lo que interesa al tipo de

\footnotetext{
${ }^{136}$ SCS Rol 9062-2010. Otros casos podemos calificar como casos intermedios son los siguientes; caso SCS Rol 22945-2014 y caso SCS Rol 5011-2014 sobre evidencia nueva consistente en deficiencia y enfermedad mental; caso SCS Rol 6678-14 sobre evidencia nueva de un testigo que se retracta; casos SCS Rol 3623-2011 y SCS Rol 14778-2015 sobre evidencia nueva consistente en nuevos peritajes, dentro de los cuales el SCS Rol 28364-2016 sobre ADN sobresale del resto; el caso SCS, Rol 3337-2011 en que el condenado hace valer evidencia que contribuye a acreditar que sí tiene la calidad profesional de médico; caso SCS Rol 24210-2014 y caso SCS Rol 10847-2014, ambos examinado más arriba, sobre la existencia de nueva evidencia de la víctima que se retracta. Nótese que aquí ni si quiera consideramos otros casos importantes, como todos aquellos en que la Corte Suprema considera que el hecho no es nuevo, o que debía ser conocido por el condenado, o que fue forjado con posterioridad.
} 
FERNÁNDEZ, José Manuel; OLAVARRÍA, Malva. "Examinando de nuevo la acción de revisión”.

evidencias hechas valer, aparece manifiesto que para la Corte Suprema el estándar para acoger la acción es uno solo: que se acredite de manera fehaciente la inocencia del condenado, y si no se acredita, el recurso debe ser rechazado. Como hemos visto, esta forma de entender la acción de revisión no describe correctamente el modelo establecido por el legislador en el CPP, relegando invariablemente los casos intermedios a la clase de acciones rechazadas, con lo cual, sucintamente, no aparece comprometida con los principios que se supone informan el mecanismo de revisión: la justicia y la verdad. Ciertamente, en este caso el condenado hace valer evidencia nueva que es suficiente, porque si se hubiera hecho valer en el juicio oral ello habría influido en la decisión condenatoria del juez. Sin embargo, la Corte no considera la posibilidad de un nuevo juicio y basado en una interpretación incorrecta del CPP, el que por el contrario no se centra en el conocimiento del condenado sino en los medios de prueba que el juez utiliza para justificar la sentencia, y el que admite expresamente medios de prueba elaborados con posterioridad, no le concede un espacio institucional al reclamo, ciertamente fundado, que el condenado ha hecho valer. Si a este caso se suman todos los otros casos en que la Corte discrecionalmente interpreta lo que es una evidencia nueva, que fue conocida por el condenado, y que fue forjada con posterioridad, aparece con claridad que no parece plausible que en Chile sólo se produzcan un $0.79 \%$ de condenas erróneas. Esta cifra se produce ciertamente porque la Corte Suprema niega la admisión de los casos intermedios al modelo adversarial de revisión, adoptando, injustificadamente, el ya fenecido modelo inquisitivo. Como consecuencia, muchos verdaderamente culpables seguramente continúan en libertad.

\subsection{Normativamente inocente}

En la sección 2.2. consideramos el término "inocencia" en sentido amplio, cubriendo todas aquellas circunstancias que vuelven la sentencia condenatoria inválida por diferentes tipos de razones, y por lo mismo incluye a los normativa y fácticamente inocentes. En esta sección examinaremos un caso muy particular acogido por la Corte Suprema y en que se adopta el sentido amplio de inocencia. Si bien el terreno no parece quedar zanjado, dicha sentencia podría impactar en la manera de entender los supuestos que eventualmente pueden hacer procedente la acción de revisión, sobre la base de una comprensión amplia de la inocencia. El caso que examinaremos es muy particular, porque se trata de un caso del antiguo CPP en base al cual el estado de Chile fue condenado por la Corte Interamericana de Derechos Humanos (CIDH), por infringir el derecho al recurso tratándose de un caso de evidencia obtenida bajo tortura. Si bien la sentencia toma como referencia el antiguo CPP, es sin embargo relevante en el contexto del nuevo CPP porque adopta un concepto amplio de inocencia capaz de guiar futuras interpretaciones en materia de revisión. Ahora bien, en la sentencia de la CIDH se estableció lo siguiente:

1. El Estado es responsable por la violación del derecho a las garantías judiciales, reconocido en el artículo 8.1 de la Convención Americana sobre Derechos Humanos, en relación con el artículo 1.1 de la misma y con las obligaciones establecidas en los artículos 1, 6 y 8 de la Convención Interamericana para Prevenir y Sancionar la Tortura, en perjuicio de Ivan Rojas Ravanal, Alberto Salustio Bustamante Rojas, Álvaro Yáñez del Villar, y Omar Humberto Maldonado Vargas, por la excesiva 
Polit. crim. Vol. 13, № 26 (Diciembre 2018) Art. 15, pp. 1190 - 1285.

[http://www.politicacriminal.cl/Vol_13/n_26/Vol13N26A15.pdf]

demora en iniciar una investigación, en los términos de los párrafos 76 a 80 de la presente Sentencia.

2. El Estado es responsable por la violación del derecho a la protección judicial, reconocido en el artículo 25.1 de la Convención Americana sobre Derechos Humanos y al deber de adoptar disposiciones de derecho interno contenido en el artículo 2 de la Convención, en relación con la obligación de respeto y garantía contenida en el artículo 1.1 de la misma, en perjuicio de Omar Humberto Maldonado Vargas, Álvaro Yáñez del Villar, Mario Antonio Cornejo Barahona, Belarmino Constanzo Merino, Manuel Osvaldo López Oyanedel, Ernesto Augusto Galaz Guzmán, Mario González Rifo, Jaime Donoso Parra, Alberto Salustio Bustamante Rojas, Gustavo Raúl Lastra Saavedra, Víctor Hugo Adriazola Meza, e Ivan Rojas Ravanal, por la ausencia de recursos para revisar las sentencias de condena en su contra, en los términos de los párrafos 118 a 142 de la presente Sentencia.

Las sentencias que la CIDH consideró para la condena de Chile fueron dos sentencias de la Corte Suprema de los años 2001 y 2002 que rechazaron la revisión de las sentencias condenatorias impuestas, y tangencialmente otra acción de revisión presentada el 2011. Veamos esta última porque condensa de alguna manera todos los problemas y errores que hemos detectado en esta investigación, y la que dispuso lo siguiente:

" $2^{\circ}$.- Que sin embargo, los supuestos fácticos que sirven de fundamento a la pretensión, no se compadecen con las exigencias de la causal alegada, toda vez que ella se hace consistir en la existencia del proceso Rol 1-73, caratulado "Aviación contra Bachelet y otros", en el cuál se habrían dictado sentencias condenatorias en contra de los aquí recurrentes de revisión, agregando que: "Han aparecido con posterioridad hechos y antecedentes nuevos, posteriores a la sentencia de terminó, que bastan para acreditar la inocencia de los condenados", por carecer las pruebas utilizadas de todo valor jurídico, las que fueron obtenidas en un procedimiento viciado que no pudieron servir de fundamento para dicho veredicto, limitándose el recurrente a criticar la valoración probatoria.

No se trata entonces, de la ocurrencia o el descubrimiento de un nuevo hecho o la aparición de algún documento, de modo que este recurso no puede ser admitido a tramitación.",137

En términos generales parece correcto indicar que la causa de la condena de la CIDH al estado de Chile reside en la forma como la Corte falla habitualmente la acción de revisión. Más precisamente, que la condena por la infracción al derecho al recurso, que es la parte atingente de la sentencia para la presente investigación, es la incorrecta aplicación por parte de la Corte Suprema de las normas sobre requisitos para interponer la acción de revisión. La Corte rechaza la acción presentada el año 2011 considerando que la evidencia hecha valer no consistía en una nueva evidencia. Luego de la condena del estado chileno, se presentó una nueva acción de revisión el año 2016 y que si fue acogida, el caso rol 275432016. La condena de Chile consiste en parte en un serio reproche moral y jurídico a la

\footnotetext{
${ }^{137}$ SCS, Rol 11338-2011.
} 
FERNÁNDEZ, José Manuel; OLAVARRÍA, Malva. "Examinando de nuevo la acción de revisión”.

forma de operar de la Corte Suprema, porque la Corte pudo acoger la revisión en el año 2016 sin que fuera necesario que el estado chileno modificara alguna norma legislativa. Esto debe resaltarse; para cumplir con la sentencia de la CIDH no fue necesario modificar el ordenamiento jurídico. Y no fue necesario porque tal y como está regulada por el CPP, esta acción es lo suficientemente sensible y flexible como para incorporar al sistema de revisión el caso por el que Chile fue condenado. Expliquemos un poco más la aseveración de que se trata de un reproche "moral".

La condena de la CIDH se dirige al estado de Chile y no a la Corte Suprema, aún cuando sea correcto afirmar que los actos de la Corte Suprema representan al Estado de Chile no todos los actos del estado de Chile representan a la Corte Suprema. En consecuencia, no parece correcto afirmar que los actos por los que el estado es responsable deba responder la Corte Suprema, y por lo tanto, si se condena al estado de Chile por infracciones a tratados internacionales en materia de derechos humanos, ello no significa necesariamente que la Corte Suprema debe acoger la acción de revisión interpuesta el 2016 si el ordenamiento jurídico no lo permite. Sin embargo, la acción fue acogida. En parte, es a ello a lo que nos referimos por "reproche moral", porque en rigor si es el ordenamiento jurídico el que ha fallado, entonces dicho ordenamiento debería ser modificado para dar respuesta a reclamaciones que deben ser escuchadas y resueltas. Pero si no fue necesario modificarlo, fue porque la Corte fue objeto de un serio reproche moral, y el que se explica por la deficiente interpretación que hace del modelo de revisión. Si bien parece admisible que la Corte Suprema tempere y corrija su interpretación de la acción de revisión, aceptando el reproche moral, ante hechos graves que son parte de la historia más oscura y criminal de Chile, no parece admisible entender que lo que ha hecho la Corte Suprema al acoger la acción del 2016 es modificar de facto el ordenamiento jurídico para adecuarlo a la condena de la CIDH. Procederemos entonces sobre la base que la acción de revisión debió ser acogida porque podía ser acogida cuando fue presentada. En atención a que no todos los aspectos de la sentencia son relevantes para la presente investigación, sólo examinaremos algunas de sus secciones.

Lo primero que debe resaltarse es que en el fallo de 2016 es la misma Corte Suprema la que cita la sentencia de la CIDH y que cuestiona la justificación que la Corte tuvo para rechazar la acción del año 2011:

"DECIMO:... En lo que concierne al período posterior al año 2005, la CIDH nota que en el año 2011, personas distintas a los denunciantes y que también habían sido juzgadas y condenadas por Consejos de Guerra en la causa $\mathrm{Rol} \mathrm{N}^{\circ} 1-73$, presentaron un recurso de revisión que igualmente fue rechazado por la Corte Suprema por no haberse verificado una ocurrencia, descubrimiento nuevo o aparición de un documento, de conformidad con los requisitos establecidos por el artículo 657 del Código de Procedimiento Penal. La CIDH advierte que la situación de los denunciantes presenta notorias similitudes con la de las personas que presentaron el recurso en el año 2011. En particular, se pudo verificar que todas fueron sentenciadas en el marco del mismo proceso por parte de los Consejos de Guerra en la causa Rol $N^{\circ} 1-73$, que todas figuran en el mismo listado de víctimas de tortura en el informe de la Comisión Valech y que algunas fueron reconocidas como víctimas en el marco del mismo proceso penal (causa Rol $\mathrm{N}^{\circ}$ 1058-2001), que fue uno de los fundamentos principales en la solicitud de revisión del año $2011 \ldots$ 
Polit. crim. Vol. 13, № 26 (Diciembre 2018) Art. 15, pp. 1190 - 1285.

[http://www.politicacriminal.cl/Vol_13/n_26/Vol13N26A15.pdf]

En ese mismo sentido, no es claro para la CIDH: a) si la prueba presentada por los accionantes del recurso de revisión de 2011 para acreditar los hechos de tortura padecidos por los condenados en el marco de la causa Rol $N^{\circ} 1-73$ era insuficiente. De ser esa la situación, ni el Estado, ni la Suprema Corte presentaron información explicando qué tipo de pruebas sobre hechos nuevos en el marco de un proceso penal, en este caso hechos de tortura, además de aquellas presentadas por los recurrentes en el escrito de 2011 y consistente inter alia en sentencias judiciales y en el informe de la Comisión Valech, es suficiente para que la Corte Suprema admita el recurso de revisión, o b) si el entendimiento de la Corte Suprema es que los hechos de tortura por su naturaleza no entran dentro de las causales de revisión previstas en el artículo 657 Código de Procedimiento Penal, en cuyo caso ese no sería el recurso adecuado y efectivo para llevar a cabo tal revisión."

Ciertamente, la CIDH acierta cuestionando el rechazo por parte de la Corte y que no fundamentó, como es habitual, la conclusión que la prueba era insuficiente. Del texto del fallo del año 2011 se desprende que la Corte ni siquiera alcanzó a determinar el peso probatorio de los antecedentes hechos valer, escudándose en que no había evidencia nueva, lo que sin embargo, tampoco justificó. En otra sección de la sentencia la Corte caracteriza la acción de revisión, curiosamente, siguiendo la descripción que propusimos de ella en nuestra investigación del año 2009, como una acción de carácter estricto, y que se aplica a casos de manifiesta injusticia ${ }^{138}$ :

"DECIMO TERCERO:... Primero, porque la acción de revisión en el sistema procesal penal sólo reconoce algunos casos de injusticia como causales que permiten anular una sentencia condenatoria firme, se trata, en consecuencia, de una acción de carácter estricto. Este carácter se expresa en la enumeración taxativa de las causales que establece el artículo 657 del Código de Procedimiento Penal, el que señala una serie cerrada de supuestos en los cuales procede la revisión de las sentencias firmes, sin que pueda aplicarse a otros casos.

Segundo, porque debe tratarse de casos de manifiesta injusticia. En Chile la acción de revisión debe explicarse en referencia a la evitación de un cierto tipo de resultados injustos, a saber, aquellas situaciones en que una persona es condenada por un delito en el cual no le cabe responsabilidad penal."

Sin embargo, la Corte elige no continuar la caracterización que propusimos y, que en este trabajo hemos desarrollado con más detalle, como una acción sensitiva a los casos de injusticia no fehacientes y que se hace efectiva a través de permitir la realización de un nuevo juicio. Posiblemente la Corte no adoptó dicha caracterización porque para la Corte la revisión debe ser caracterizada dentro de un modelo inquisitivo, el que precisamente se aplica exclusivamente a casos de manifiesta injusticia. Efectivamente, como se ha evidenciado a lo largo de esta investigación, la Corte todavía se inclina en caracterizar la acción de revisión bajo el modelo inquisitivo. En particular, la Corte continúa considerando que la revisión puede utilizarse de manera fraudulenta, y que el legislador, previendo dicha posibilidad, dispuso lo siguiente:

\footnotetext{
${ }^{138}$ FERNÁNDEZ y OLAVARRÍA, “Teoría y Práctica”, cit. nota no 5, p. 219.
} 
FERNÁNDEZ, José Manuel; OLAVARRÍA, Malva. "Examinando de nuevo la acción de revisión”.

"TRIGESIMO:... no debe olvidarse que cuando la causal 4ta del artículo 657 del Código de Procedimiento Penal exige que el hecho invocado haya ocurrido o sido descubierto "con posterioridad al fallo", busca con ello el legislador evitar que el imputado o su defensa, reserven elementos de prueba exculpatorios que pudiendo invocar en el juicio para, de esa manera, hacerse de mala fe, de un medio para invalidarlo posteriormente en caso de obtener un pronunciamiento desfavorable. En último término se busca evitar el uso de la acción de revisión de forma fraudulenta. Pues bien, malamente podría postularse que en el caso de los acusados ante el Consejo de Guerra $\mathrm{N}^{\circ} 1-73$, voluntariamente omitieron alegar ante dicho Consejo la ilicitud de sus confesiones y declaraciones incriminatorias de los otros encartados, sino que tal omisión obedece al quebrantamiento claro del principio al debido proceso cometido durante dicho procedimiento, pues en tales circunstancias, no cabía sino esperar que esa protesta o alegación por parte de los detenidos hubiera resultado, no sólo inútil, sino además los hubiera puesto en riesgo de un atentado o represalia mayor."

Ciertamente aquí la Corte desarrolla de manera explícita sus preocupaciones respecto del uso de la acción de revisión de manera fraudulenta, lo que como hemos visto, no tiene fundamento empírico ni racionalidad alguna. Otro aspecto importante que cabe resaltar, y que es muy preocupante se desprende del siguiente considerando:

"DECIMO SEXTO:... que el fallo en análisis debe ser examinado a la luz de la causal de revisión invocada del artículo $657 \mathrm{~N}^{\circ} 4$ del Código de Procedimiento Penal, desde dos ópticas, primero, su dictación en sí constituye la ocurrencia de un hecho posterior a las sentencias cuestionadas que impulsa a su revisión y, segundo, es un elemento que sirve para acreditar los hechos ocurridos durante la sustanciación de esos procesos -las torturas aplicadas para obtener sus confesiones y declaraciones-, y que se descubren con posterioridad a ellos, que son de tal naturaleza que bastan para establecer la inocencia de los condenados."

Es altamente problemático que la Corte considere que el hecho nuevo es la sentencia de la $\mathrm{CIDH}$, por que la sentencia no es propiamente un "hecho nuevo" que se "descubre con posterioridad". En efecto, los hechos relevantes son los hechos de tortura, y la evidencia que las confirma son los informes de la Comisión Valech y la Comisión Rettig, es decir, no la sentencia de la CIDH. También continúa siendo problemático que la Corte considere la exigencia de conocimiento desde la perspectiva del condenado, y no enfatice lo que sí es central, que la evidencia no haya sido considerada por la sentencia, tal como ocurrió en este caso, lo que ciertamente es independiente de que el procedimiento estuviera completamente viciado por la realización de torturas:

"TRIGESIMO: Que la causal 4ta del articulo 657 del Código de Procedimiento Penal distingue varias situaciones desde un punto de vista temporal, pero bajo el supuesto de que hayan acaecidos con posterioridad a la sentencia condenatoria materia de la pretensión de revisión. Es exigencia legal de esta causal el que estas situaciones anulatorias deben reunir como requisito esencial el desconocimiento absoluto de su acaecimiento durante el curso del proceso impugnado, puesto que ocurrirán, se descubrirán o aparecerán inevitablemente luego de ejecutoriado el fallo de condena. Como segunda exigencia de la norma aludida, es que de la gravedad y fuerza de estos sucesos posteriores, se derive inequívocamente la inocencia del condenado. 
Polít. crim. Vol. 13, № 26 (Diciembre 2018) Art. 15, pp. 1190 - 1285.

[http://www.politicacriminal.cl/Vol_13/n_26/Vol13N26A15.pdf]

\begin{abstract}
Ahora bien, las torturas sufridas por los acusados ante el Consejo de Guerra Rol $\mathrm{N}^{\circ} 1$ 73 se avienen a la hipótesis mencionada, desde que, como ha quedado señalado en los motivos anteriores, se ha tratado de hechos producidos durante el proceso reclamado pero descubiertos con posterioridad a la sentencia. En efecto, dada la naturaleza del hecho nuevo invocado en el caso sub judice, la existencia del mismo, desde luego conocida por los acusados y probablemente también por sus defensas, las torturas no pudieron alegarse ante el mismo Consejo de Guerra y sólo se develaron con mucha posterioridad al mismo. Cabe reiterar que el Informe Rettig afirmó que los Tribunales Militares que actuaron en dicha calidad para sancionar hechos perpetrados con anterioridad al 11 de septiembre de 1973, lo hicieron contrariando la legislación vigente y quebrantando fundamentales normas de derecho (Informe Rettig, T. I, p. 83), además, según reconoció el Fiscal del Consejo de Guerra Rol N ${ }^{\circ} 1-73$, Orlando Gutiérrez Bravo, en sus declaraciones judiciales ya aludidas arriba, el interrogatorio de los procesados era efectuado ante algunos de los oficiales que trabajaban con él, quienes contaban con toda su confianza, y que sabia de algunos de los apremios realizados a los detenidos -principalmente, "sistema de la gotita"-, de manera que, considerando que ese Fiscal debía participar de la audiencia ante el Consejo de Guerra, incluso de haberse alegado en el juicio la existencia de los tormentos y apremios, por el contexto de restricciones y vulneraciones en que se hallaban los acusados, y las exacerbadas limitaciones a su defensa, que ya se mencionaron, las posibilidades de probar dichas torturas, tormentos y apremios ante el mismo Consejo de Guerra o ante el Comandante que aprobó su sentencia, para que éstos no consideraran esas confesiones e imputaciones, resultaban irreales."
\end{abstract}

Esta interpretación de la Corte Suprema es indudablemente problemática. Nuevamente la Corte considera "...que estas situaciones anulatorias deben reunir como requisito esencial el desconocimiento absoluto de su acaecimiento durante el curso del proceso impugnado..." pero esto no es verdadero del proceso que la Corte está examinando. En efecto, todos los injustamente condenados sabían perfectamente que habían sido torturados por lo que ya aparece con claridad que no se cumple la condición que el condenado desconozca la evidencia que hace valer en revisión. Cierto, la Corte afirma que no era razonable que se hubiera incorporado las torturas como prueba, pero entonces no puede ser, como la Corte afirma, "absoluto" el "desconocimiento" durante el proceso penal, y ciertamente no lo es porque lo relevante, como hemos demostrado, no es que el condenado o el tribunal hayan conocido la evidencia, sino que la evidencia haya o no sido utilizada por el tribunal al fundamentar la sentencia. En cualquier caso, el tema fundamental aquí es el de inocencia en sentido normativo, porque podría pensarse en un caso hipotético en el que se trató de incorporar la evidencia de torturas experimentadas durante el proceso penal. La Corte podría aducir que no se trata de evidencia nueva, pues en conformidad al paradigma subjetivo de valoración de la prueba que la Corte sostiene, no es necesario que los medios de prueba respectivos sean utilizados en la sentencia, porque basta el mero conocimiento subjetivo del juez o del condenado sobre los hechos, por ende, incluso si la evidencia de tortura no se rindió, aún podría la Corte afirmar que el juez y el condenado "conocieron" los medios de prueba.

Fuera de estos aspectos que cabe criticar hay otros que la Corte desarrolla correctamente. En efecto, afirma que no es necesario que se establezca por sentencia judicial que ciertos 
FERNÁNDEZ, José Manuel; OLAVARRÍA, Malva. "Examinando de nuevo la acción de revisión”.

testimonios son falsos "...pudiendo adquirirse convicción de ello por esta Corte por cualquier medio de prueba admisible legalmente con dicho fin.". Si bien esto es correcto, y ciertamente es una postura que la Corte ha tomado en algunos casos, debe recalcarse que este es un caso especial en que los testimonios han sido obtenidos mediante tortura:

"DECIMO QUINTO: Que en sus alegatos el apoderado de algunos de los condenados en el proceso Rol $\mathrm{N}^{\circ} 1-73$ sostuvo que éstos no sólo sufrieron torturas, tormentos o apremios por parte de sus agresores con el objeto de que reconocieran los hechos que se les imputaban, sino además para que incriminaran a los demás acusados...

Por otra parte, y esto resulta capital, para los efectos que interesan en esta revisión, no parece siquiera pertinente demandar que previamente una sentencia establezca que las declaraciones prestadas por los acusados en la parte en que inculpan a otros coacusados, son falsas, pues la imposibilidad de que ellas sirvan de fundamento a las condenas de los otros no derivaría estrictamente de su falsedad, sino de que la forma en que fueron obtenidas [40] dichas confesiones se encuentra proscrita en nuestro ordenamiento. En otras palabras, dado que en esta revisión resulta del todo intrascendente si alguna parte de lo expuesto en las declaraciones prestadas por los acusados del Consejo de Guerra Rol $\mathrm{N}^{\circ} 1-73$ bajo tortura, tormento o apremio, no es mendaz -con esto, cabe poner el acento, esta Corte ni siquiera insinúa que ello así sea-, no puede entonces exigirse que en forma previa a la revisión de las sentencias se demande que una sentencia criminal haya declarado la falsedad del contenido de esos atestados."

El aspecto central que queremos enfatizar de la sentencia de la Corte es el alcance del debido proceso y las consecuencias que ello tiene para la comprensión de la inocencia y la acción de revisión, argumentos que la Corte Suprema desarrolla principalmente en el considerando $10^{\circ}$ y $30^{\circ}$ de su sentencia. En otras palabras, lo central y novedoso de la argumentación de la Corte es que considera que la nueva evidencia hecha valer proporciona información sobre un proceso penal que no debe ser caracterizado como debido, porque lo que dicha evidencia revela es precisamente un proceso penal en que se condenó a los acusados en violación del debido proceso. La nueva evidencia demuestra que existió un procedimiento ilegal sin las garantías del debido proceso, en suma, una ejecución o asesinato. La Corte considera esto en relación a los intervalos temporales en que puede descubrirse u ocurrir la nueva evidencia, y que por lo tanto hacen procedente la acción de revisión:

“...malamente podría postularse que en el caso de los acusados ante el Consejo de Guerra $N^{\circ} 1-73$, voluntariamente omitieron alegar ante dicho Consejo la ilicitud de sus confesiones y declaraciones incriminatorias de los otros encartados, sino que tal omisión obedece al quebrantamiento claro del principio al debido proceso cometido durante dicho procedimiento, pues en tales circunstancias, no cabía sino esperar que esa protesta o alegación por parte de los detenidos hubiera resultado, no sólo inútil, sino además los hubiera puesto en riesgo de un atentado o represalia mayor."

Entre las razones que justifican el acogimiento de la acción de revisión, entonces, se encuentra como principio fundamental el debido proceso, de tal manera que sin debido proceso no puede existir propiamente una sentencia condenatoria. Esto permite, desde luego, dar una lectura del término "inocente" no reducible al sentido fáctico, y resaltar que 
Polít. crim. Vol. 13, № 26 (Diciembre 2018) Art. 15, pp. 1190 - 1285.

[http://www.politicacriminal.cl/Vol_13/n_26/Vol13N26A15.pdf]

este es un claro e importante ejemplo del normativamente inocente.Evidentemente, la gravedad de los acontecimientos que demuestra la causa, los eventos de tortura y sufrimiento humano, permiten concluir que en ciertos casos es más relevante que el descubrimiento de la verdad el respeto y las garantías de un justo proceso penal. No puede considerarse jurídicamente válido un proceso penal claramente carente de legitimidad moral y política como el precedente, pero si esto es correcto, ello quiere decir que algunas de las mismas consideraciones se aplican a procesos penales efectuados en un estado de derecho, porque dichos derechos deben ser respetados independientemente de cómo se caracterice al estado en cuestión. Es decir, que cabe considerar que en aquellos casos en que se han infringido seriamente las garantías individuales, y la nueva evidencia hecha valer así lo acredita al menos suficientemente, también deberían ser acogidos en sede de revisión. Lo que implica, naturalmente, sostener un concepto amplio de inocente.

\subsection{Las otras causales del artículo 473 del CPP}

Del examen de las 550 sentencias dictadas en los últimos 10 años, no se ha podido identificar ningún caso acogido en virtud de la causal letra a), letra b), letra c), o letra e) del artículo 473 del CPP. Ya hemos mencionado y examinado con anterioridad los casos en que testigos y víctimas se retractan, y el caso del normativamente inocente en la sección 3.4., indicando, como lo ha hecho algunas veces la Corte Suprema, que ésta considera innecesario que se condene por falso testimonio como condición para acoger la acción de revisión. Sin perjuicio de lo anterior, existen algunas sentencias, correctamente fundamentadas, que se pronuncian respecto de la letra a) "Cuando, en virtud de sentencias contradictorias, estuvieren sufriendo condena dos o más personas por un mismo delito que no hubiere podido ser cometido más que por una sola", y que revelan ciertos aspectos interesantes sobre dicha causal. Una primera duda interpretativa reside en qué debe entenderse por "sentencias contradictorias". Aparentemente, esto se aclara una vez que se considera el resto del texto de la causal, es decir, que en virtud de dos sentencias estén condenadas diferentes personas por un mismo delito que no haya podido ser cometido más que por una sola. Aunque, con ello no se logran eliminar todas las incertidumbres, ¿cómo es posible que un delito pueda ser cometido solamente por una persona? Una primera alternativa podría ser considerar sólo aquellos delitos que pueden ser cometidos "de propia mano", es decir, que sólo respecto de los delitos de propia mano podría establecerse que ciertas personas han sido condenadas erróneamente, porque dicho delito sólo podría ser cometido por una sola persona.

Piénsese por ejemplo en el delito de violación, aparentemente si $X$ ha sido condenado como autor de violación contra la víctima $\mathrm{Z}$, y luego en otra sentencia $\mathrm{Y}$ es condenado por el mismo delito respecto de la misma víctima Z, entonces la causal parece concurrir. Sólo X o sólo Y debería haber sido condenado. Sin embargo, el delito de violación también puede cometerse de forma múltiple, y ciertamente la violación puede cometerse por autoría mediata. Esto sugiere que los casos en que concurre la causal no son fáciles de identificar, por que el delito de violación puede ser cometido por más de una persona, y entonces, aparentemente la causal no debería concurrir. Quizás sólo algunos tipos de delitos pueden ser cometidos "más que por una sola" persona, es decir, sólo una sub-clase de delitos de propia mano, como cuando el autor es definido por ciertas cualidades específicas, como el delito de parricidio. Sin perjuicio que la causa de la muerte de una persona pueda ser 
FERNÁNDEZ, José Manuel; OLAVARRÍA, Malva. "Examinando de nuevo la acción de revisión”.

explicada por la concurrencia de varias acciones y omisiones de varias personas, sólo aquellos en que concurre la calidad puede ser parricida. Pero nuevamente, es posible que existan varios descendientes, y entonces varias personas pueden ser parricidas, y más importante aún, incluso aceptando que sólo una persona pueda ser autor, ello no excluye la existencia de otras formas de autoría, como inducción, y tampoco se excluye la complicidad $^{139}$. Por último, quizás esta causal se aplica a un grupo aún más reducido de delitos, aquellos delitos en que el injusto es definido como la infracción de un deber al que sólo un círculo reducido de personas está sujeto ${ }^{140}$. Sin embargo, parece poco plausible que la causal tenga por objeto aplicarse a este grupo tan reducido de casos, por lo demás, incluso aún en estos casos quedaría la posibilidad de que otra persona sea inductor o cómplice. Exploremos una segunda alternativa interpretativa.

De acuerdo con esta segunda alternativa no es el tipo de delito el que delimita al responsable, sino la descripción de los hechos hecha valer por las partes y que el juez considera como suficiente para dar por probados los hechos. Lo que determina la existencia de dos sentencias contradictorias, entonces, son dos sentencias que condenan a dos personas distintas por los mismos hechos. Es decir, existen dos sentencias que si bien describen el hecho de manera diferente, pues atribuyen la participación a personas diferentes, el hecho o lo que es lo mismo, el estado de cosas que significa la infracción de un bien jurídico, es el mismo desde un punto de vista temporal y espacial. Estos dos últimos criterios, de identidad espacial y temporal, permiten identificar el hecho punible y vincular a dos o más personas, y por ende, a dos o más sentencias que condenan a diferentes personas por el mismo hecho. Ciertamente, esto plantea una restricción importante para el Ministerio Público y para la Corte Suprema y que cabe resaltar. Podría suceder, y de hecho ha sucedido en la experiencia comparada, que el fiscal en revisión plantee una teoría alternativa del caso bajo cuya descripción el delito si habría podido ser cometido por más de una persona. El problema es que con ello alteraría la descripción de los hechos aceptada por el juez en la sentencia porque supone que existe nueva evidencia que apunta a una teoría alternativa. Así ocurrió en Estados Unidos, en un famoso caso en que se hizo valer evidencia de ADN para acreditar la inocencia del condenado y en el que el fiscal sostuvo que, a pesar de que dicha evidencia acreditaba que el ADN encontrado en la víctima no pertenecía al condenado, había existido un co-autor no acusado, lo que no fue parte de su teoría del caso ni de los hechos considerados por el juez para acreditar el caso $^{141}$. El riesgo también se ha evidenciado en Chile en el siguiente caso, aquí no por parte del Ministerio Público sino por parte de la Corte Suprema, la que al plantear una teoría alternativa interfiere en la función exclusiva del Ministerio Público. Véase el siguiente caso

\footnotetext{
${ }^{139}$ Sobre las complejas posibilidades relativas a la participación de un intraneus en un delito común y el extraneus en un delito especial, véase DÍAZ Y GARCIA CONLLEDO, Miguel, La Autoría en Derecho Penal, Barcelona: PPU, 1991, pp. 156-166; DÍAZ Y GARCIA CONLLEDO, Miguel, “Autoría y Participación", Revista Estudios de la Justicia, no 10 (2008), pp. 56-57.

${ }^{140}$ Para una visión panorámica de las diferentes teorías sobre los delitos de propia mano, véase RoxIN, Claus, Derecho Penal Parte General, Especiales Formas de Aparición del Delito, Madrid: t. II, Civitas, 2014, pp. 189-198.

${ }^{141}$ RITTER, Hillary, “It's the Prosecution's Story, But They’re Not Sticking to it: Applying Harmless Error and Judicial Estoppel to Exculpatory Post-Conviction DNA Testing Cases", Fordham Law Review, $\mathrm{n}^{\circ} 74$ (2005), pp. 843-844.
} 
Polit. crim. Vol. 13, № 26 (Diciembre 2018) Art. 15, pp. 1190 - 1285.

[http://www.politicacriminal.cl/Vol_13/n_26/Vol13N26A15.pdf]

en que aparentemente la existencia de otros co-autores no fue parte de la teoría del caso del fiscal:

"La solicitud se sostiene, en síntesis, en que con fecha 28 de junio de 2006 se condenó a A.G.G. como único autor del delito de robo con homicidio en la persona de R.B.I., y a L.A.G. como autor del delito de robo con intimidación en contra de la misma persona. Posteriormente, el 3 de febrero de 2007 se condenó al solicitante R.A. como autor del delito de robo con homicidio en la persona de R.B.I.

$2^{\circ}$ Que como se lee tanto en la sentencia de 28 de junio de 2006, acompañada a fs. 2 y ss., por la que se condenó a los acusados A.G.G. y L.A.G., como en la sentencia de 3 de febrero de 2007 , de fs. 16 y ss., en que se condena al peticionario de revisión, ambos dictámenes derivan de la misma acusación formulada por el Ministerio Público, en la que se describen hechos que consideran como partícipes en el delito de robo con homicidio tanto a A.G.G., L.A.G y R.A., sin que el primer fallo descarte o excluya de manera alguna la participación en el delito del encartado R.A., cuestión que se determinó desfavorablemente para éste, sólo en el juicio oral posterior en que fue juzgado.

$3^{\circ}$ Que como se evidencia de lo expuesto, distintos acusados por los mismos hechos han sido juzgados en oportunidades diversas, estableciéndose en cada una de ellas la participación que en el hecho ilícito imputado les ha correspondido, sin que al realizar esta labor jurisdiccional se haya incurrido en contradicción alguna. De esa manera, el delito de robo con homicidio por el cual fue sentenciado el peticionario R.A., tanto fáctica como normativamente pudo ser cometido por más de una persona, tal como resolvió el Tribunal de la instancia en los respectivos juicios orales, lo que impide estimar cumplidos los extremos que prevé la causal invocada de la letra a) del articulo 473 del Código Procesal Penal, para la revisión de la sentencia cuestionada."142

Desde luego, es posible que las acusaciones hayan sido separadas en conformidad al artículo 274 del CPP, y es ciertamente posible que haya sido conveniente dicha separación aún de tratarse de un mismo hecho, esto, sin embargo no es lo problemático de la sentencia. Lo problemático es que la Corte considere prudente evaluar si los hechos pueden haber sido cometidos por más de una persona, sin precisar si ello fue efectivamente considerado por el tribunal en su sentencia, o por el Ministerio Público en su teoría del caso. Lo mismo ocurre en la siguiente sentencia:

“...que la Corte Suprema podrá rever extraordinariamente las sentencias firmes en que se hubiere condenado a alguien por un crimen o simple delito, para anularlas: a) cuando en virtud de sentencias condenatorias, estuvieren sufriendo condena dos o más personas por un mismo delito que no hubiere podido ser cometido más que por una sola.

$2^{\circ}$ : Que, sin embargo, las razones en que la recurrente funda su petición no configuran la causal invocada, pues se limita a reclamar la valoración de algunos de los antecedentes de cargo y a impugnar la cuantía de la pena, debiendo tenerse en

\footnotetext{
${ }^{142}$ SCS, Rol 8316-2014.
} 
FERNÁNDEZ, José Manuel; OLAVARRÍA, Malva. "Examinando de nuevo la acción de revisión”.

consideración, además, que en la especie se trata de un delito que si puede cometerse por uno o más individuos y no sólo en la forma en que está insinúa."143

Con esto finalizamos el examen de las sentencias en materia de revisión.

\section{Conclusión}

Podemos concluir que la práctica de la Corte Suprema ha sido deficitaria en muchos aspectos, y que el CPP contribuye a este estado de la situación porque entrega una muy poco detallada regulación legal, lo que ha significado la permanencia de un modelo inquisitivo de revisión, aún cuando no se encuentra vigente. Sin lugar a dudas la acción de revisión podría ser modificada legislativamente para corregir estas imperfecciones, pero un mejor modelo requiere que los tribunales adopten la correcta interpretación de la regulación legislativa. De lo que hemos examinado queda en evidencia que la acción de revisión entendida como un modelo adversarial permite un examen de los casos lo suficientemente complejo para hacer parte del sistema a aquellos casos que hemos denominado "casos intermedios". Debemos enfatizar que la regulación si bien es escueta no es por ello poco sofisticada. Hemos visto que no es a primera vista evidente qué es lo que puede entenderse por "evidencia nueva", por "desconocido", y como debe discriminarse apropiadamente entre los estándares con arreglo a los cuales la Corte puede proceder al conocer de la acción de revisión.

Esperamos que esta investigación aporte la claridad que es necesaria para entender el verdadero modelo adversarial de revisión previsto por el legislador y que se encuentra vigente, de manera que en un futuro cercano podamos finalmente dimensionar realmente el problema que representa las sentencias condenatorias erróneas.

Ciertamente, el modelo adversarial de revisión tiene por propósito maximizar la precisión en la identificación de los posibles inocentes, pero adicionalmente, permitiría perseguir a los verdaderos culpables, y evitar, que ciertos delitos queden sin sanción, mejorando en general el ideal de seguridad jurídica.

\footnotetext{
${ }^{143}$ SCS, Rol 5912-2011.
} 
Polít. crim. Vol. 13, № 26 (Diciembre 2018) Art. 15, pp. 1190 - 1285.

[http://www.politicacriminal.cl/Vol_13/n_26/Vol13N26A15.pdf]

\section{Bibliografia}

ACCATINO SCAGLIOTTI, Daniela, "Certezas, dudas y propuestas en torno al estándar de la prueba penal", Revista de Derecho de la Pontificia Universidad Católica de Valparaíso, Vol. 37 (2011), pp. 483-511.

ACCATINO SCAGLIOTTI, Daniela, "Convicción, justificación y verdad en la valoración de la prueba", Anuario de Filosofía Jurídica y Social, Vol. 26 (2006), pp. 39-50.

ACKER, James, "The Flipside Injustice of Wrongful Convictions: When the Guilty Go Free", Albany Law Review, Vol. 76 (2013), pp. 1629-1712.

ALLEN, Ronald, "Laudan, Stein, and the Limits of Theorizing About Juridical Proof", Law and Philosophy, Vol. 29 (2010), pp. 195-230.

AROCA, Juan Montero y GOMEZ COLOMER, Juan-Luis, MONTON REDONDO, Alberto y BARONA VILAR, Silvia, Derecho Jurisdiccional: Proceso Penal, Valencia: Tirant Lo Blanch, 2001.

ATRIA, Fernando, "Jurisdicción e Independencia Judicial: El Poder Judicial Como Poder Nulo", Revista de Estudios de la Justicia, Vol. 5 (2004), pp. 119-142.

ATRIA, Fernando, La Forma del Derecho, Madrid: Marcial Ponds, 2016.

BAKKEN, Tim, "Exonerating the Innocent: Pretrial Innocence Procedure", New York Law School Law Review, Vol .56 (2012), pp. 826-834.

BAKKEN, Tim, "Models of Justice to Protect Innocent Persons", New York Law School Law Review, Vol. 56 (2012), pp. 838-867.

BAKKEN, Tim, "Truth and Innocence Procedures To Free Innocent Persons: Beyond The Adversarial System", University of Michigan Journal of Law Reform, Vol. 41 (2008), pp. 547-583.

BANDES, Susan, "Framing Wrongful Convictions", Utah Law Review, Vol. 5 (2008), pp. 5-24.

BEDAU, Hugo y RADELET, Michael, "Miscarriages of justice in potentially capital cases", Stanford Law Review, Vol. 40 (1987) pp. 21-179.

BLUME, John y JOHNSON, Sheri Lynn y MILLOR, Susan, "Convicting Lennie:

Mental Retardation, Wrongful Convictions, and the Right to a Fair Trial", New York Law School Law Review, Vol. 56 (2012), pp. 943-967.

BORCHARD, Edwin, Convicting The Innocent: Sixty-Five Actual Errors of Criminal Justice, New Haven: Yale University Press, 1932.

BRANDON, Ruth y DAVIES, Christie, Wrongful Imprisonment: Mistaken Convictions and their Consequences, London: Allen an Unwin, 1973.

BRENNAN, Mary Ellen, "Interpreting the Phrase "Newly Discovered Evidence": May Previously Unavailable Exculpatory Testimony Serve as the Basis for a Motion for a New Trial Under Rule 33?", Fordham Law Review, Vol. 77 (2008), pp. 1095-1146.

CAROCCA PÉREZ, Alex, El Nuevo Sistema Procesal Penal, Chile: LexisNexis, 2005.

CASSELL, Paul, "Freeing the Guilty Without Protecting the Innocent: Some Skeptical Observations on Proposed New "Innocence" Procedures", New York Law School Law Review, Vol 56 (2012), pp. 1063-1096.

CASSELL, Paul, "The Guilty and The 'Innocent': An Examination Of Alleged Cases Of Wrongful Conviction From False Confessions", Harvard Journal of Law and Public Policy, Vol 22 (1998), pp. 523-603. 
FERNÁNDEZ, José Manuel; OLAVARRÍA, Malva. "Examinando de nuevo la acción de revisión”.

CASTILLO, Ignacio, "Enjuiciando al proceso penal chileno desde el inocentrismo (algunos apuntes sobre la necesidad de tomarse en serio a los inocentes)", Política Criminal, Vol. 8 (2013), pp. 249-313.

CERDA SAN MARTÍN, Rodrigo, Etapa Intermedia. Juicio Oral y Recursos, Chile: Librotecnia, 2003.

CHAHUÁN SARRÁS, Sabas, Manual del Nuevo Procedimiento Penal, 6a Edición, Chile: LegalPublishing, 2009.

CHALMERS, James y LEVERICK, Fiona, "When Should a Retrial be Permitted After a Conviction is Quashed on Appeal?", Modern Law Review, Vol 74 (2011), pp. 721 749.

COBO DEL ROSAL, M, Tratado de Derecho Procesal Penal Español, Madrid: Centro de Estudios Superiores de Especialidades Jurídicas, 2008.

CORREA SELAMÉ, Jorge Danilo, Recursos Procesales Penales, Chile: LexisNexis, 2005.

COUTURE, Eduardo, Fundamentos de Derecho Procesal Civil, Tercera Edición, Buenos Aires: Depalma, 1958.

DAVIDSON, Donald, Truth and Predication, Cambridge Massachusetts: Harvard University Press, 2005.

DÍAZ Y GARCÍA CONLLEDO, Miguel, “Autoría y Participación”, Revista Estudios de la Justicia, Vol. 10 (2008), pp. 13-61.

DÍAZ Y GARCÍA CONLLEDO, Miguel, La Autoría en Derecho Penal, Barcelona: PPU, 1991.

DUCE, Julio Mauricio, “Algunas Lecciones a Partir de Cuatro Casos de Condena de Inocentes en Chile", Revista de Derecho Universidad Católica del Norte, Vol. 22 (2015), pp. 149-208.

DUCE, Mauricio, "La condena de inocentes en Chile: una aproximación empírica a partir de los resultados de los recursos de revisión acogidos por la Corte Suprema en el período 2007-2013”, Política Criminal, Vol. 10 (2015), pp. 159-191.

ENDICOTT, Timothy, La Vaguedad en el Derecho, Madrid: Dykinson, 2006.

ENDICOTT, Timothy, "Arbitrariness", Canadian Journal of Law and Jurisprudence, Vol.27 (2014), pp. 49-71.

ETCHEVERRY, Juan, "Discrecionalidad Judicial", en: FABRA ZAMORA; Jorge Luis; NÚÑEZ VAQUERO, Álvaro (eds.), Enciclopedia de Filosofía y Teoría del Derecho, Vol. 2, México: Universidad Nacional Autónoma de México, 2015. pp. 1389-1418.

FERNÁNDEZ Ruiz, José Manuel y OLAVARRÍA AVENDAÑO, Malva, “Teoría y Práctica de la Acción de Revisión en el Nuevo Código Procesal Penal, Causal Letra D) del Artículo 473", Ius Et Praxis, Vol. 15 (2009), pp. 215-255.

FERRER BELTRAN, Jordi, La Valoración General de la Prueba, Madrid: Marcial Pons, 2007.

FERRER BELTRÁN, Jordi, Prueba y Verdad en el Derecho, Madrid: Marcial Pons, Segunda Edición, 2005.

FINDLEY, Keith, "Adversarial Inquisitions: Rethinking the Search for the Truth", New York Law School Law Review, Vol. 56 (2012), pp. 911-941.

FINDLEY, Keith, "Defining Innocence”, Albany Law Review, Vol. 74 (2010), pp. 1157-1208. 
Polit. crim. Vol. 13, № 26 (Diciembre 2018) Art. 15, pp. 1190 - 1285.

[http://www.politicacriminal.cl/Vol_13/n_26/Vol13N26A15.pdf]

FORST, Brian, "Wrongful Convictions In A World Of Miscarriages Of Justice", en; HUFF, Ronald; KILLIAS, Marrin (eds.), Wrongful Convictions and Miscarriages of Justice: Causes and Remedies in North American and European Criminal Justice Systems, London y New York: Routledge, 2013, pp. 15-44.

FORST, Brian, Errors of Justice, Nature, Sources, and Remedies, New York: Cambridge University Press, 2004.

FRANK, Barbara; FRANK, Jerome, Not Guilty, Garden City, New York: Doubleday \& Company Inc., 1957.

FRIEDMAN, Leon, "Problem of Convicting Innocent Persons- How Often Does It Occur and How Can It Be Prevented?," New York Law School Law Review, Vol. 56 (2012), pp. 1053-1061.

GARDNER, Erle Stanley,,The Court of Last Resort, USA: William Sloane Associates, 1952.

GARRETT, Brandon, Convicting the Innocent: Where Criminal Prosecutions Go Wrong, Cambridge Massachusetts: Harvard University Press, 2011.

GASCÓN ABELLÁN, Marina, Los Hechos en el Derecho: Bases Argumentales de la Prueba, Tercera Edición, Madrid: Marcial Pons, 2010.

GASCÓN ABELLÁN, Marina, "Validez y Valor de las Pruebas Científicas: La Prueba del ADN", Cuadernos Electrónicos de Filosofía del Derecho, Vol. 15 (2007), http://www.uv.es/cefd/15/gascon.pdf (visto en Junio del 2017), pp. 1-12.

GÓMEZ DE LIAÑO, F., El Proceso Penal: Tratamiento Jurisprudencial, Oviedo: Editorial Forum, 1992.

GREENAWALT, Kent, Law and Objectivity, Oxford y New York: Oxford University Press, 1992.

GRIFFIN, Lissa, "Pretrial Procedures for Innocent People: Reforming Brady", New York Law School Law Review, Vol. 56 (2012), pp. 969-1006.

GROSS, Samuel, "Convicting the Innocent", Annual Review of Law and Social Science, Vol. 4 (2008), pp. 173-192.

GROSS, Samuel y GROSS, Alexandra, "Witness Recantation Study: Preliminary

Findings: National Registry of Exonerations", University of Michigan Law School Scholarship Repository, 2013, en http://repository.law.umich.edu/cgi/viewcontent.cgi?article=1090\&context=other (visto en Junio del 2017), pp. 1-10.

GROSS, Samuel, "Pretrial Incentives, Post-Conviction Review, and Sorting Criminal Prosecutions by Guilt or Innocence", New York Law School Law Review, Vol. 56 (2012), pp. 1009-1030.

HART, H. L. A., "Post Scriptum”, Estudios Públicos, Vol. 65 (1997), pp. 225-263.

HORVITZ LENNON, María Inés \& LÓPEZ MASLE, Julián, Derecho Procesal Penal Chileno, Tomo II, Chile: Editorial Jurídica de Chile, 2004.

LASO CORDERO, Jaime; "Lógica y sana crítica", Revista Chilena de Derecho, Vol. 36 (2009), pp. 143-164.

LAUDAN, Larry, Truth, Error, and Criminal Law: An Essay in Legal Epistemology, Cambridge: Cambridge University Press, 2006.

LEO, Richard, "Rethinking the Study of Miscarriages of Justice: Developing a Criminology of Wrongful Conviction", Journal of Contemporary Criminal Justice, Vol. 21 (2005), pp. 201-223. 
FERNÁNDEZ, José Manuel; OLAVARRÍA, Malva. "Examinando de nuevo la acción de revisión”.

MACCORMICK, Neil, "Reasonableness and Objectivity", Notre Dame Law Review, Vol. 74 (1999), pp.1575-1604.

2014.

MARMOR, Andrei, The Language of Law, Oxford: Oxford University Press,

MARQUIS, Joshua, “The Myth of Innocence”, The Journal of Criminal Law and Criminology, Vol. 95 (2005), pp. 501-522.

MEDWED, Daniel, "Innocentrism", University of Illinois Law Review, 2008, pp. $1549-1572$.

MENESES PACHECO, Claudio, "Fuentes de prueba y medios de prueba en el proceso civil”, Ius Et Praxis, Vol. 14 (2008), pp. 43-86.

MIR PUIG, Santiago, "Bien jurídico y bien jurídico-penal como límites del «lus puniendi»", Estudios Penales y Criminológicos, Vol. 14 (1991), Santiago de Compostela, pp. 204-215.

MONTESQUIEU, Charles de Secondat Baron de, Del Espíritu de las Leyes, Madrid: Tecnos, 1995.

MORESO, Josep Joan, Lógica, Argumentación, e Interpretación del Derecho, Barcelona: Editorial UOC, 2006.

MOSQUERA RUIZ, Mario; MATURANA MIQUEL, Cristián, Los Recursos Procesales, Chile: Editorial Jurídica de Chile, 2010.

NAUGHTON, Michael, "Redefining Miscarriages of Justice: A Revived HumanRights Approach to Unearth Subjugated Discourses of Wrongful Criminal Conviction”, The British Journal of Criminology, Vol. 45 (2005), pp. 165-182.

NÚÑEZ VÁSQUEZ, Cristóbal, Tratado del Proceso Penal y del Juicio Oral, Chile: Editorial Jurídica de Chile, 2003.

PARDO, Michael, "On Misshapen Stones and Criminal Law's Epistemology", Texas Law Review, Vol. 86 (2007), pp. 347-383.

PAVLAKOS, George, Our Knowledge of the Law: Objectivity and Practice in Legal Theory, Oxford: Hart Publishing, 2007.

POSCHER, Ralf, "Ambiguity and Vagueness in Legal Interpretation", en; SOLAN, Lawrence; TIERSMA; Peter (eds.), The Oxford Handbook of Language and Law, Oxford: Oxford University Press, 2012, pp. 128-144.

RADIN, Edward, The Innocents, USA: Morrow, 1964.

RAWLS, John, A Theory of Justice, Second Edition, Cambridge Massachusetts: Harvard University Press, 1999.

RAZ, Joseph, "Legal Principles and the Limits of Law", Yale Law Journal, Vol. 81 (1972), pp. 823-854.

RISINGER, Michael y RISINGER, Lesley, "Innocence Is Different: Taking Innocence into Account in Reforming Criminal Procedure", New York Law School Law Review, Vol. 56 (2012), pp. 869-909.

RISINGER, Michael, "Unsafe Verdicts: The Need For Reformed Standards For The Trial And Review Of Factual Innocence Claims", Houston Law Review, Vol. 41 (2004), pp. 1281-1336.

RITTER, Hillary, “It's the Prosecution's Story, But They're Not Sticking to it: Applying Harmless Error and Judicial Estoppel to Exculpatory Post-Conviction DNA Testing Cases", Fordham Law Review, Vol. 74 (2005), pp. 825-870. 
Polit. crim. Vol. 13, № 26 (Diciembre 2018) Art. 15, pp. 1190 - 1285.

[http://www.politicacriminal.cl/Vol_13/n_26/Vol13N26A15.pdf]

ROXIN, Claus, Derecho Penal Parte General, Especiales Formas de Aparición del Delito, Tomo II, Madrid: Civitas, 2014.

SÁNCHEZ BRÍGIDO, Rodrigo; SELEME, Hugo Omar, "Justificación sin verdad", Analisi e Diritto, 2001, pp. 285-294.

SANCHEZ MONTENEGRO, J.C, El Recurso de Revisión Penal, Madrid: Edisofer, 2005.

SCHANE, Sanford, "Ambiguity and Misunderstanding in the Law", Thomas Jefferson Law Review, Vol. 25 (2002), pp. 169-172.

SENDRA, Vicente Gimeno, Manual de Derecho Procesal Penal, 2a Edición, Madrid: Colex, 2010.

SILVA SÁNCHEZ, Jesus María, La Expansión del Derecho Penal: Aspectos de la Política Criminal en las Sociedades Postindustriales, Segunda Edición, Madrid: Civitas, 2001.

SIMON, Dan, In Doubt: the Psychology of the Criminal Justice Process, Cambridge Massachusetts: Harvard University Press, 2012.

TARUFFO, Michele, "Algunas Consideraciones sobre la Relación entre Prueba y Verdad", en TARUFFO, Michele, La Prueba: Artículos y Conferencias, Chile: Editorial Metropolitana, 2009, pp. 41-72.

TARUFFO, Michele, La Prueba de los Hechos, Segunda Edición, Madrid: Trotta, 2005.

TWINING, William, Rethinking Evidence: Exploratory Essays, Second Edition, Cambridge: Cambridge University Press, 2006.

VERNENGO PELLEJERO, Nancy Carina, La Revisión de la Sentencia Firme en el Proceso Penal, Barcelona: Tesis Doctoral, Universitat de Barcelona, 2015.

WARE, Mike, "Dallas County Conviction Integrity Unit and the Importance of Getting It Right the First Time", New York Law School Law Review, Vol. 56 (2012), pp. 1033-1050.

WHITMAN, James, The Origins of the Reasonable Doubt: Theological Roots of the Criminal Trial, New Heaven: Yale University Press, 2008.

www.prisonreformtrust.org.uk (visto en Junio del 2017).

www.proyectoinocentes.cl (visto en Junio del 2017). 